IZA DP No. 9906

Persuasion and Gender:

Experimental Evidence from Two Political Campaigns

Vincenzo Galasso

Tommaso Nannicini

April 2016 


\title{
Persuasion and Gender: Experimental Evidence from Two Political Campaigns
}

\author{
Vincenzo Galasso \\ Bocconi University, \\ IGIER, Dondena, CESifo and CEPR \\ Tommaso Nannicini \\ Bocconi University, \\ IGIER, CEPR and IZA
}
Discussion Paper No. 9906
April 2016

\author{
IZA \\ P.O. Box 7240 \\ 53072 Bonn \\ Germany \\ Phone: +49-228-3894-0 \\ Fax: +49-228-3894-180 \\ E-mail: iza@iza.org
}

\begin{abstract}
Any opinions expressed here are those of the author(s) and not those of IZA. Research published in this series may include views on policy, but the institute itself takes no institutional policy positions. The IZA research network is committed to the IZA Guiding Principles of Research Integrity.

The Institute for the Study of Labor (IZA) in Bonn is a local and virtual international research center and a place of communication between science, politics and business. IZA is an independent nonprofit organization supported by Deutsche Post Foundation. The center is associated with the University of Bonn and offers a stimulating research environment through its international network, workshops and conferences, data service, project support, research visits and doctoral program. IZA engages in (i) original and internationally competitive research in all fields of labor economics, (ii) development of policy concepts, and (iii) dissemination of research results and concepts to the interested public.
\end{abstract}

IZA Discussion Papers often represent preliminary work and are circulated to encourage discussion. Citation of such a paper should account for its provisional character. A revised version may be available directly from the author. 


\section{ABSTRACT \\ Persuasion and Gender: Experimental Evidence from Two Political Campaigns*}

This paper investigates the differential response of male and female voters to competitive persuasion in political campaigns. We implemented a survey experiment during the (mixed gender) electoral race for mayor in Milan (2011), and a field experiment during the (same gender) electoral race for mayor in Cava de' Tirreni (2015). In both cases, a sample of eligible voters was randomly divided into three groups. Two were exposed to either a positive or a negative campaign by one of the opponents. The third (control) group received no electoral information. In Milan, the campaigns were administered online and consisted of a bundle of advertising tools (videos, texts, slogans). In Cava de' Tirreni, we implemented a large scale door-to-door campaign in collaboration with one of the candidates, randomizing positive vs. negative messages. In both experiments, stark gender differences emerge. Females vote more for the opponent and less for the incumbent when they are exposed to the opponent's positive campaign. Exactly the opposite occurs for males. These gender differences cannot be accounted for by gender identification with the candidate, ideology, or other observable attributes of the voters.

JEL Classification: D72, J16, M37

Keywords: gender differences, political campaigns, randomized controlled trials, competitive persuasion

Corresponding author:

Tommaso Nannicini

Bocconi University

Department of Economics

Via Rontgen 1

20136 Milan

Italy

E-mail: tommaso.nannicini@unibocconi.it

\footnotetext{
* We thank Steve Ansolabehere, Manuel Bagues, Niall Hughes, Christopher Kam, Paola Profeta, Guido Tabellini, and seminar participants at CEPR Public Policy Symposium, NBER Political Economy Meeting, LSE-NYU Political Economy Conference, European Political EconomyWorkshop at Mannheim, Collegio Carlo Alberto, EPSA Conference, IGIER, Lisbon, Lucern, Lugano, ZEW Mannheim, and Zurich for helpful comments. Maria Carreri, Aniello Dell'Anno, Enrico Di Gregorio, Valeria Ferraro, Monica Morlacco, Teresa Talò, and Stefano Ventura provided excellent research assistance. We thank Carlo Erminero (CE\&CO), Massimo Di Filippo and Fabrizio Monaci (IPR Feedback) for conducting the Milan and Cava surveys, and Davide Baldi (DUDE) for producing the electoral materials. A previous version circulated with the title "Men Vote in Mars, Women Vote in Venus: A Survey Experiment in the Field." Financial support from the European Research Council (Grants No. 230088 and No. 648833) is gratefully acknowledged. Remaining errors are ours and follow a random walk.
} 


\section{Introduction}

Persuasion has long been deemed to be an art, and a very rewarding one. ${ }^{1}$ Persuading customers to purchase a new product, a recruiting committee to award a promotion, potential donors to contribute to a campaign, or citizens to vote for a candidate is a key to success in business, personal career, fund-raising, and politics. ${ }^{2}$ "Persuasive communication" involves one or more senders trying to influence the behavior of a set of receivers (DellaVigna and Gentzkow, 2010). Often, senders actively compete against each other to persuade receivers. ${ }^{3}$ A key decision in competitive persuasion is whether to run an aggressive campaign against rivals or to concentrate on self-promotion. For example, marketing strategies may range from pure brand promotion to comparative advertising, political campaigns may feature both positive and negative advertising, and even coworkers competing for promotion may choose to praise themselves or to belittle the others. This issue has been mainly addressed in political campaigns, where negative advertising is largely allowed. However, no conclusive evidence emerges from the literature. ${ }^{4}$

Persuasion styles are largely idiosyncratic, as they depend on the sender's characteristics. However, the personal traits of the receivers are just as important in determining how effective persuasion can be. This is particularly noticeable in political campaigns. During the last decade, the wealth of information about eligible voters available in large commercial and administrative database and the introduction of randomized controlled trials (also known as A/B tests in the consulting industry) have allowed political can-

\footnotetext{
${ }^{1}$ According to Aristoteles and later to Plato, the art of persuasion consisted of five elements: "inventio," the research of the best arguments of persuasion; "dispositio," the internal organization of those arguments; "elocutio," the style of communicating them; "memoria," how to memorize arguments and responses to possible counter-arguments, and "actio," mimic or visual expression.

${ }^{2}$ Several evaluation studies suggest that persuasive communication matters, although the size of the effect varies across markets and persuasion tools. For example, the experimental literature summarized in Green and Gerber (2004) shows that specific tools of political campaigns do affect turnout. In charity donations, DellaVigna, List, and Malmendier (2012) find a strong effect of door-to-door persuasive communication. Bertrand et al. (2010) randomize commercial mailers and show that advertising content affects demand. A different strand of this literature evaluates the role of news media on political outcomes (e.g., see DellaVigna and Kaplan, 2007; Gentzkow, Shapiro, and Sinkinson, 2011). Bassi and Rasul (2015) analyze religious persuasion by studying the effect of Papal messages on fertility in Brazil. DellaVigna and Gentzkow (2010) review the empirical evidence on persuasion.

${ }^{3}$ See Gentzkow and Kamenica (2011) for a theoretical framework where competition in persuasion increases the extent of information revealed.

${ }^{4}$ See Lau et al. (2007) for a meta-analytic assessment.
} 
didates to "microtarget" their messages, based on the observable characteristics of the potential voters, such as gender, age, education, but also individual choices on food, TV shows, cars, and so on. ${ }^{5}$ These techniques have been exploited to optimize the campaign in a continuous effort to obtain more donations and to get out the vote, that is, to increase turnout among partisan voters. ${ }^{6}$

A natural candidate among these personal traits that may determine the impact of different electoral messages is the gender of the receiver. Advertisers have long used different arguments to convince female and male buyers. ${ }^{7}$ Yet, little effort has been made to study behavioral differences by gender in response to more or less aggressive communication strategies, although a recent empirical literature suggests that gender differences emerge in many circumstances. Males and females are recognized to differ in their risk attitudes, attitudes toward competition and negotiation, social preferences (see Croson and Gneezy, 2009; Bertrand, 2010; Niederle and Vesterlund, 2011; and Niederle, 2016, for reviews), ideology (Edlund and Pande, 2002), and preferences for public policy (Cavalcanti and Tavares, 2011; Funk and Gathmann, 2013). Should we expect males and females to react differently also as receivers of hostile (toward rivals) messages from competing senders?

To tackle this question, we study gender differences in the response to competitive persuasion in two political campaigns. We implemented a survey experiment in the field and a large scale field experiment during two different electoral campaigns in Italy, and analyzed the effect of positive vs. negative electoral campaigning on turnout and voting behavior of male and female voters. First, we ran a survey experiment during the 2011 electoral race for mayor in Milan, which featured a female incumbent facing a male main opponent. We randomized several items of the opponent's electoral campaign-videos,

\footnotetext{
${ }^{5}$ US politics has a long history of targeting messages to voters, according to the socio-demographic characteristics prevailing in the electoral precincts. See Issenberg (2012) for an historical description of electoral campaigning in the US, and of the introduction of big data and randomized controlled trials.

${ }^{6}$ While being very effective to increase donations and to get out the vote in the short run (see Rush, 2012; Issenberg, 2012), these very granular targeting approaches, usually based on machine learning algorithms, have little external validity. Additionally, we are not aware of studies or electoral campaigns where this granular approach was directly exploited in order to provide different messages to the undecided voters to swing their electoral choice.

${ }^{7}$ Studies on consumer behavior suggest that ads relating the advertised product to success over others positively affect males' intention to purchase (Prakash, 1992). On the other hand, males seem less likely to be convinced by marketing campaigns emphasizing the quality of the product (Vilela and Nelson, 2006). See Kahn and Kenney (2011) and Preece and Stoddard (2015a) for studies of political messages that explicitely consider the gender of the receiver.
} 
letters, slogans - in a positive vs. negative tone. For this election, we were also able to exploit a natural experiment occurred during the campaign to examine the effect of an attack by the (female) incumbent to the (male) main opponent on voters' perceptions. Second, we ran a large scale field experiment during the 2015 electoral race for mayor in Cava de' Tirreni (a midsize town in the south of Italy), which featured a male incumbent facing male opponents. In this experiment, our randomized treatments consisted of positive vs. negative canvassing, that is, door-to-door campaigning by volunteers.

Overall, we thus use different methodologies - survey, natural, and field experiment - in different geographic environments (Milan, the largest city in the North of Italy, and Cava de' Tirreni, a midsize city in the South), with different gender races - mixed in Milan and "all males" in Cava de' Tirreni-and exploit several electoral campaign instruments (video ad, slogan, flyer, and canvassing). All this experimental evidence points in the same direction. The gender of the receiver matters: among female voters, positive campaigning by the opponent increases his vote share and reduces the incumbent's votes, while the opposite occurs among male voters.

Our first experiment was implemented in Milan during the 2011 election by providing four surveys to an online sample of about 1,500 eligible voters. Respondents to the initial profiling survey, conducted at the end of March 2011, were randomly assigned to two treatment groups - positive vs. negative campaign by the main opponent - and to a control group exposed to no campaign information. Exploiting the fact that, for the purpose of most survey questions, individuals were asked to comment on specific pieces of information, such as a video or a text, participants in the positive (negative) group were exposed to electoral campaign messages with a positive (negative) tone by the main opponent. All participants in both the positive and the negative group were also exposed to the actual (non-randomized) campaign by the incumbent, which was mainly perceived as negative by individuals in the control group. We departed from existing studies on positive vs. negative campaigning by administering a "complete" electoral campaign, ${ }^{8}$ exploiting the notion that different communication tools could potentially reinforce each other (e.g., see Green and Gerber, 2004). To improve the intensity and realism of our informational treatments, we

\footnotetext{
${ }^{8}$ Previous experiments on negative campaigning have typically randomized one single campaign tool, such as a video (Ansolabehere et al., 1994) or canvassing (Arceneaux and Nickerson, 2010).
} 
thus expose individuals in our sample to four devices of political persuasion: 1) a video interview with the candidate, 2) an electoral slogan, 3) an open letter to the voters, and 4) a video ad endorsed by the candidate (see Appendix A). Each of these items was proposed to the two treatment groups in a positive or in a negative tone. However, both positive and negative ads addressed the same issue, with the same format, and in the same setting (e.g., background images, length of the text). We administered these four tools by using two surveys, which we also exploited to measure their instantaneous effect on the perceived credibility and approval rate of the candidates, as in a standard survey experiment. The "in the field" component of our experimental design comes from collecting turnout and voting choices through a final survey, run in the days immediately after the May 15-16 election. This survey was identical for the two treatment groups (positive and negative) and for the control group. Voting declarations thus enable us to evaluate the overall effect of our randomized campaigns on the actual electoral behavior.

The empirical results from this first experiment unveil large differences in the gender response to political persuasion strategies. Male and female voters tend to respond in opposite ways to the degree of aggressiveness of the opponent's campaign. Negative advertising increases men's turnout by about 8 percentage points, but has no effect on women. Gender differences are even stronger for electoral choices. Females vote more for the opponent (by 8 points) and less for the incumbent (by 8 points) if exposed to the opponent's positive campaign. Exactly the opposite happens for males, who vote less for the opponent (by 11 points) and more for the incumbent (by 12.7 points) if exposed to the opponent's positive campaign. Overall, these effects amount to persuasion rates ranging from $21 \%$ to $24 \%$ depending on the outcome (see DellaVigna and Kaplan, 2007). The intensity of our bundle of informational treatments was hence strong, as these numbers fit in the upper tail of the distribution of persuasion rates unveiled so far in the literature.

Our first experimental evidence thus suggests that gender matters in the response to competitive persuasion. This effect may however be driven by gender identity (see Akerlof and Kranton, 2000). Since the 2011 election in Milan featured a mixed gender race with a male opponent attacking a female incumbent, female voters may "identify" themselves with the female incumbent and thereby dislike the attacks by the male opponent and his negative campaign. This seems unlikely in the context of the Milan election, as female 
voters in the control group show a bias in favor of the male candidate. However, to test the relevance of this gender identity motive, we exploit a natural experiment that took place during our third survey. During a campaign debate on Sky TV, the (female) incumbentLetizia Moratti - violently attacked the (male) opponent - Giuliano Pisapia - by accusing him of strong ties with communist terrorists in his youth. This debate was aired on May 11, during our third survey, which took place between May 6 and 14. By comparing the responses of individuals who happened to answer the survey just before or just after the show was aired, we find that again males and females have opposite reactions. Males lean more toward the (female) sender of the negative attack, and females align with the (male) candidate targeted by the attack. We also collected Twitter data related to the electoral race between Ms. Moratti and Mr. Pisapia, and performed a sentiment analysis on the tweets sent by male and female users 24 hours before and 24 hours after the Sky TV debate. Our sentiment analysis confirms the findings from the survey data. After the Sky TV debate, more negative tweets were sent by males on Mr. Pisapia and by females on Ms. Moratti. All of this evidence thus suggests that gender identification is not a first-order mechanism in our context.

To further rule out this gender identification channel and - most of all - to corroborate the validity of our findings in a large scale field experiment, we implemented a second randomized controlled trial during the 2015 electoral race for mayor in Cava de' Tirreni, which featured a same-gender (all males) electoral race. The experiment was designed to examine the differential gender effects of negative (and positive) electoral campaigning by a (male) opponent against the (male) incumbent. This field experiment featured a randomization at the electoral precinct level: 18 precincts (out of 55) were randomly assigned to the positive treatment, 18 to the negative treatment, and 19 to the control group, which did not receive any treatment. The treatments consisted of positive and negative canvassing, done by a campaign team of 20 young supporters (see Figure C1 in Appendix C) of one of the opponents-Armando Lamberti. Volunteers tried to engage in personal interaction with eligible voters, by knocking on their apartments' door, and distributed electoral material, either personally in the hands of the eligible voters or in their mailboxes. The electoral material consisted of a flyer and a hanger with either a positive or a negative message. Both types of flyers (or hangers) had the same format and 
addressed the same issues. Canvassing took place in the three weeks before the election. Volunteers used a script with a positive or a negative message (see Appendix C).

Clearly, door-to-door canvassing coexisted with the actual overall campaign, so that its effect (if any) operated at the margin. However, our randomized controlled trial represented the only type of canvassing administered by our candidate's campaign. The volunteers covered the entire voting population - either personally or by leaving electoral materials in the mailbox - in all of the 36 precincts (out of 55) randomly assigned to either negative or positive campaigning. Furthermore, to the best of our knowledge, other candidates did not use systematic canvassing. Finally, we conducted a post-electoral survey for a sample of the eligible voters to obtain (self-reported) information on turnout and actual votes, in order to evaluate the effect of our randomized campaign messages on electoral behavior. This final survey was identical for all eligible voters, regardless of whether they belonged to the treatment or control groups.

The empirical results from the field experiment in Cava de' Tirreni persuasively confirm our previous findings from the election in Milan. Even in a same-gender electoral race, the difference in the gender response to political persuasion strategies is statistically significant and politically relevant. Among male voters, negative campaigning by the (male) opponent against the (male) incumbent increases his votes by 15.4 percentage points, while reducing the votes for the incumbent (by 27 points). Among females, positive campaigning by the opponent increases his vote shares by 12.8 points, while reducing votes for the incumbent (by 18 points). Overall, these effects amount to persuasion rates that - depending on the outcome and the treatment-range from $16 \%$ to $34 \%$ and are again sizeable.

This paper contributes to a growing literature on gender differences by providing experimental findings on a differential response (by gender) to political persuasion strategieswhether negative or positive. Indeed, recent experimental evidence unveiled several gender differences. For instance, unlike males, females tend to shy away from competition, their performance worsens during a competition, and they are less likely to choose competitive environments (see Niederle and Vesterlund, 2011, for a review) ${ }^{9}$. Other studies have highlighted gender differences in the degree of risk aversion, altruism, and social preferences

\footnotetext{
${ }^{9}$ Preece and Stoddard (2015b) run a field experiment to show that priming about the competitive nature of politics has a negative effect on women's interest in political office, but not in men's.
} 
(see Croson and Gneezy, 2009, and Bertrand, 2010, for a review). Gender differences have also been found in attitudes toward violence and war (see Sapiro and Conover, 1993). Finally, a neuropsychological literature (see Baron-Cohen, Knickmeyer, and Belmonte, 2005) shows that males have a greater reactivity than females to stressful situations, such as watching a scary or violent movie.

Few existing (non-experimental) studies have addressed the possible gender difference in the behavioral response to the different tone of electoral campaigns. ${ }^{10}$ Goldstein and Freedman (2002) exploit National Electoral Study data and report no gender difference in the effect of campaign attacks on electoral participation. Using survey and observational data, Kahn and Kenney (2011) show insetad that females are less tolerant than males to (both civil and uncivil) negative campaigns.

Our empirical findings contribute also to a large literature on the effects of negative campaigning on electoral turnout and (individual) voting behavior. ${ }^{11}$ In their seminal paper on negative campaigning, Ansolabehere et al. (1994) exposed a sample of 1,655 eligible voters in three electoral races in California to a single (positive vs. negative) political ad, aired during a commercial break. Using responses from a post-test questionnaire, they found that the negative ad reduced average voting intentions by $5 \%$. Arceneaux and Nickerson (2010) implemented a field experiment, in which volunteers personally delivered a political message to their treatment groups to find that, while canvassing is effective in influencing voters, there is little evidence of a differential effect between negative and positive campaigning. Other studies on negative campaigning followed a different approach: they used aggregate and survey data, and classified the negativity of the actual campaign advertisement. Most of these papers find either no impact of negative campaigning

\footnotetext{
${ }^{10}$ Studies of political persuasion have emphasized characteristics of the receivers different from gender (Fridkin and Kenney, 2011), such as being a politician's core supporter (Glaeser, Ponzetto, and Shapiro, 2005), or the role of social networks in magnifying the effectiveness of political communication (Murphy and Shleifer, 2004). Gender has instead been widely studied as a politician's attribute, looking at its impact on public policy (Chattopadhyay and Duflo, 2004), party selection (Bagues and Esteve-Volart, 2012; Baltrunaite et al., 2014), or government duration (Gagliarducci and Paserman, 2012).

${ }^{11}$ More generally, the effectiveness of electoral campaigns in mature democracies is the subject of a large literature, including, among others, Ansolabehere and Iyengar (1995), Gerber and Green (2000), Green and Gerber (2004), Gerber, Green, and Shachar (2003), Nickerson (2008), and Dewan, Humphreys, and Rubenson (2014). Typically, these studies rely on either small scale experiments for partisan ads, or on large scale non-partisan campaigns for turnout. For (randomized) partisan campaigns, see Gerber et al. (2011), Kendall, Nannicini, and Trebbi (2015), Pons (2016), and Braconnier, Dormagen, and Pons (2016).
} 
(Wattenberg and Brians, 1999), or even supporting evidence for a "stimulation" effect on electoral turnout (Finkel and Geer, 1998; Freedman and Goldstein, 1999; Kahn and Kenney, 1999; Goldstein and Freedman, 2002; Clinton and Lapinski, 2004; and Brooks and Geer, 2007). A meta-analytic assessment of this literature by Lau et al. (2007) reports inconclusive results: negative campaigns are neither effective to win votes, although they may be more memorable, nor seem to depress turnout. Our results suggest that the lack of an average treatment effect may mask large heterogenous gender effects.

The paper is organized as follows. The next section analyzes the survey experiment in Milan, by providing a brief description of the political background, the experimental design, and the results. Section 3 addresses the natural experiment during the Milan election by explaining context, identification, Twitter data, and results. Section 4 presents the field experiment in Cava de' Tirreni: after a brief description of the political background, the experimental design and the results are shown. Section 5 concludes. All questionnaires and campaign materials can be downloaded at: www.people.eco.usi.ch/galassov (Milan) and www.igier.unibocconi.it/cavaexperiment (Cava). Descriptions and English translations of the (randomized) campaign tools for all experiments are in the Appendices.

\section{Survey Experiment in Milan}

\subsection{Political Background}

The two main candidates in the 2011 municipal election in Milan were Letizia Moratti, the incumbent mayor supported by a center-right coalition, and Giuliano Pisapia, her main opponent supported by a center-left coalition. Letizia Moratti had first been elected mayor in May 2006, at the first round with $52 \%$ of the votes.

During her five-year term as mayor of Milan, Ms. Moratti introduced a pollution charge for cars entering the city center. She was also active in promoting the candidacy of Milan to host the Expo 2015, which was in fact awarded to the city in March 2008. She was hardly criticized for her spoil-system; upon her arrival, in fact, she fired several municipal managers and replaced them with high-wage external consultants. She was often accused

of absenteeism, as she failed to participate to around $95 \%$ of the official meetings of the city council. These were among the main issues of the 2011 electoral campaign. 
Giuliano Pisapia announced his candidacy to mayor of Milan as soon as June 2010. In November 2010, he - somewhat unexpectedly - won the center-left coalition primary elections with $45 \%$ of the votes against Stefano Boeri (40\%), who was officially supported by the Democratic Party, the main party in the coalition. ${ }^{12}$

At the beginning of the electoral campaign, Ms. Moratti was considered to have a large electoral advantage. In fact, besides the usual incumbency advantage, she could count on a solid center-right electorate, as Milan had been run by a center-right mayor for eighteen consecutive years. Ms. Moratti's electoral campaign was largely perceived as negative, with frequent attacks against her main political opponent. On the contrary, the style of Mr. Pisapia's electoral campaign was mainly accommodating. He tried to portray himself as a gentle force and concentrated his campaigning effort on social networks. This difference in campaigning styles was perceived by individuals in our control group. In fact, $76 \%$ of the respondents in the control group perceive Ms. Moratti's campaign as negative, while only $22 \%$ perceive Mr. Pisapia's campaign as such. Interestingly, no gender differences in these perceptions emerge among eligible voters not exposed to our informational treatments.

At the first round of the 2011 election, which took place on May 15-16, Mr. Pisapia obtained $48 \%$ of the votes, against $41.6 \%$ for Ms. Moratti. Mr. Pisapia then went on to win the runoff ballot on May 29-30, receiving $55.1 \%$ of the votes, and became mayor of Milan. The turnout rate was $67.6 \%$ in the first round and $67.2 \%$ in the runoff.

\subsection{Experimental Design}

We examine the effects of positive vs. negative campaigning on a sample of (male and female) eligible voters, who accepted to participate in a series of online surveys prior to the election for mayor of Milan in May 2011. Unlike the existing experimental literature, we randomly administered a "complete" electoral campaign, consisting of several advertising items. This increases the strength, and the realism, of our treatment, but at the price of reducing the possibility of pinning down the effect of each campaign tool. Specifically, we randomized our positive vs. negative treatment over four items of the opponent's

\footnotetext{
${ }^{12} \mathrm{Mr}$. Pisapia had previously been elected to the lower house of the Italian Parliament in 1996 and again in 2001, in the electoral list of the Communist Party ("Rifondazione Comunista").
} 
electoral campaign: 1) a video interview with the candidate; 2) a campaign slogan; 3) a letter to the voters signed by the candidate; and 4) a video ad endorsed by the candidate. All of these tools were designed by professionals under our direction and in collaboration with the opponent's campaign. Clearly, the informational treatments coexisted with the real campaign, going on independently of our surveys, and therefore their effects (if any) operated at the margin. However, we designed the experiment so that the intensity of the overall treatment could be strong, as different campaign items with the same tone might reinforce each other (see Green and Gerber, 2004), especially on individuals who did not want or did not have time to follow the real campaign closely.

Our strategy represents a departure from the previous political science literature on negative advertisement, where only one single element of the electoral campaign has typically been randomized. We do however follow this literature in the design of each single ad, as we kept the format fixed and only changed the tone of the content.

Our survey experiment was implemented between March and May 2011 by providing four surveys to the eligible voters in our online sample (see Figure 1). The first survey was conducted between March 28 and April 4 for all individuals in our sample with the goal of obtaining relevant personal information and the individuals' political and social attitudes. Respondents to the initial survey were then randomly assigned to three groups. Individuals in group A were exposed to the positive treatment, consisting of an electoral campaign with a positive tone by the opponent; individuals in group B to the negative treatment, consisting of an electoral campaign with a negative tone by the opponent; while individuals in groups $\mathrm{C}$ received no electoral information. All individuals in groups $\mathrm{A}$ and $\mathrm{B}$ also observed a (non-randomized) electoral campaign by the incumbent, composed of items extracted from the incumbent's actual campaign.

Between April 26 and May 2, the second survey was conducted, but only for individuals in the treatment groups (A and B). This survey contained the first wave of the electoral campaign: the video interview and the campaign slogan. The third survey was releasedagain to groups A and B only-between May 6 and 14, and contained the second wave of the electoral campaign: the open letter to the voters and the video ad. The mayoral election took place on May 15 and 16. The (fourth and last) post-electoral survey was conducted for all three groups immediately after the election, starting on May 17, and 
lasted for a week. This survey collected information on self-reported electoral outcomes (such as turnout and actual vote for the candidates), voting intentions regarding the runoff election, and personal perceptions about the electoral campaign. ${ }^{13}$

\subsubsection{Our Sample}

We conducted our experiment using an online panel of eligible voters for the upcoming election. A Milan-based commercial survey company ("CE\&Co") was contacted to run the online surveys. They used different techniques (such as exploiting their existing online panel, or producing new contacts using phone books, etc.) to construct an initial sample of about 1,536 eligible voters, aged between 18 and 65, in the 2011 election for mayor in Milan. "CE\&Co" stratified the sample along three dimensions: i) neighborhood, ii) age group, and iii) gender. Of courese, the sample was not representative of the electorate aged from 18 to 65 years in the 2011 Milan election, as it is difficult to convince certain demographic groups to participate to online surveys. The internal validity of the experimental design, however, is guaranteed by the randomization protocol. In any case, this sample was very similar to the population along the first two stratifying dimensions. ${ }^{14}$

The first survey was administrated with the goal of obtaining relevant personal information (gender, age, marital status, education), as well as more specific information on political and social attitudes (political orientation, voting behavior in previous local and national elections, exposure to the media, knowledge of local politics). Respondents to the initial survey were then randomly assigned to our three (treatment and control) groups. However, not all individuals profiled in the first survey responded also to the subsequent surveys. We include in the final (estimation) survey only the 1,140 voters who declared whether they voted or not in the fourth survey on electoral outcomes.

\footnotetext{
${ }^{13}$ All surveys are available online at: www.people.usi.ch/galassov/projects.html.

${ }^{14}$ These are the relevant comparisons by neighborhood: City center, $6 \%$ in our sample vs. $8 \%$ in Milan; Stazione etc., 11\% vs. 11\%; Citt studi etc., 14\% vs. 11\%; Porta romana etc., 11\% vs. 11\%; Ticinese etc., $8 \%$ vs. $9 \%$; Porta Genova etc., $12 \%$ vs. 11\%; Baggio etc., $11 \%$ vs. $13 \%$; Fiera etc., $13 \%$ vs. $13 \%$; Bovisa etc., $14 \%$ vs. $13 \%$. The same holds for age groups. Note that we targeted a population aged between 18 and 65 , because (i) we were only interested in eligible voters, and (ii) people over 65 are unlikely to participate in an online survey. The relevant comparisons follow: Aged between 18 and $30,23 \%$ in our sample vs. 22\% in Milan; Aged between 31 and 45, 46\% vs. 43\%; Aged between 46 and 65, 31\% vs. 35\%. To save on the budget and due to the fact that we were less concerned about external validity (an online sample can never be a representative sample of the population at large), we agreed with the "CE\&Co" to have a slight over-representation of females, who are more likely to participate in online surveys: Females, $59 \%$ in our sample vs. $52 \%$ in Milan; Males, $41 \%$ vs. $48 \%$.
} 
The main characteristics of the estimation sample are summarized at Table A.1 in Appendix A, which provides descriptive statistics by treatment group. Besides standard demographic characteristics and education, we measure the ideological position of each voter, the interest in politics, and the knowledge about local politics ("did not know mayor" meaning that the name of the incumbent mayor was misreported). All variables but the nonresponse dummy ("missing") come from the first survey, which provided the (pre-randomization) individual characteristics. The first column reports the "missing" dummy for the original sample of 1,536 individuals profiled in the first survey; the dummy is equal to one if the (profiled) individual did not answer to the fourth survey and therefore does not belong to the final (estimation) sample.

The estimation sample is largely composed of females (59\%), college graduates (44\%), and married individuals (48\%). There is a large share of individuals younger than 30 $(23 \%)$, and only very few respondents have a low interest in politics (4\%) or did not know the name of the mayor (3\%). Table A.2 in Appendix A shows that all of these observable characteristics are balanced across treatment groups, with the only exception of the information measure at the $10 \%$ significance level. The attrition rate caused by nonresponses to the fourth survey (something that we could not check ex ante) is also balanced across groups. This confirms the (ex post) validity of the experimental design. ${ }^{15}$

\subsubsection{Informational Treatments}

We exposed individuals in the treatment groups to an entire electoral campaign by the opponent composed of four electoral tools either with a positive (group A) or a negative (group B) tone. All individuals in the two treatment groups were also exposed to the same electoral campaign by the incumbent, again characterized by the same four electoral tools.

The first tool of the opponent's randomized campaign was a 100-second video interview to the candidate sitting at his office desk. The video with the positive tone ran under the header "my ideas for Milan," the one with the negative tone under the header "Moratti's mistakes." The second tool was the opponent's main campaign slogan: respectively "Pisapia for Mayor = Less Traffic \& More Green. A Change for Milan is Possible." in the

\footnotetext{
${ }^{15} \mathrm{As}$ a matter of fact, the observable characteristics of voters in the sample are also balanced across treatment status within gender strata (see Section 2.3), and the same holds for the strata by neighborhood and by age group (available upon request).
} 
positive tone campaign, and "5 Years of Moratti = More Traffic \& Less Green. A Change for Milan is Possible." in the negative one (see Figures A1 and A2 in Appendix A). The third tool was a letter to the voters. In the positive tone, under the header "this is my commitment with the city," the letter described the opponent's main projects for the future of Milan, and ended with a positive plea: "Milan deserves to become once again one of the capitals of Europe." In the negative tone, under the header "Milan does not deserve to be led by Ms. Moratti," the letter charged the incumbent for her mistakes while in office, and ended with a negative plea: "Milan does not deserve other five years of Moratti administration." The final tool was a 60-second video ad endorsed by the opponent on relevant issues for the city (transportation, pollution, Expo). Each video ad addressed the same issues, with the same format and in the same setting, and was proposed in either a positive (under the header "My ideas for Milan") or a negative tone ("Is Ms. Moratti's Milan also yours?"). The videos and all graphical information were realized by professionals and are available online at: www.people.usi.ch/galassov/projects.html. In Appendix A, we provide further details and the English translation of all texts.

Participants in the (second and third) surveys were also exposed to the incumbent's campaign, which was fixed and administered in exactly the same way to both group A and group B. Also for this campaign, we used the same four tools: video with the candidate; campaign slogan; open letter to voters; video ad endorsed by the candidate. We acquired these items from Ms. Moratti's actual campaign. Details on their format and content are in Appendix A. For each tool, we randomized whether survey respondents were first exposed to the opponent's or to the incumbent's campaign message.

\subsubsection{Outcome Variables}

The fourth and last survey, administrated immediately after the election, collected the (self-reported) voting outcomes. Individuals were asked whether they voted at the election, and (if yes) which candidate and party they voted for (choosing among a list of names for the candidates, and among a list of symbols for the parties). As the result of the

first electoral round led to a runoff, individuals were also asked whether they expected to vote at the runoff, and if so for which of the two candidates. These answers provided the "in the field" component of our survey experiment, and represent our main outcomes of 
interest in the empirical analysis. Additionally, respondents were asked their motivations for the voting decisions (whether it was based on ideology or on the candidates' attributes), how confident they felt about their vote, and how negative or positive they perceived the incumbent's and the opponent's electoral campaigns.

The first-round results capture (self-declared) actual choices, while second-round results capture voting intentions. In both cases, we concentrate on (actual or expected) turnout, the vote share of the opponent, and the vote share of the incumbent. For the first round, we also measure the vote share of the remaining (minor) candidates; for the second round, we measure the share of voters who were still undecided at the time of our survey. In both the first and second round of elections, the average treatment effect was not statistically significant: neither positive nor negative campaigning influenced voting behaviors with respect to the control group, or when compared between each other (see Tables A.3 and A.4 in Appendix A).

\subsection{Identification}

Our survey experiment in the field provides an ideal environment to investigate how females and males react to political communication, because the share of female and male voters is almost equal and observable characteristics are orthogonal to the informational treatments within gender strata. As a matter of fact, although we did not design the survey experiment to investigate gender effects, due to our sampling and randomization procedures, all observable characteristics are perfectly balanced across treatment status also within gender strata. Had we stratified the randomization algorithm by gender, we would have reached the same outcome. Tables A.5 and A.6 (in Appendix A) show that observable covariates are balanced across treatment groups for both females and males, respectively. Most importantly, the nonresponse rate - which is determined after our treatments took place - is also balanced across treatment groups by gender. We also replicated standard randomization checks within gender strata, i.e., the kind of tests we would have run, had we stratified the randomization algorithm too (see Table A.7 in Appendix A).

These checks also confirm the validity of the randomization procedure within gender. As a result, the randomization design allows us to estimate the causal impact of positive vs. negative campaigning for both men and women. 
We thus estimate the following linear probability model by OLS:

$Y_{i}=\alpha_{1} P O S_{i}+\alpha_{2} N E G_{i}+\beta_{1} P O S_{i} \times F E M A L E_{i}+\beta_{2} N E G_{i} \times F E M A L E_{i}+\delta F E M A L E_{i}+\varepsilon_{i}$,

where POS and NEG are dummies that identify the exposure to positive or negative campaign, respectively, FEMALE is a dummy identifying female voters, and standard errors are clustered by ZIP code to account for spatial correlation. ${ }^{16}$ This specification allows us to estimate the treatment effect of positive and negative campaign for males and females both with respect to the control group and between each other. ${ }^{17}$

\subsection{Empirical Results}

Table 1 shows the results on first-round voting choices. Negative campaigning increases male turnout with respect to both the control group (at the $5 \%$ significance level) and positive campaigning (10\% significance). In particular, when facing the opponent's negative campaign, males show up more at the polls by 8 percentage points, which amount to a persuasion rate of about $24 \% .^{18}$ Negative campaigning has instead no effect on female turnout. Receiving any kind of campaign information has opposite effects on male and female turnout (H8): positive on the former and negative on the latter, although the effects in the two subpopulations are borderline insignificant at standard levels.

Gender differences are even more pronounced if we look at the candidates' vote shares. Females vote more for the opponent (by 8 percentage points) and less for the incumbent

\footnotetext{
${ }^{16}$ Results are quantitatively equivalent with probit and logit models, even slightly more robust in terms of statistical significance (available upon request). We prefer to report results from the linear probability model to make the interpretation of the interaction coefficients more intuitive.

${ }^{17}$ Specifically, $\alpha_{1}\left(\alpha_{2}\right)$ captures the treatment effect of positive (negative) campaign for males, and $\beta_{1}$ $\left(\beta_{2}\right)$ the differential treatment effect of positive (negative) campaign between males and females. When we estimate our baseline equation (1), we also implement the following Wald tests: (H1) treatment effect of positive campaign for females: $\alpha_{1}+\beta_{1}=0$; (H2) treatment effect of negative campaign for females: $\alpha_{2}+\beta_{2}=0$; (H3) treatment effect of positive vs. negative campaign for males: $\alpha_{1}-\alpha_{2}=0$; (H4) treatment effect of positive vs. negative campaign for females: $\left(\alpha_{1}+\beta_{1}\right)-\left(\alpha_{2}+\beta_{2}\right)=0$; (H5) differential treatment effect of positive vs. negative campaign between males and females: $\beta_{1}-\beta_{2}=0$; $(\mathrm{H} 6)$ treatment effect of any campaign vs. no campaign for males: $\alpha_{1}+\alpha_{2}=0$; (H7) treatment effect of any campaign vs. no campaign for females: $\left(\alpha_{1}+\beta_{1}\right)+\left(\alpha_{2}+\beta_{2}\right)=0$; (H8) differential treatment effect of any campaign vs. no campaign between males and females: $\beta_{1}+\beta_{2}=0$.

${ }^{18}$ Following DellaVigna and Kaplan (2007), we calculate the persuasion rate of our informational treatments as follows: $p=\frac{Y_{t}-Y_{c}}{e_{t}-e_{c}} \frac{1}{1-Y_{0}}$, where $Y_{t}$ and $Y_{c}$ are the shares of individuals adopting the behavior of interest (e.g, turnout) in the treated and control group, respectively; $e_{t}$ and $e_{c}$ are the shares of individuals receiving the message in the two groups (i.e., $e_{t}=1$ and $e_{c}=0$ in our case); and $Y_{0}$ is the share that would adopt the behavior of interest without the message (e.g., actual turnout in the population).
} 
(by exactly the same 8 points) when they are exposed to the opponent's positive campaign. The persuasion rate of the positive campaign is about $21 \%$. The opposite happens for males, who vote less for the opponent (by 11 percentage points) and more for the incumbent (by 12.7 points) if exposed to the opponent's positive campaign. In this case, the (counterproductive) persuasion rate of the positive campaign on males is about $23 \%$. The effects of positive campaign are statistically significant for males with respect to the control group, and for females with respect to negative campaign. There are no significant effects on the cumulative vote shares of the other (minor) candidates. Overall, the above persuasion rates fit in the upper tail of the distribution of the effects unveiled so far in the literature on persuasion, where the maximum is around $30 \%$ according to the review by DellaVigna and Gentzkow (2010).

In Table 2, the same gender differences show up in the results on (expected) voting behavior in the runoff. ${ }^{19}$ Here, the opponent's positive campaign affects also the share of the undecided among women, which decreases by 9.5 percentage points with respect to negative campaign. Both in the first round and in the runoff, when men and women vote for a candidate, they tend to react in opposite ways to our treatments (H5). From the opponent's viewpoint, positive campaign is extremely fruitful in attracting female voters, but backfires with male voters. Indeed, males are more likely to vote for the incumbent when they are exposed to any campaign (H6), although the negative campaign attenuates this effect by recovering some votes for the opponent. This finding could be related to the tone of the incumbent's campaign, which, as inferred from our control group, was generally perceived to be negative. Hence, males seem to be attracted by negative campaigns.

Table 3 examines the impact effect of each campaign tool, as measured by the replies to questions on the approval rate of the two candidates, asked after each tool was administered. Specifically, Panel A at Table 3 uses the questions asked after the video interview ("Do you agree with what the candidate says in the video?") and after the campaign slogan ("How much do you feel you can trust the candidate?"). Panel B at Table 3 uses the questions asked after the open letter ("Do you agree with the general sense of this letter?") and after the video ad ("How truthful does this electoral message seem to you?"). As the control group did not participate in the second and third survey, which provided

\footnotetext{
${ }^{19}$ Results in Tables 1 and 2 are robust to the inclusion of ZIP code fixed effects (available upon request).
} 
our treatments, for these (impact) outcomes we can only evaluate the relative effect of positive vs. negative campaign. By measuring the instantaneous reaction of respondents to the messages, the above variables resemble standard outcomes in existing lab or survey experiments. Results on gender differences are again striking: responses go systematically in opposite directions, and most of the time the difference is statistically significant at standard levels. In both the second and third survey, males are more in favor of the incumbent if they are exposed to the opponent's positive campaign, but this is never true for females, who actually tend to trust less the incumbent if they are exposed to the opponent's positive video interview and campaign slogan.

Although the behavioral response to campaign communication is different between males and females, their perceptions about the tone of the campaign is similar. Table A.9 in Appendix A shows that both males or females perceive the overall campaign (first column) and the opponent's campaign (second column) as more negative, if they are exposed to the (opponent's) negative treatment. Direct questions on perceptions may fail to capture the true impact of our treatments on voters' beliefs. Nevertheless, it is reassuring that these effects have the expected sign, and do not differ between males and females. Gender differences emerge again on the incumbent's campaign, however: those females who observed the opponent's positive campaign tend to perceive the incumbent as more negative, and the opposite occurs for males, although these effects are not statistically significant. Table A.9 also shows that our treatments have no effect on how confident voters are about their choice (third column) or on the motivation of their vote (fourth column).

What drives this gender difference in the behavioral response to political campaigning? Males and females are recognized to differ along many dimensions, such as educational attainments, political ideology (Edlund and Pande, 2002), preferences towards competition (Bertrand, 2010) or cooperation (Niederle, 2016), and preferences for public policy (Cavalcanti and Tavares, 2011; Funk and Gathmann, 2013). Some of these aspects can be addressed by using the information obtained in our first survey. Table A.8 in Appendix A shows in fact that, in our sample, female respondents differ along several observable characteristics, such as age, marital status, left-wing orientation, and interest in politics. ${ }^{20}$

\footnotetext{
${ }^{20}$ These gender differences in observables, however, do not represent a threat to the validity of our estimates, as they are not systematically different across treatment groups (see Table A.7 in Appendix A). Moreover, we have shown that covariates are balanced across treatment groups within gender strata.
} 
To analyze potential channels, which may drive gender differences, at Table 4 we add to our baseline specification (reported again at column 1 for the sake of comparison), one at a time, each of the following variables and their interaction with the treatment indicator: young (column 2), college (column 3), left (column 4), and low interest in politics (column 5). Table 4 reports the effect of our informational treatments, while accounting for these additional variables, on the opponent's (panel A) and on the incumbent's (panel B) vote share. ${ }^{21}$ The results indicate that the introduction of these additional explanatory variables (and of the respective interaction terms) does not eliminate (or even reduce) our gender effect. Hence, our gender differences in political persuasion cannot be accounted for by these observable differences in age, education, and political ideology between male and female voters. Similar conclusions can be drawn from the results at Table 5, which provides the same analysis for the run-off election. Gender differences in political ideology, education and interest in politics are unable to produce the difference in the behavioral response to political campaigning. These channels cannot explain our results. ${ }^{22}$

As a final robustness check, we include in our baseline specification all observable characteristics and their full set of interactions with the treatment indicators in order to capture the net effect of gender, after controlling for everything else at the same time. This specification is quite demanding from a statistical viewpoint, because it increases the number of cells where we are trying to estimate the treatment effects, and the statistical significance is considerably reduced. Actually, also from a substantive viewpoint, some regressors such as marital status might be an example of over-controlling, because gender might be intrinsically associated with different preferences in this respect. Nevertheless, we report these specifications in Appendix A (Table A.11 for the first round and Table A.12 for the runoff) as the most conservative test on pure gender differences. Notably, the direction of the results discussed above is unchanged even when we control for a full set of interactions, although some of the effects lose statistical significance. The bottom line is that a residual underlying gender difference still lies behind our findings.

\footnotetext{
${ }^{21}$ To save on space, the channels on voters' turnout are reported at Table A.10 in Appendix A.

${ }^{22}$ Moreover, as we can rely on multiple outcome variables originated from different surveys, it is reassuring that gender systematically displays heterogeneous effects with respect to all outcomes. The same does not hold for other, less robust, heterogeneity dimensions, which are sometimes statistically different from zero at the $10 \%$ significance level but only for secondary outcomes (available upon request). This reinforces the conclusion that gender differences in our data are not simply due to random chance.
} 


\section{Natural Experiment in Milan}

\subsection{Background and Data}

Since the 2011 Milan election featured a mixed-gender race, between a female incumbent and a male opponent, gender identification may drive our results (see Akerlof and Kranton, 2000). Females may dislike negative advertising against a female candidate, whereas males may accept (or even like) the male opponent attacking the female incumbent. Would the results be different if a female politician attacked a male politician?

The emergence of a natural experiment during the 2011 Milan election allows us to test this situation, since the female incumbent staged an aggressive campaign attack against the male opponent in a TV debate. On May 11, during a political debate broadcast on Sky TV, Ms. Moratti accused Mr. Pisapia of taking part in a car robbery with other communist terrorists in his youth. Exploiting the rules of the debate, Ms. Moratti used her closing statement for her attack, so that Mr. Pisapia was unable to reply and defend himself. The opponent was clearly shocked by the attack, and refused to shake hands with the incumbent at the end of the TV show. Only after the debate, Mr. Pisapia was able to explain to the press that he had been fully and immediately acquitted from the charge, and announced his intention (not carried out) to sue Ms. Moratti. The negative attack had a huge echo in local and national news media, and marked a turning point in the campaign. ${ }^{23}$ To study the effect of this episode of negative campaign by a female politician (the incumbent) against a male politician (the opponent), we use two different approaches with survey and Twitter data.

\subsubsection{Survey and Twitter Data}

Thanks to the (exogenous) timing of our survey experiment, we can exploit the above (endogenous) episode as a natural experiment. In fact, our third survey was still under way when the Sky TV show was aired (see Figure 1). As a result, some individuals had already participated in the third survey, while others (14\% of the sample) had not. We therefore exploit the timing of the survey response, in order to evaluate the impact of a negative attack carried out by a female candidate against a male candidate. To

\footnotetext{
${ }^{23}$ Roberto Basso, spin doctor of Mr. Pisapia's campaign, in an interview with the newspaper "Europa" (August 21, 2013), defined the attack by Ms. Moratti on Sky TV as the defining moment of the campaign.
} 
implement this evaluation, we must restrict the attention to the outcomes measured in the third survey, because at the time of the fourth survey all voters had already come to know about the Sky TV episode.

To further examine this event, we acquired Twitter data related to the 2011 Milan election from a London-based social media monitoring platform company ("FACE"). We then performed a sentiment analysis to assess the effects of the Sky TV debate. We obtained an initial dataset of around 87,000 tweets regarding the 2011 Milan electoral race for mayor, covering a period of two months (from April 1 to May 31). We considered tweets for which we could obtain information about the gender of the user, and that contained the word "Moratti" and/or "Pisapia." Furthermore, to avoid potential assignment-bias in the sentiment analysis, we excluded the tweets that contain the name of both the incumbent and the opponent. In the end, we are left with almost 45,000 tweets referring only either to "Pisapia" or to "Moratti," sent from accounts for which we can recognize the gender of the sender. On these tweets, we perform a sentiment analysis to study the effect of the negative campaign episode. In particular, using the gender of the sender, we test whether Ms. Moratti's attack during the TV debate had a differential gender effect on the tone (negative or positive) of the tweets just before vs. just after the Sky TV show.

To perform our sentiment analysis, we initially identified a list of stems (root of a word or of many words), which are relevant to infer the sentiment towards a candidate. A positive stem is related to an emotion, such as joy or love, or to an expression of political support, such as "vote for." Conversely, a negative stem is related to a pessimistic emotion, or to an expression of political dislike. We also included some emoticons as they are widely used on Twitter to express feelings. The complete list contains 108 stems, of which 54 are coded as positive and 54 as negative (see Appendix B).

For each tweet, we thus count the number of "negative" and "positive" words, and we construct four indicators. The Moratti (Pisapia) Negative Index measures the difference between negative and positive words in a tweet that refers only to Moratti (Pisapia). The Moratti (Pisapia) Negative Dummy indicates whether there are more negative than positive words in a tweet referring only to Moratti (Pisapia). 


\subsection{Identification}

To test the differential gender effect of Ms. Moratti attack during the Sky TV debate, we use two specifications for both our data sources. We estimate the following OLS model:

$$
Y_{i}=\alpha_{1} A F T E R_{i}+\beta_{1} A F T E R_{i} \times F E M A L E_{i}+\delta F E M A L E_{i}+\varepsilon_{i},
$$

where $Y_{i}$ is either the response to questions in the third survey or the tone of the tweets, as captured by the indicators described above, and the dummy $A F T E R_{i}$ captures respectively whether the individual responded to the third survey or sent the tweet after the Sky TV show or before.

We are aware that individuals responding earlier or later to the survey, and sending tweets before or after the TV show, may be different along some unobservable dimensions. To control for this, in our second specification, we augment equation (2) with a spline third-order polynomial in the distance from the time of the event:

$$
Y_{i}=\alpha_{1} A F T E R_{i}+\beta_{1} A F T E R_{i} \times F E M A L E_{i}+\delta F E M A L E_{i}+f\left(D I S T A N C E_{i}\right)+\varepsilon_{i},
$$

where DISTANCE $E_{i}$ is measured in minutes. This amounts to a regression discontinuity (RD) design in the distance from the Sky TV show. For the Twitter data, we restrict the analysis to tweets sent 24 hours before and 24 hours after the broadcast of the show.

\subsection{Empirical Results}

When using data from our third survey, we consider the same outcomes analyzed at Panel A in Table 3 and estimate whether female and male voters who replied to the survey after the Sky TV show have different evaluations on the quality of both the incumbent's and the opponent's campaign. Clearly, these are intention-to-treat effects, because we are unable to know whether those individuals who replied after the show actually heard about the episode. Results are reported at Table 6: Panel A for the OLS and Panel B for the RD specification at equations (2) and (3), respectively.

The dependent variables are the answers to the questions on whether respondents agree with the candidates' open letter and video ad. Female voters - again - tend to punish the candidate who went negative (even though this time it is a woman): they agree less with the letter and trust less the video by the incumbent after the negative attack. On the 
contrary, male voters do not punish the female incumbent. If anything, they tend to rally in her favor even if she went negative against a male candidate. Also for the RD specification at Panel B, all outcomes convey the same conclusion as the OLS estimations. Even in a small neighborhood of the event (that is, comparing individuals who answered the survey just before or just after the show), females and males respond differently to the negative attack carried out by the incumbent, thereby suggesting that no gender identification is at work in our sample.

When analyzing the Twitter data, we use the four indicators described in Section 3.1.1 to estimate whether female and male voters tweeting after the Sky TV show modified the tone of the tweets toward the two candidates. As in the previous case, these represent intention-to-treat effects, as we are unable to assess whether those who sent tweets after the show actually knew about the episode. Results from Twitter data are reported in Table 7 (at Panel A for the OLS and at Panel B for the RD specification).

Results from the OLS specification at Panel A show that the number of negative tweets against Ms. Moratti increased after the Sky debate among females, while the number of negative tweets against Mr. Pisapia — and their intensity, as measured by the net number of negative words - increased among males. The specification at Panel B conveys the same conclusion as the OLS estimations. In this case, there is evidence of more negative tweets against Ms. Moratti after the Sky show even among males, but the effect is stronger for females.

In the end, the same empirical findings emerge from two different data sources that exploit this natural experiment occurred during the 2011 electoral race in Milan. The attack by the female incumbent against the male opponent that took place during a TV show reduced the appeal of the incumbent among female voters, who agreed less with the incumbent in our survey data, and resorted to more negative tweets against the incumbent herself. On the opposite, males increased the number of negative tweets against the opponent. Hence, females seem to dislike negative campaigning even when staged by a female candidate against a male candidate. 


\section{Field Experiment in Cava de' Tirreni}

This field experiment is designed to examine the effects of positive vs. negative electoral campaigning in an election in which the incumbent and the two main opponents are males. This allows us to test the effect on male and female voters of a negative (vs. positive) electoral campaign in which a male candidate attacks another male candidate. Moreover, while running a field - as opposed to a survey - experiment can improve the internal validity of our results, running it in a different political context, with respect to Milan, can also improve their external validity.

\subsection{Political Background}

Cava de' Tirreni is an Italian town of 55 thousand people (around 46 thousand eligible voters), located in the province of Salerno, $40 \mathrm{~km}$ south of Naples. The municipal elections were held in Cava on May 31, 2015. The incumbent mayor, Marco Galdi, from the centerright party "Forza Italia," ran for re-election. Mr. Galdi had previously been elected in March 2010 with $60 \%$ of the votes. Besides the incumbent, several other candidates ran for mayors in 2015. Mr. Galdi's main opponents were Vincenzo Servalli, supported by the center-left party "Partito Democratico," and Armando Lamberti, supported by three civic lists ("Cava unica;" "Cava ci appartiene;" and "Citt Democratica").

The overall tone of the electoral campaign was rather neutral, with some occasional confrontations between the incumbent, Mr. Galdi, and the opponent from the center-left party, Mr. Servalli. Mr. Lamberti used instead a more positive approach and concentrated on explaining his electoral program. In the few occasions in which he used a more negative tone, his main target was the incumbent and his inability to properly manage the city. Typical tools in the campaign were press releases, candidates' interviews with local media (newspapers and TV channels), candidates' speeches at local events, street posters and flyers. TV ads played no role. The main issues that surfaced the electoral campaign concerned the provision of local services (in particular, the future developments of the local hospital, which was under treat of being closed down), the political instability of the previous executive, and fiscal issues at local level, such as spending, taxes, and debt.

At the May 2015 election, the incumbent Marco Galdi, with 25.3\% of the votes, and 
his opponent from the center-left party "Partito Democratico," Vincenzo Servalli, with $28.7 \%$, advanced to the second round. Armando Lamberti received $14.7 \%$ of the votes. At the runoff ballot on June 14, 2015, Vincenzo Servalli was then elected mayor with $60.6 \%$ of the votes. The turnout was $69.7 \%$ in the first round and $50.17 \%$ in the runoff.

\subsection{Experimental Design}

The experiment was designed to examine the differential effect by gender of positive vs. negative campaigning in the 2015 Cava de' Tirreni municipal election.

Our treatments consisted of positive and negative messages administrated through either door-to-door canvassing, or through the delivery of electoral materials to mailboxes. During the three weeks prior to the election, a campaign team of volunteers, supporters of Mr. Lamberti, knocked on doors of private residences, and buzzed private residences' intercoms, to engage in personal interaction with eligible voters. These personal interactions featured the campaign volunteers soliciting the voters to communicate their ideas about what the new mayor should do for Cava de' Tirreni. These ideas would then be reported to the candidate, Mr. Lamberti. Volunteers then took the opportunity to present to these voters Mr. Lamberti's ideas, and to hand them electoral materials. Alternatively, electoral materials were just left in the mailboxes of the other eligible voters, who were not engaged in personal interactions. As a result, the informational treatments were administered both by canvassing and by flyers and hangers on different subsamples of eligible voters.

The canvassing took place from May 10 to May 30, 2015. Twenty volunteers, aged from 18 to 25 years (their group picture is at Figure C1 in Appendix C), were involved in the canvassing, under the supervision of a campaign manager. They walked, drove and ride in Cava de' Tirreni, typically in couples, in order to reach the different locations, where the canvassing took place. They were recognizable for their blue T-shirt with the symbols of the three civic lists and the slogan "Lamberti for Mayor."

While being largely exploited in the US, as part of "get out the vote" strategies, canvassing represented a novelty for Italian politics. ${ }^{24}$ When we first approached Mr. Lamberti

\footnotetext{
${ }^{24}$ To our knowledge, Cantoni and Pons (2016) are the only other canvassing experiment run in Italy. They compare the effect on turnout of canvassing done by paid volunteers vs. canvassing done by local candidates to the city council. Their testing ground is a 2014 municipal election in a mid-sized town in Northern Italy (38 precincts).
} 
and proposed him to run an experiment using canvassing as an electoral campaign tool, his response was enthusiastic. He immediately decided to launch a campaign called "Around the city listening to Citizens." ${ }^{25}$ The volunteers were provided by the candidate, and they underwent a one-day training stage with one of the authors and the campaign manager.

The volunteers did two types of canvassing: positive, by emphasizing Mr. Lamberti's ideas, and negative, by concentrating on the incumbent (Mr. Galdi) wrong-doing while in office. We randomized our positive vs. negative treatments by means of canvassing (which included both personal interaction and electoral materials) or electoral materials left in the mailboxes. The electoral materials consisted of a flyer and a hanger. All these tools were designed by professionals under our direction and in collaboration with the Lamberti's campaign. Clearly, the informational treatments coexisted with the real overall campaign, and therefore their effects (if any) operated at the margin. However, our canvassing was the only door-to-door campaigning implemented in Cava either by Mr. Lamberti or by the other candidates.

In this field experiment, we randomized at electoral precinct level. Cava has 55 electoral precincts, which were randomly assigned to tree groups: positive treatment, negative treatment, and control group. The positive treatment, consisting of canvassing with a positive message, was implemented in 18 precincts, which include 15,925 eligible voters; the negative treatment, consisting of canvassing with a negative message, in 18 precincts (with 15,424 eligible voters), while the control group consisted of 19 precincts $(15,174$ eligible voters), which did not receive any treatment. Table C.1 in Appendix C reports the ex ante balance tests of predetermined variables at the precinct level. The available variables refer to the previous elections for mayor in Cava de' Tirreni in 2006 and 2010. For both elections, they include the number of eligible voters (absolute and by gender), the voter share of the center-right, center-left and other candidates, as well as the voter share of the different party lists. ${ }^{26}$ For all these predetermined variables, our precinct-level randomization is perfectly balanced.

Our experiment was implemented between April 16 and June 12, 2015. A first phone

\footnotetext{
${ }^{25}$ In Italian: "Sportelli itineranti per una campagna di ascolto della citt."

${ }^{26}$ The distinction between the vote share of the candidate and of the party list is of interest. In fact, according to the electoral rule, mayoral candidates can be supported by one or more party lists, and voters are allowed to cast separate votes for a candidate and for a party list supporting another candidate.
} 
survey was conducted by "IPR Feedback," a Salerno-based commercial survey company, between April 16 and April 30, 2015. With this survey, we obtained relevant personal information and individuals' political and social preferences for eligible voters (the text is available at: www.igier.unibocconi.it/cavaexperiment). According to the electoral precinct they belonged to, these voters were then treated with the positive or negative canvassing (or not treated). Volunteers attempted to reach the eligible voters interviewed in our first survey with personal interaction by knocking on their doors, and buzzing their intercoms (see Figure C.2 in Appendix C). Canvassing was also attempted with all eligible voters living in the same apartment buildings as the interviewed voters. For the remaining apartment buildings and private houses in the (positive or negative) treatment precincts, volunteers distributed (positive or negative) electoral materials in the mailboxes, but did not attempted to establish any personal contact. A follow-up post-electoral survey was conducted after the election from June 1 to June 12, 2015. This survey collected information on self-reported outcomes (turnout and actual vote), and voters' perceptions about the different candidates' political position, valence and about the tone of their electoral campaign.

As a result of this experimental design, we have two different campaigning formatscanvassing with flyers and hangers vs. flyers and hangers alone- and two different units of observations - precincts vs. surveyed voters. In this paper, as we are after differential responses by gender, we focus on the survey data.

\subsubsection{Our Sample(s)}

"IPR feedback" used the Cava de' Tirreni public phone database to obtain an initial random sample of about 1,400 eligible voters in the 2015 municipal election. The first survey was administrated with the goal of obtaining relevant personal information (gender, age, marital status, education, number of children), as well as more specific information on economic characteristics (profession, house-ownership), and on political and social attitudes (political orientation, voting behavior in the previous local election, individual perceptions about the political positioning and the valance of the mayoral candidates, individual opinion regarding the more pressing problem that the mayor should address). Additionally, the respondents were asked some questions to elicit their degree of competitiveness 
(self-reported and stemming from actual participation to profesional sport competitions or to contests), and their view on the importance of cooperative behavior in life. The respondents to the initial survey fall into the treatment or control group, depending on the precinct they lived in. However, not all of these individuals participated in the second (post-electoral) survey that we implemented to measure voting choices. Therefore, our final (estimation) sample consists of 857 voters, who answered to the second survey.

The main characteristics of this sample are summarized at Table C.2 in the Appendix C, which provides descriptive statistics by treatment group. Besides standard demographic characteristics and education, we measure the ideological position of each voter, and the preferences for competition and cooperation. All variables come from the post-electoral

survey that reports the voters' post electoral outcomes. The estimation sample is largely composed of females (74\%), and married individuals (76\%) with children (83\%). The share of individuals younger than 30 years (7\%), left wing supporters (13\%), college graduate $(22 \%)$ and who participated in a competition or contest $(19 \%)$ is limited. The first column of Table C.2 reports that $55 \%$ and $51 \%$ of the surveyed eligible voters, who belong respectively to the positive and negative treatment, were not personally reached by the volunteers. Our sample, of course, was not representative of the electorate in the 2015 Cava de' Tirreni election. The internal validity of the experimental design, however, rests on the validity of the randomization protocol (see Table C.1 in Appendix C).

\subsubsection{Informational Treatments}

We administered our positive vs. negative informational treatments by using different campaigning tools: 1) personal interactions with the volunteers; 2) a flyer, either distributed personally to the voter or left on the mailbox; and 3) a hanger, placed on their apartments' door. All political advertising materials were distributed by the volunteers.

Both the positive and the negative version of the flyer are in light blue, portray the candidate and the symbols of the three civic lists with a well-recognizable monument in Cava de' Tirreni on the background (see Figures C.3 and C.4 in Appendix C). They share the slogan on the top line: "Cava belongs to us." In the version with the positive message, the top slogan on the second line is "Let's Put Ourselves on the Line." The remaining of the flyer reads: "In the next 5 years, with Lamberti: more dialogue with the citizens; 
more competence and transparency; more health and local services." In the version with the negative message, the top slogan on the second line is "Together to Take the City Back." The remaining of the flyer reads: "In the past 5 years, with Galdi: too much old politics; too much waste of resource and too high taxes; too much debt on the citizens."

Positive and negative versions of the hangers share the light blue color, the portray of the candidate and the symbols of the three civic lists with a well-recognizable monument in Cava de' Tirreni on the background, the top slogan "Cava belongs to us," and the bottom slogan "Lamberti for Mayor." The only difference is that the version with the positive message has as top slogan on the second line "Let's Put Ourselves on the Line," while the negative version has "Together to Take the City Back" (see Figures C.5 and C.6 in Appendix C).

Hence, the look of the two versions of the flyers and hangers is identical. They only differ in the slogans described above. The topics of the different slogans were also the same, namely, political behavior by the mayor, valence, and policy; and even the length of the different slogans was approximately the same (in Italian, 89 characters for the positive and 92 characters for the negative). Also the script provided to the volunteer to approach the voters was the same in the positive and negative version (see Appendix C). Obviously, the material distributed to the voters, and the discussion that followed when the volunteers were able to gain personal access to the voters, differed depending on the negative or positive treatment.

\subsubsection{Outcome Variables}

The second survey, administrated immediately after the election, collected the (self-reported) voting outcomes. Individuals were asked whether they voted at the election, and (if so) which candidate they voted for. These answers represent our main outcomes of interest in the empirical analysis. Additionally, respondents were asked when they decided whom to vote for, and how much they followed the electoral campaign. Moreover, for each of the three main candidates (Galdi, Servalli and Lamberti), respondents were asked to define the political position of the candidate, to judge his ability level (valence), and to assess whether he ran a positive or negative campaign.

Unlike in the 2011 Milan election at section 2, this post-electoral survey shows that 
our treatments did have some statistically significant average effect. As shown at Tables C.3 and C.4 in Appendix C, respectively for the full sample of eligible voters, and for the sample of canvassed voters, the negative campaign increased the vote share of the opponent and of other candidates (in the canvassed sample at Table C.4), while reducing the vote share of the incumbent. The incumbent's vote share was also decreased by the positive treatment.

\subsection{Identification}

Our field experiment provides an ideal environment to investigate how females and males react to political communication, in an electoral race featuring a male incumbent and male (main) opponents. Tables C.5 and C.6 in Appendix C show that observable covariates are balanced across treatment groups for both females and males, respectively. As in the survey experiment in Milan, described at Section 2.3, we also replicated standard randomization checks within gender strata (see Table C.7 in Appendix C). These checks confirm the validity of the randomization procedure within gender. We then proceed to estimate equation (1) by OLS. This specification allows us to estimate the treatment effect of positive and negative campaign for males and females, both with respect to the control group and between each other. Exactly as in Milan, we also run the Wald tests described in footnote 17.

\subsection{Empirical Results}

Table 8 shows the results on voting choices for the full sample of voters in Cava de' Tirreni, who answered the second (post electoral) survey - regardless of whether the individuals in the treatment groups were personally reached by the canvassing. Positive campaigning increases male turnout with respect to the control group (at the $10 \%$ significance level). When looking at the candidates' vote shares, females vote more for the opponent and less for the incumbent when they are exposed to the opponent's positive campaign, whereas males vote less for the incumbent if exposed to the opponent's negative campaign. Receiving any kind of campaign information by the opponent leads both male and female voters to vote less for the incumbent.

In Table 9, we show the results for our sample of canvassed voters, namely for those 
individuals who were personally reached by our volunteers, either by intercom or at their apartments. Electoral campaigning has no impact on turnout rates, but stronger gender differences emerge in this sample for the effects on the candidates' vote shares. On the one hand, negative campaigning (by the opponent) increases male votes for the opponent both with respect to the control group (at the $10 \%$ significance level) and to positive campaigning (H3, at 5\% significance level), while reducing male votes for the incumbent with respect to the control group (at the $1 \%$ significance level). These effects are sizable: negative campaigning increases the opponent's votes by 15.4 percentage points, while reducing the votes for the incumbent by 27 points. On the other hand, positive campaigning (by the opponent) increases female votes for the opponent with respect to the control group (H1, at the $10 \%$ significance level), while reducing female votes for the incumbent with respect to the control group (H1, at the 5\% significance level). Again, the magnitude of the effects is large: positive campaigning increases the opponent's vote shares by 12.8 points, while reducing incumbent's by 18 points. Overall, these effects amount to persuasion rates that - depending on the outcome and the treatment-range from $16 \%$ to $34 \%$. Finally, the differential treatment effect of positive versus negative campaigning between male and female voters (H5) is particularly evident for the opponent's vote shares. Receiving any kind of campaign information by the opponent leads female voters to vote more for the opponent and less for the incumbent.

Gender differences thus emerge also in an electoral race among males, with a male opponent attacking a male incumbent. But what drives them? Exploiting questions in our post-electoral survey, in which voters were asked whether different candidates run positive or negative campaigns, we can rule out the fact that male and female voters had different perceptions about the tone of the electoral campaign. Gender differences in the behavioral response to political campaigning may be due to observable differences between males and females along other dimensions. Besides the differences in political ideology or education, our initial survey provides information also on individual preferences towards competition and cooperation. ${ }^{27}$ Table C.8 in Appendix C shows in fact that, in our sample,

\footnotetext{
${ }^{27}$ In particular, to exert their degree of competitiveness, voters were asked whether during their life they participated to a sport competition or to any other kind of competition, such as a musical, or any artistic contest. To learn about their preferences for cooperation, voters were asked whether they believed that to succeed in life is more important to cooperate with the others or to be better than the others.
} 
respondents indeed differ by gender along several observable characteristics, including their preferences for competition and cooperation. ${ }^{28}$

We test for these possible channels in Table 10, which shows results for the effects of our informational treatment on voting outcomes - namely, opponent's vote share in panel A and incumbent's vote share in panel B. ${ }^{29}$ We report our baseline specification (at column 1), as well as the specification in which one at a time, each of the following variables and its interaction with the treatment indicator are included: young (column 2), college (column 3), left (column 4), and preferences for competition (column 5) and cooperation (column 6). Results at Table 10 show however that controlling for education, political ideology and competition (and their interaction with our treatments) does not eliminate (or even reduce) our gender effect. A different picture emerges instead when we control for cooperation (column 6): gender differences completely disappear for the incumbent vote share (panel B), but they remain for the opponent vote share (panel A). Nevertheless, the positive campaign is still found to be particularly effective in increasing the opponent vote share among cooperative individuals. This result may suggest that our gender effect is at least partially related to gender differences in cooperative behavior (see Niederle, 2016, for a review). Although the results on a possible gender difference in altruism and social preferences are mixed, women have been found more reciprocal than men in experimental (trust) games (see Croson and Gneezy, 2009). Positive campaigning, which mostly amounts to present future projects for the city, may thus be more in line with this cooperative approach than negative ads.

Our final robustness check is to include in our baseline specification all observable characteristics and their full set of interactions with the treatment indicators. This specification identifies the net effect of gender, after controlling for all these channels. As discussed in section 2.4, this specification is very demanding. The results at Table C.10 (Appendix C) suggest that indeed no gender effect survives after controlling for all these channels. This is hardly surprising ad these variables include cooperation, which we have already shown to mask gender differences.

\footnotetext{
${ }^{28}$ These gender differences in observables, however, do not represent a threat to the validity of our estimates, as they are not systematically different across treatment groups (see Table C.7 in Appendix C). Moreover,we have already shown that covariates are balanced across treatment groups within gender strata (see Tables C.5 and C.6 in Appendix C).

${ }^{29}$ The effect on voters' turnout is reported at Table C.9 in Appendix C.
} 


\section{Conclusion}

Competitive persuasion has become increasingly more important, and thereby more sophisticated, in business and politics. Multiple senders of advertising messages compete for the attention of a large mass of receivers - being them buyers or voters - and try to influence their decisions. The diffusion of social networks and the ability of processing the huge amount of information collected in large datasets have allowed sellers and politicians to identify with strong precision their favorite targets: undecided, potential buyers, and swing voters. Since the ads can now be placed in front of the right receiver, shouldn't also the message be tailored to persuade him or her?

Our experimental evidence from electoral campaigns in Milan (2011) and Cava de'

Tirreni (2015) strongly suggests that the gender of the receiver does indeed matter. In our randomized campaigns, a positive electoral campaign by the opponent increased his vote share, and reduced the incumbent's votes, among female voters. The opposite occurred instead among male voters. Our results are robust to different environment (size and location of the city), gender composition of the electoral race (mixed and all male), experimental methodology (survey, natural, field), and electoral campaign instruments (videos, slogans, flyers, canvassing).

Our findings contribute to the literature on gender difference. Besides other well recognized differences in political ideology, risk aversion, preferences for competition or public policy, we find that gender differences exist also in the behavioral response to aggressive political persuasion. Our empirical tests suggest that this gender difference is neither driven by gender identification, nor by other channels such as females being more left leaning. We are also able to discard that this deep difference in voting behavior is attributed to different tastes for competition - in this case for different forms of electoral competition. We instead find suggestive evidence compatible with the existing findings that females have more cooperative behavior. When we can control for preferences for cooperation (in the Cava de' Tirreni election), in fact most of our gender results disappear.

Additional explanations may however be at work, which we cannot test. For instance, gender differences have been found in attitudes toward violence, even when the phenomenon does not directly affect the respondents (see Smith, 1984; Sapiro and Conover, 
1993). ${ }^{30}$ Although we always used a civil tone in our negative campaigns, females might have perceived the attacks towards the other candidates as violent behavior. Finally, the existence of several gender differences has largely been recognized also by a neuropsychological literature (Baron-Cohen, Knickmeyer, and Belmonte, 2005). Males have been shown to have greater reactivity than females to stressful situations, such as watching a scary or violent movie. Hence, to the extent that a persuasion strategy based on negative advertising is perceived as a more arousing event, it may stimulate more actions among males than among females, who may find more appealing an inclusive persuasion strategy.

\footnotetext{
${ }^{30}$ In a controlled experiment using war scenarios, Brooks and Valentino (2011) show that women are less likely to support war than men, and that female support for war increases when missions have humanitarian objectives and are approved by the United Nations.
} 


\section{References}

[1] Akerlof, G.A., and R.E. Kranton (2000), "Economics and Identity," Quarterly Journal of Economics, 115(3): 715-753.

[2] Ansolabehere, S., S. Iyengar, A. Simon, and N. Valentino (1994), "Does Attack Advertising Demobilize the Electorate?" American Political Science Review, 88(4): 829-838.

[3] Ansolabehere, S., and S. Iyengar (1995), Going Negative: How Political Advertisements Shrink and Polarize the Electorate, New York: The Free Press.

[4] Arceneaux, K., and D.W. Nickerson (2010), "Comparing Negative and Positive Campaign Messages," American Politics Research, 38(1): 54-83.

[5] Bagues, M., and B. Esteve-Volart (2012), "Are Women Pawns in the Political Game? Evidence from Elections to the Spanish Senate," Journal of Public Economics, 96: 387-399.

[6] Baltrunaite, A., P. Bello, A. Casarico, and P. Profeta (2014), "Gender Quotas and the Quality of Politicians," Journal of Public Economics, 118(C): 62-74.

[7] Baron-Cohen, S., R.C. Knickmeyer, and M.K. Belmonte (2005), "Sex Differences in the Brain: Implications for Explaining Autism," Science, 310(4): 819-823.

[8] Bassi, V., I., Rasul (2015), "Persuasion: A Case Study of Papal Influences on FertilityRelated Beliefs and Behavior,"mimeo, University College London

[9] Bertrand, M. (2010), "New Perspectives on Gender", in D. Card and O. Ashenfelter (eds), Handbook of Labor Economics, Vol 4, Part B, Amsterdam: Elsevier Ltd.

[10] Bertrand, M., D.S. Karlan, S. Mullainathan, E. Shafir, and J. Zinman (2010), "What's Advertising Content Worth? Evidence from a Consumer Credit Marketing Field Experiment," Quarterly Journal of Economics, 125: 263-305.

[11] Braconier, C., J-Y., Dormagen, and V. Pons (2016), "Voter Registration Costs and Disenfranchisement: Experimental Evidence from France," Harvard Business School Working Paper 16-098 
[12] Brooks, D.J., and B.A. Valentino (2011), “A War on One's Own: Understanding the Gender Gap in Support of the War," Public Opinion Quarterly, 75(2): 270-286.

[13] Brooks, D.J., and J.G. Geer (2007), "Beyond Negativity: The Effects of Incivility on the Electorate," American Journal of Political Science, 51(1): 1-16.

[14] Cantoni, E., V. Pons, (2016), "Do Interactions With Candidates Increase Voter Support and Participation? Experimental Evidence from Italy," Harvard Business School Working Paper 16-080

[15] Cavalcanti, T.V., and J. Tavares (2011), "Women Prefer Larger Governments: Growth, Structural Transformation, And Government Size," Economic Inquiry, 49(1): 155-171.

[16] Chattopadhyay, R., and E. Duflo (2004), "Women as Policy Makers: Evidence from a Randomized Policy Experiment in India," Econometrica, 72(5): 1409-1443.

[17] Clinton, J.D., and J.S. Lapinski (2004), "Targeted Advertising and Voter Turnout: An Experimental Study of the 2000 Presidential Election," Journal of Politics, 66(1): 69-96.

[18] Croson, R., and U. Gneezy (2009), "Gender Differences in Preferences," Journal of Economic Literature, 47(2): 448-474.

[19] DellaVigna, S., and E. Kaplan (2007), "The Fox News Effect: Media Bias and Voting," Quarterly Journal of Economics, 122(3): 1187-234.

[20] DellaVigna, S., and M. Gentzkow (2010), "Persuasion: Empirical Evidence," Annual Review of Economics, 2: 643-69.

[21] DellaVigna, S., J.A. List, and U. Malmendier (2012), "Testing for Altruism and Social Pressure in Charitable Giving," Quarterly Journal of Economics, 127(1): 1-56.

[22] Dewan, T., M. Humphreys, and D. Rubenson (2014), "Elements of Political Persuasion: Content, Contact, or Cue," Economic Journal, 124 (574): 257-292.

[23] Edlund, L., and R. Pande (2002), "Why Have Women Become Left-Wing? The Political Gender Gap And The Decline In Marriage," Quarterly Journal of Economics, 117: 917-961. 
[24] Finkel, S.E., and J.G. Geer (1998), "A Spot Check: Casting Doubt on the Demobilizing Effect of Attack Advertising," American Journal of Political Science, 42(2): 573-595.

[25] Freedman, P., and K. Goldstein (1999), "Measuring Media Exposure and the Effects of Negative Campaign Ads," American Journal of Political Science, 43(4): 1189-1208.

[26] Fridkin, K.L., and P.J. Kenney (2011), "Variability in Citizens' Reactions to Different Types of Negative Campaigns," American Journal of Political Science, 55(2): 307-325.

[27] Funk, P., and C. Gathmann (2013), "How do Electoral Systems Affect Fiscal Policy? Evidence from State and Local Governments, 1890 to 2005," Journal of the European Economic Association, 11(5): 1178-1203.

[28] Gagliarducci, S., and M.D. Paserman (2012), "Gender Interactions within Hierarchies: Evidence from the Political Arena," Review of Economic Studies, 79(3): 1021-1052.

[29] Gentzkow, M., and E. Kamenica (2011), "Competition in Persuasion," NBER Working Paper 17436.

[30] Gentzkow, M., J.M. Shapiro, and M. Sinkinson (2011), "The Effect of Newspaper Entry and Exit on Electoral Politics," American Economic Review, 101(7): 2980-3018.

[31] Gerber, A.S., J.G. Gimpel, D.P. Green, and D. Shaw (2011), "How Large and Long-lasting Are the Persuasive Effects of Televised Campaign Ads? Results from a Randomized Field Experiment," American Political Science Review, 105: 135-150.

[32] Gerber, A.S., and D.P. Green (2000), "The Effects of Canvassing, Telephone Calls, and Direct Mail on Voter Turnout: A Field Experiment," American Political Science Review, 94: $653-63$.

[33] Gerber, A.S., D.P. Green, and R. Shachar (2003), "Voting May Be Habit-Forming: Evidence from a Randomized Field Experiment," American Journal of Political Science, 47: 540-50.

[34] Glaeser, E.L., G. Ponzetto, and J.M. Shapiro (2005), "Strategic Extremism: Why Republicans and Democrats Divide on Religious Values," Quarterly Journal of Economics, 120(4): $1283-1330$. 
[35] Goldstein, K., and P. Freedman (2002), "Campaign Advertising and Voter Turnout: New Evidence for a Simulation Effect," Journal of Politics, 64(3): 721-740.

[36] Green, D.P., and A.S. Gerber (2004), Get Out the Vote: How to Increase Voter Turnout, Washington, D.C.: Brookings Institution Press.

[37] Kahn, K.F., and P.J. Kenney (1999), "Do Negative Campaigns Mobilize or Suppress Turnout? Clarifying the Relationship between Negativity and Participation," American Political Science Review, 93(4): 877-889.

[38] Kahn, K.F., and P.J. Kenney (2011), "Variability in Citizens Reactions to Different Types of Negative Campaigns," American Journal of Political Science, 55(2): 307-325.

[39] Kendall, C., T. Nannicini, and F. Trebbi (2015), "How Do Voters Respond to Information? Evidence from a Randomized Campaign," American Economic Review, 105: 322-353.

[40] Issenberg, S. (2012), The Victory Lab: The Secret Science of Winning Campaigns, New York: Crown.

[41] Lau, R., L. Sigelman, and I.B. Rovner (2007), "The Effects of Negative Political Campaigns: A Meta-Analytic Reassessment," Journal of Politics, 69(4): 1176-1209.

[42] Murphy, K.M., and A. Shleifer (2004), "Persuasion in Politics," American Economic Review PEP, 94(2): 435-439.

[43] Nickerson, D.W. (2008), "Is Voting Contagious? Evidence from Two Field Experiments," American Political Science Review, 102: 49-57.

[44] Niederle, M., (2016), "Gender", in J. Kagel and A.E. Roth (eds), Handbook of Experimental Economics, second edition

[45] Niederle, M., and L. Vesterlund (2011), "Gender and Competition" Annual Review in Economics, 3: 601-630.

[46] Pons, V. (2016), "Will a Five-Minute Discussion Change Your Mind? A Countrywide Experiment on Voter Choice in France," Harvard Business School Working Paper 16-079 
[47] Prakash, V. (1992), "Sex Roles and Advertising Preferences," Journal of Advertising Research, May/June: 43-52.

[48] Preece, J., O., Stoddard (2015a), "'Does the message matter? A field experiment on political party recruitment," Journal of Experimental Political Science, 2: 1-10.

[49] Preece, J., O., Stoddard (2015b), "Why women don't run: Experimental evidence on gender differences in competition aversion," Journal of Economic Behavior and Organization, 117: 296-308.

[50] Rush, K., (2012), "Optimization at the Obama campaign: a/b testing" at http://kylerush.net/

[51] Sapiro, V., and P.J. Conover (1993), "Gender, Feminist Consciousness, and War," American Journal of Political Science, 37(4): 1079-1099.

[52] Smith, T.W. (1984), "The Polls: Gender and Attitudes Toward Violence," Public Opinion Quarterly, 48: 384-396.

[53] Vilela, A.M., and M.R. Nelson (2006), "Values: Better than Sex Segmentation Strategy for Cause-Related Marketing Messages," paper presented at the Annual Meeting of the International Communication Association, Dresden.

[54] Wattenberg, M.P., and C.L. Brians (1999), "Negative Campaign Advertising: Demobilizer or Mobilizer?" American Political Science Review, 93(4): 891-899. 


\section{Figures and Tables}

Figure 1 - Timing of the Experimental Design in Milan

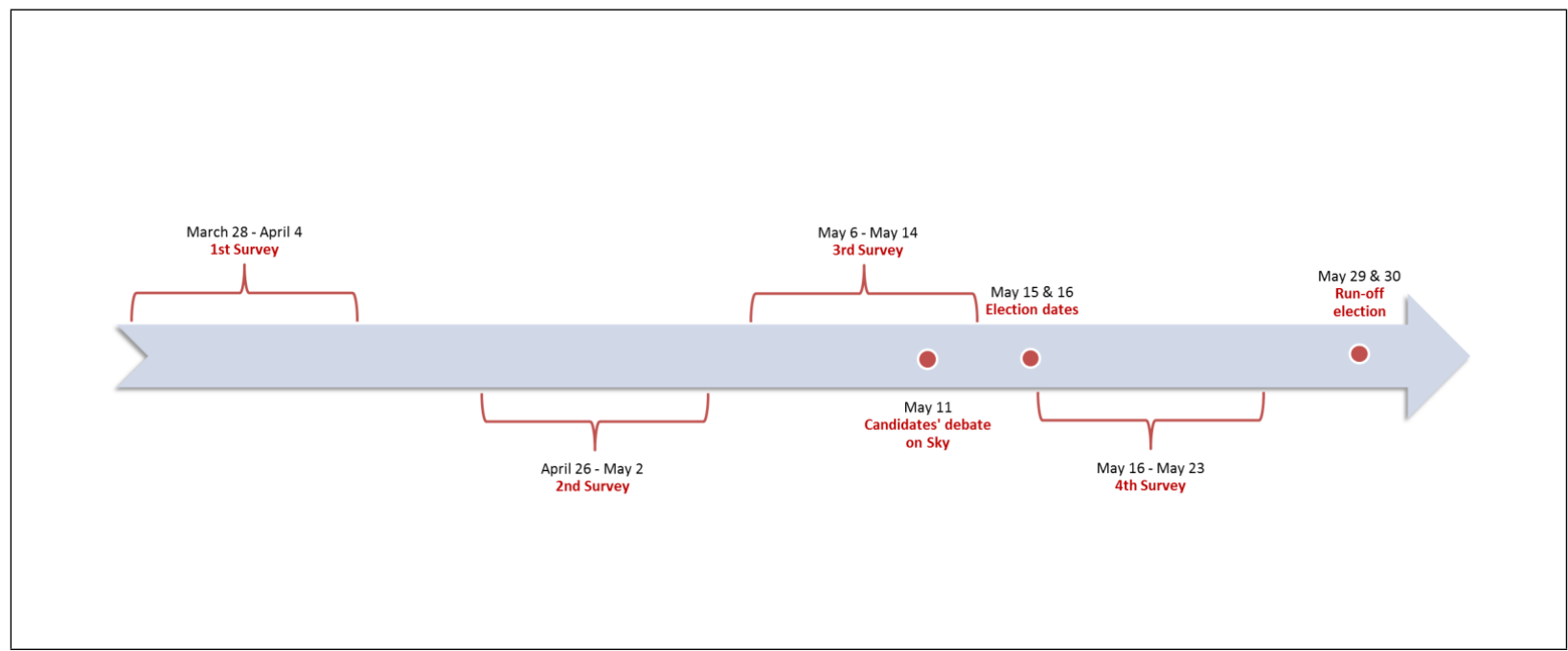

Notes. All dates refer to 2011. The timeline reports the starting and ending dates of the four online surveys; the date of the candidates' debate on Sky TV; and the dates of the elections (first round and runoff). The first (pre-randomization) survey profiled the eligible voters in the sample. The second survey administered the first two informational treatments: video interviews with the candidates; campaign slogans. The third survey administered the last two informational treatments: open letters to voters; video ads endorsed by the candidates. The fourth (post-election) survey elicited voting behaviors. 
Table 1 - Effects of Campaign Information by Gender in Milan, First Round

\begin{tabular}{|c|c|c|c|c|}
\hline & $\begin{array}{l}\text { Turnout } \\
\text { rate }\end{array}$ & $\begin{array}{l}\text { Opponent's } \\
\text { vote share }\end{array}$ & $\begin{array}{l}\text { Incumbent's } \\
\text { vote share }\end{array}$ & $\begin{array}{c}\text { Others' } \\
\text { vote share }\end{array}$ \\
\hline \multirow{2}{*}{ Positive campaign $\left(\alpha_{1}\right)$} & 0.031 & $-0.110^{*}$ & $0.127^{* *}$ & -0.018 \\
\hline & {$[0.043]$} & {$[0.059]$} & {$[0.054]$} & {$[0.063]$} \\
\hline \multirow{2}{*}{ Negative campaign $\left(\alpha_{2}\right)$} & $0.082^{* *}$ & -0.075 & 0.100 & -0.025 \\
\hline & {$[0.037]$} & {$[0.069]$} & {$[0.061]$} & {$[0.054]$} \\
\hline \multirow{2}{*}{ Positive campaign $\times$ Female $\left(\beta_{1}\right)$} & -0.080 & $0.190 * *$ & $-0.207^{* * *}$ & 0.018 \\
\hline & {$[0.051]$} & {$[0.080]$} & {$[0.075]$} & [0.070] \\
\hline \multirow[t]{2}{*}{ Negative campaign $\times$ Female $\left(\beta_{2}\right)$} & $-0.114^{* *}$ & 0.065 & -0.101 & 0.036 \\
\hline & {$[0.049]$} & {$[0.083]$} & {$[0.077]$} & [0.065] \\
\hline \multirow{2}{*}{ Female } & 0.061 & 0.004 & 0.067 & -0.071 \\
\hline & {$[0.040]$} & {$[0.071]$} & {$[0.057]$} & {$[0.052]$} \\
\hline 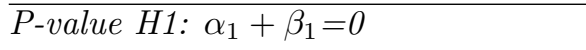 & $0.068^{*}$ & 0.154 & 0.119 & 0.994 \\
\hline$P$-value H2: $\alpha_{2}+\beta_{2}=0$ & 0.289 & 0.851 & 0.982 & 0.770 \\
\hline$P$-value H3: $\alpha_{1}-\alpha_{2}=0$ & $0.092^{*}$ & 0.435 & 0.619 & 0.876 \\
\hline$P$-value $H_{4}: \alpha_{1}+\beta_{1}-\left(\alpha_{2}+\beta_{2}\right)=0$ & 0.556 & $0.062^{*}$ & $0.074^{*}$ & 0.776 \\
\hline$P$-value $H 5: \beta_{1}-\beta_{2}=0$ & 0.365 & $0.035^{* *}$ & $0.076^{*}$ & 0.785 \\
\hline P-value H6: $\alpha_{1}+\alpha_{2}=0$ & 0.137 & 0.132 & $0.033^{* *}$ & 0.694 \\
\hline$P$-value H7: $\alpha_{1}+\beta_{1}+\alpha_{2}+\beta_{2}=0$ & 0.102 & 0.460 & 0.342 & 0.870 \\
\hline P-value $H 8: \beta_{1}+\beta_{2}=0$ & $0.043^{* *}$ & 0.104 & $0.034^{* *}$ & 0.656 \\
\hline Obs. & 1,140 & 912 & 912 & 912 \\
\hline \multicolumn{5}{|c|}{$\begin{array}{l}\text { Notes. Estimated OLS regression: } Y_{i}=\alpha_{1} P O S_{i}+\alpha_{2} N E G_{i}+\beta_{1} P O S_{i} \times F E M A L E_{i}+\beta_{2} N E G_{i} \times F E M A L E_{i}+\delta F E M A L E_{i}+ \\
\varepsilon_{i} \text {. (H1) Treatment effect of positive vs. no campaign for females: } \alpha_{1}+\beta_{1}=0 \text {. (H2) Treatment effect of negative vs. no } \\
\text { campaign for females: } \alpha_{2}+\beta_{2}=0 \text {. (H3) Treatment effect of positive vs. negative campaign for males: } \alpha_{1}-\alpha_{2}=0 \text {. (H4) } \\
\text { Treatment effect of positive vs. negative campaign for females: }\left(\alpha_{1}+\beta_{1}\right)-\left(\alpha_{2}+\beta_{2}\right)=0 \text {. (H5) Differential treatment effect } \\
\text { of positive vs. negative campaign between males and females: } \beta_{1}-\beta_{2}=0 \text {. (H6) Treatment effect of any campaign vs. no } \\
\text { campaign for males: } \alpha_{1}+\alpha_{2}=0 \text {. (H7) Treatment effect of any campaign vs. no campaign for females: }\left(\alpha_{1}+\beta_{1}\right)+\left(\alpha_{2}+\beta_{2}\right)= \\
0 \text {. (H8) Differential treatment effect of any campaign vs. no campaign between males and females: } \beta_{1}+\beta_{2}=0 \text {. Robust } \\
\text { standard errors are in brackets. Significance at the } 10 \% \text { level is represented by } * \text {, at the } 5 \% \text { level by **, and at the } 1 \% \text { level } \\
\text { by }{ }^{* * *} \text {. }\end{array}$} \\
\hline
\end{tabular}


Table 2 - Effects of Campaign Information by Gender in Milan, Runoff

\begin{tabular}{|c|c|c|c|c|}
\hline & $\begin{array}{l}\text { Expected } \\
\text { turnout }\end{array}$ & $\begin{array}{l}\text { Vote for } \\
\text { opponent }\end{array}$ & $\begin{array}{l}\text { Vote for } \\
\text { incumbent }\end{array}$ & Undecided \\
\hline \multirow[t]{2}{*}{ Positive campaign $\left(\alpha_{1}\right)$} & 0.022 & -0.085 & $0.184^{* * *}$ & $-0.099^{* *}$ \\
\hline & {$[0.046]$} & {$[0.058]$} & {$[0.057]$} & {$[0.043]$} \\
\hline \multirow[t]{2}{*}{ Negative campaign $\left(\alpha_{2}\right)$} & $0.067^{*}$ & -0.051 & $0.129 * *$ & $-0.078^{*}$ \\
\hline & {$[0.035]$} & {$[0.063]$} & {$[0.062]$} & {$[0.043]$} \\
\hline \multirow[t]{2}{*}{ Positive campaign $\times$ Female $\left(\beta_{1}\right)$} & -0.017 & $0.163^{*}$ & $-0.272^{* * *}$ & $0.109^{*}$ \\
\hline & {$[0.046]$} & {$[0.081]$} & {$[0.082]$} & {$[0.060]$} \\
\hline \multirow{2}{*}{ Negative campaign $\times$ Female $\left(\beta_{2}\right)$} & $-0.089^{* *}$ & 0.124 & $-0.139^{*}$ & 0.015 \\
\hline & {$[0.042]$} & {$[0.086]$} & {$[0.080]$} & {$[0.053]$} \\
\hline \multirow[t]{2}{*}{ Female } & 0.051 & -0.042 & 0.096 & -0.054 \\
\hline & {$[0.035]$} & {$[0.070]$} & {$[0.068]$} & {$[0.051]$} \\
\hline$\overline{P \text {-value } H 1:} \alpha_{1}+\beta_{1}=0$ & 0.835 & 0.135 & $0.085^{*}$ & 0.816 \\
\hline P-value H2: $\alpha_{2}+\beta_{2}=0$ & 0.459 & 0.111 & 0.816 & $0.054^{*}$ \\
\hline P-value HЗ: $\alpha_{1}-\alpha_{2}=0$ & 0.141 & 0.467 & 0.300 & 0.569 \\
\hline P-value $H_{4}: \alpha_{1}+\beta_{1}-\left(\alpha_{2}+\beta_{2}\right)=0$ & 0.256 & 0.921 & $0.061^{*}$ & $0.032^{* *}$ \\
\hline$P$-value $H 5: \beta_{1}-\beta_{2}=0$ & $0.059^{*}$ & 0.473 & $0.028^{* *}$ & $0.087^{*}$ \\
\hline$P$-value $H 6: \alpha_{1}+\alpha_{2}=0$ & 0.251 & 0.228 & $0.006^{* * *}$ & $0.028 * *$ \\
\hline$P$-value H\%: $\alpha_{1}+\beta_{1}+\alpha_{2}+\beta_{2}=0$ & 0.716 & $0.081^{*}$ & 0.247 & 0.450 \\
\hline$P$-value $H 8: \beta_{1}+\beta_{2}=0$ & 0.190 & $0.078^{*}$ & $0.010^{* * *}$ & 0.225 \\
\hline Obs. & 1,119 & 1,034 & 1,034 & 1,034 \\
\hline \multicolumn{5}{|c|}{$\begin{array}{l}\text { Notes. Estimated OLS regression: } Y_{i}=\alpha_{1} P O S_{i}+\alpha_{2} N E G_{i}+\beta_{1} P O S_{i} \times F E M A L E_{i}+\beta_{2} N E G_{i} \times F E M A L E_{i}+\delta F E M A L E_{i}+ \\
\varepsilon_{i} \text {. (H1) Treatment effect of positive vs. no campaign for females: } \alpha_{1}+\beta_{1}=0 \text {. (H2) Treatment effect of negative vs. no } \\
\text { campaign for females: } \alpha_{2}+\beta_{2}=0 \text {. (H3) Treatment effect of positive vs. negative campaign for males: } \alpha_{1}-\alpha_{2}=0 \text {. (H4) } \\
\text { Treatment effect of positive vs. negative campaign for females: }\left(\alpha_{1}+\beta_{1}\right)-\left(\alpha_{2}+\beta_{2}\right)=0 \text {. (H5) Differential treatment effect } \\
\text { of positive vs. negative campaign between males and females: } \beta_{1}-\beta_{2}=0 \text {. (H6) Treatment effect of any campaign vs. no } \\
\text { campaign for males: } \alpha_{1}+\alpha_{2}=0 \text {. (H7) Treatment effect of any campaign vs. no campaign for females: }\left(\alpha_{1}+\beta_{1}\right)+\left(\alpha_{2}+\beta_{2}\right)= \\
0 \text {. (H8) Differential treatment effect of any campaign vs. no campaign between males and females: } \beta_{1}+\beta_{2}=0 \text {. Robust } \\
\text { standard errors are in brackets. Significance at the } 10 \% \text { level is represented by } * \text {, at the } 5 \% \text { level by } * * \text {, and at the } 1 \% \text { level } \\
\text { by } * * * \text {. }\end{array}$} \\
\hline
\end{tabular}


Table 3 - Instantaneous Effects of Campaign Tools in Milan

\begin{tabular}{|c|c|c|c|c|}
\hline & \multicolumn{4}{|c|}{ Panel A. $2^{\text {nd }}$ Survey } \\
\hline & $\begin{array}{l}\text { Agree with } \\
\text { opponent's } \\
\text { video }\end{array}$ & $\begin{array}{l}\text { Agree with } \\
\text { incumbent's } \\
\text { video }\end{array}$ & $\begin{array}{c}\text { Trust } \\
\text { opponent }\end{array}$ & $\begin{array}{c}\text { Trust } \\
\text { incumbent }\end{array}$ \\
\hline \multirow{2}{*}{ Positive campaign $\left(\alpha_{1}\right)$} & -0.067 & $0.147^{* *}$ & -0.060 & $0.157^{* * *}$ \\
\hline & {$[0.051]$} & {$[0.060]$} & {$[0.049]$} & {$[0.056]$} \\
\hline \multirow{2}{*}{ Positive campaign $\times$ Female $\left(\beta_{1}\right)$} & 0.108 & $-0.196^{* *}$ & 0.092 & $-0.244^{* * *}$ \\
\hline & {$[0.070]$} & {$[0.078]$} & {$[0.072]$} & {$[0.065]$} \\
\hline \multirow[t]{2}{*}{ Female } & -0.013 & 0.076 & -0.024 & $0.088^{*}$ \\
\hline & {$[0.060]$} & {$[0.051]$} & {$[0.055]$} & {$[0.045]$} \\
\hline$P$-value H1: $\alpha_{1}+\beta_{1}=0$ & 0.374 & 0.384 & 0.481 & $0.088^{*}$ \\
\hline \multirow[t]{3}{*}{ Obs. } & 793 & 793 & 793 & 793 \\
\hline & \multicolumn{4}{|c|}{ Panel B. $3^{r d}$ Survey } \\
\hline & $\begin{array}{l}\text { Agree with } \\
\text { opponent's } \\
\text { letter }\end{array}$ & $\begin{array}{c}\text { Agree with } \\
\text { incumbent's } \\
\text { letter }\end{array}$ & $\begin{array}{c}\text { Trust } \\
\text { opponent's } \\
\text { video }\end{array}$ & $\begin{array}{c}\text { Trust } \\
\text { incumbent's } \\
\text { video }\end{array}$ \\
\hline \multirow{2}{*}{ Positive campaign $\left(\alpha_{1}\right)$} & 0.055 & $0.156^{* *}$ & -0.061 & $0.143^{* *}$ \\
\hline & {$[0.060]$} & {$[0.059]$} & {$[0.058]$} & {$[0.057]$} \\
\hline \multirow[t]{2}{*}{ Positive campaign $\times$ Female $\left(\beta_{1}\right)$} & -0.008 & $-0.200^{* *}$ & 0.103 & $-0.181^{* *}$ \\
\hline & {$[0.068]$} & {$[0.078]$} & {$[0.076]$} & {$[0.078]$} \\
\hline \multirow[t]{2}{*}{ Female } & 0.005 & 0.020 & 0.016 & 0.023 \\
\hline & {$[0.049]$} & {$[0.049]$} & {$[0.058]$} & {$[0.053]$} \\
\hline$P$-value H1: $\alpha_{1}+\beta_{1}=0$ & 0.269 & 0.380 & 0.359 & 0.424 \\
\hline Obs. & 762 & 762 & 762 & 762 \\
\hline \multicolumn{5}{|c|}{$\begin{array}{l}\text { Notes. Estimated OLS regression in the subsample exposed to any campaign (non-missing values only): } Y_{i}=\alpha_{1} P O S_{i}+ \\
\beta_{1} P O S_{i} \times F E M A L E_{i}+\delta F E M A L E_{i}+\varepsilon_{i} . \text { (H1) Treatment effect of positive vs. negative campaign for females: } \alpha_{1}+\beta_{1}=0 . \\
\text { In Panel A, the first two columns refer to questions asked after the video interview with each candidate ("do you agree } \\
\text { with what the candidate says in the video?"); last two columns refer to questions asked after the campaign slogan of each } \\
\text { candidate ("how much do you feel you can trust the candidate?"). In Panel B, the first two columns refer to questions asked } \\
\text { after each candidate's open letter to voters ("do you agree with the general sense of this letter?"); last two columns refer to } \\
\text { questions asked after the video ad endorsed by each candidate ("how truthful does this electoral message seem to you?"). } \\
\text { Robust standard errors are in brackets. Significance at the } 10 \% \text { level is represented by *, at the } 5 \% \text { level by **, and at the } \\
1 \% \text { level by } * * * \text {. }\end{array}$} \\
\hline
\end{tabular}




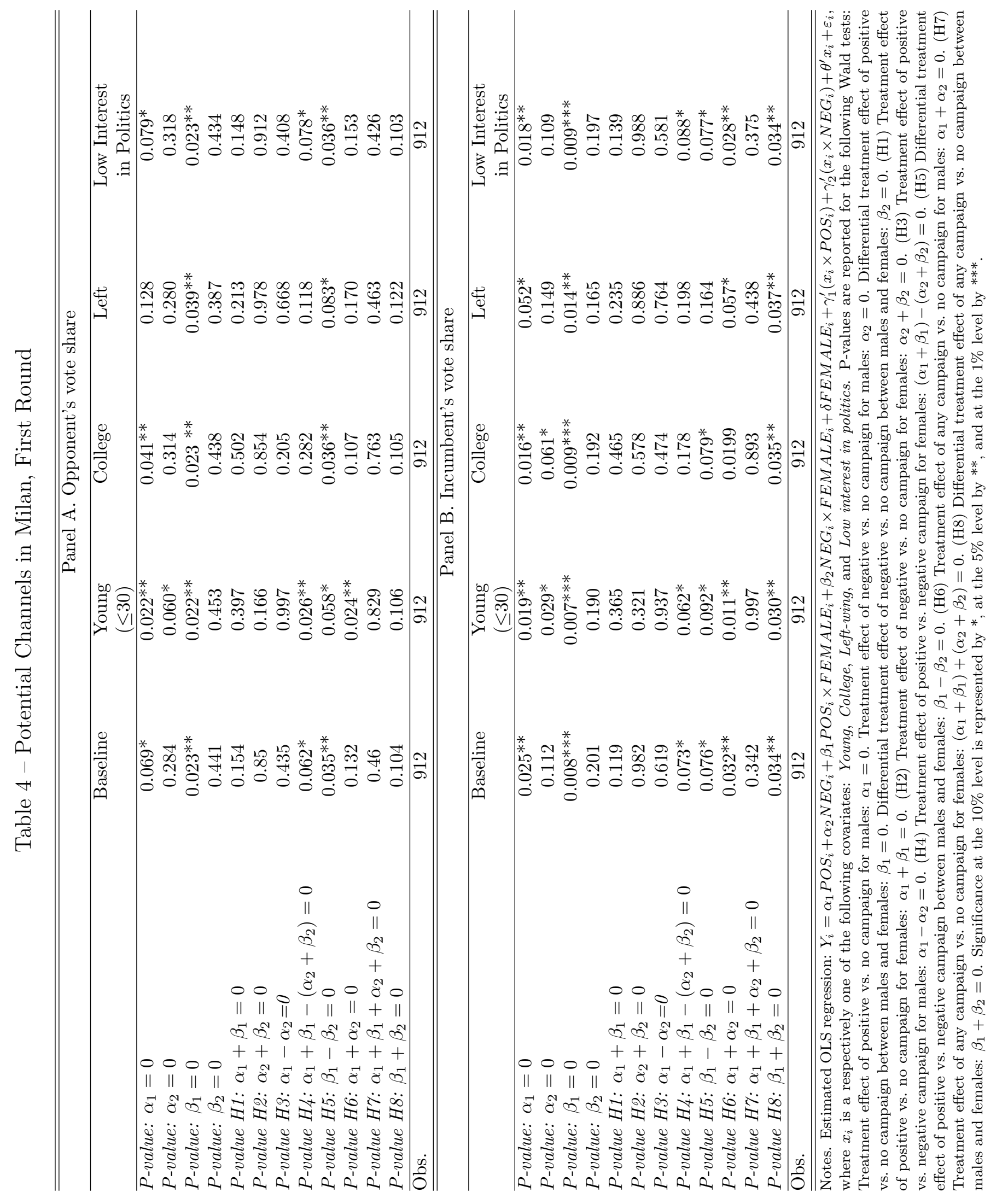




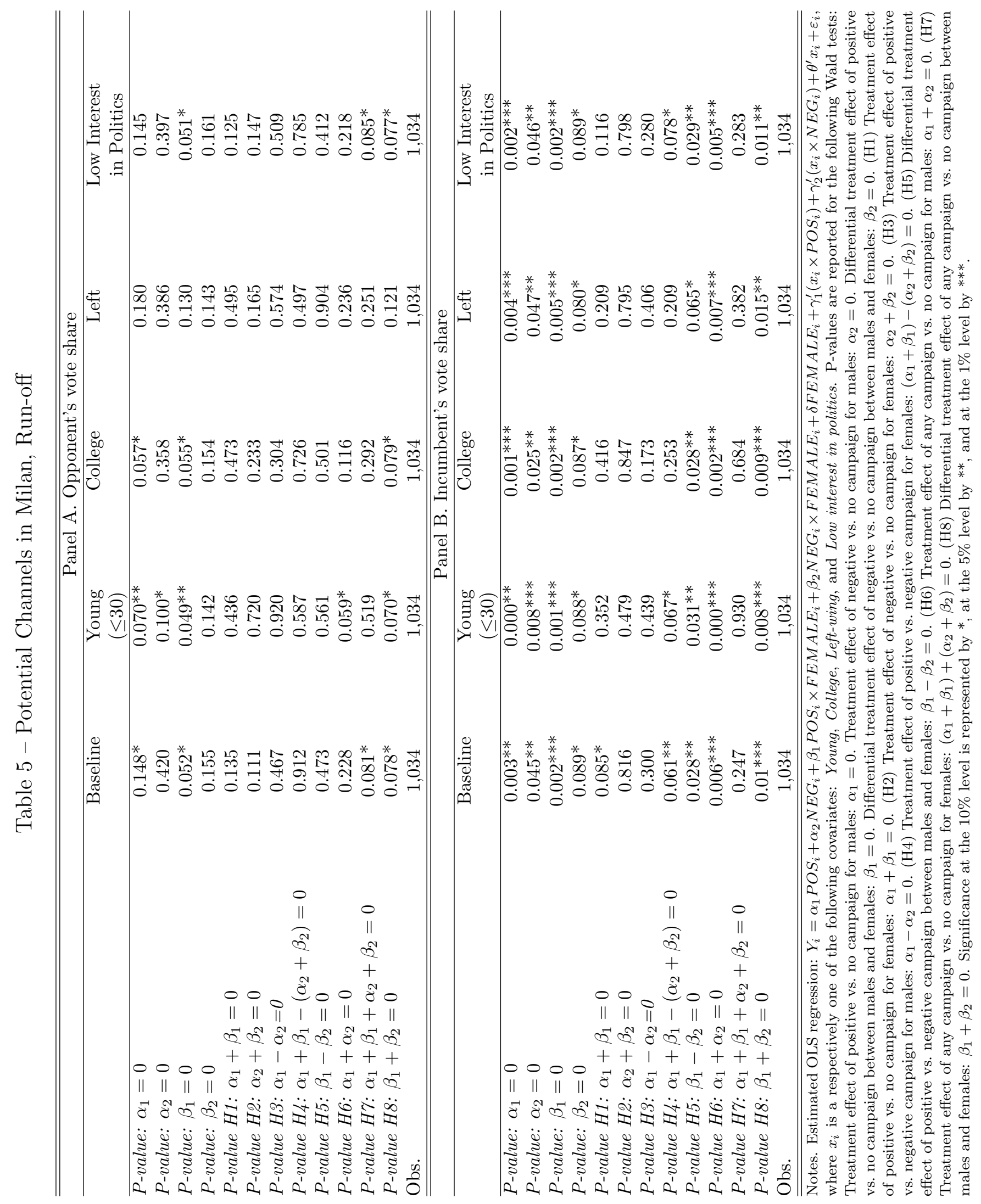


Table 6 - Effects of Sky TV Show on $3^{\text {rd }}$ Survey Outcomes

\begin{tabular}{|c|c|c|c|c|}
\hline & $\begin{array}{l}\text { Agree with } \\
\text { opponent's } \\
\text { letter }\end{array}$ & $\begin{array}{c}\text { Agree with } \\
\text { incumbent's } \\
\text { letter }\end{array}$ & $\begin{array}{c}\text { Trust } \\
\text { opponent's } \\
\text { video }\end{array}$ & $\begin{array}{c}\text { Trust } \\
\text { incumbent's } \\
\text { video }\end{array}$ \\
\hline & \multicolumn{4}{|c|}{ Panel A. OLS specifications } \\
\hline \multirow[t]{2}{*}{ After Sky $\left(\alpha_{1}\right)$} & -0.113 & 0.113 & -0.043 & 0.092 \\
\hline & {$[0.069]$} & {$[0.078]$} & {$[0.086]$} & {$[0.079]$} \\
\hline \multirow{2}{*}{ After Sky $\times$ Female $\left(\beta_{1}\right)$} & $0.189 * *$ & $-0.207^{* *}$ & -0.021 & $-0.213^{* *}$ \\
\hline & {$[0.087]$} & {$[0.079]$} & [0.109] & {$[0.083]$} \\
\hline \multirow[t]{2}{*}{ Female } & -0.024 & -0.045 & 0.067 & -0.033 \\
\hline & {$[0.042]$} & {$[0.038]$} & {$[0.040]$} & {$[0.034]$} \\
\hline \multirow[t]{2}{*}{ P-value H1: $\alpha_{1}+\beta_{1}=0$} & 0.166 & $0.091^{*}$ & 0.273 & $0.041^{* *}$ \\
\hline & \multicolumn{4}{|c|}{ Panel B. RD specifications } \\
\hline \multirow[t]{2}{*}{ After Sky $\left(\alpha_{1}\right)$} & -0.142 & 0.139 & -0.121 & 0.071 \\
\hline & {$[0.089]$} & {$[0.088]$} & {$[0.117]$} & {$[0.093]$} \\
\hline \multirow{2}{*}{ After Sky $\times$ Female $\left(\beta_{1}\right)$} & $0.182^{* *}$ & $-0.201^{* *}$ & -0.040 & $-0.219^{* *}$ \\
\hline & {$[0.086]$} & {$[0.077]$} & {$[0.109]$} & {$[0.083]$} \\
\hline \multirow[t]{2}{*}{ Female } & -0.021 & -0.050 & $0.069^{*}$ & -0.041 \\
\hline & {$[0.043]$} & [0.039] & {$[0.041]$} & {$[0.035]$} \\
\hline P-value H1: $\alpha_{1}+\beta_{1}=0$ & 0.631 & 0.409 & 0.113 & 0.116 \\
\hline Obs. & 762 & 762 & 762 & 762 \\
\hline \multicolumn{5}{|c|}{$\begin{array}{l}\text { Notes. Panel A reports the OLS specifications: } Y_{i}=\alpha_{1} A F T E R_{i}+\beta_{1} A F T E R_{i} \times F E M A L E_{i}+\delta F E M A L E_{i}+\varepsilon_{i} ; \text { where } \\
A F T E R_{i} \text { is a dummy equal to one if the voter responded before the Sky TV show was aired, and equal to zero otherwise. } \\
\text { Panel B reports the RD specifications: } Y_{i}=\alpha_{1} A F T E R_{i}+\beta_{1} A F T E R_{i} \times F E M A L E_{i}+\delta F E M A L E_{i}+f\left(D I S T A N C E_{i}\right)+\varepsilon_{i} \text {; } \\
\text { where } f(.) \text { is a spline third-order polynomial control function, and } D I S T A N C E_{i} \text { is the distance from the time of the show } \\
\text { measured in minutes. (H1) Treatment effect of positive vs. negative campaign for females: } \alpha_{1}+\beta_{1}=0 \text {. Robust standard } \\
\text { errors are in brackets. Significance at the } 10 \% \text { level is represented by }{ }^{*} \text {, at the } 5 \% \text { level by } * * \text {, and at the } 1 \% \text { level by ***. }\end{array}$} \\
\hline
\end{tabular}


Table 7 - Effects of Sky TV Show on the Tweets' Tone

\begin{tabular}{|c|c|c|c|c|}
\hline & $\begin{array}{l}\text { Moratti } \\
\text { Negative } \\
\text { Dummy }\end{array}$ & $\begin{array}{l}\text { Moratti } \\
\text { Negative } \\
\text { Index }\end{array}$ & $\begin{array}{l}\text { Pisapia } \\
\text { Negative } \\
\text { Dummy }\end{array}$ & $\begin{array}{l}\text { Pisapia } \\
\text { Negative } \\
\text { Index }\end{array}$ \\
\hline & \multicolumn{4}{|c|}{ Panel A. OLS specifications } \\
\hline \multirow[t]{2}{*}{ After Sky $\left(\alpha_{1}\right)$} & 0.016 & -0.023 & $0.044^{* * *}$ & $0.134^{* * *}$ \\
\hline & {$[0.020]$} & [0.037] & {$[0.014]$} & [0.033] \\
\hline \multirow{2}{*}{ After Sky $\times$ Female $\left(\beta_{1}\right)$} & $0.094^{* *}$ & 0.045 & -0.019 & 0.085 \\
\hline & {$[0.039]$} & {$[0.075]$} & {$[0.026]$} & {$[0.068]$} \\
\hline \multirow[t]{2}{*}{ Female } & -0.035 & -0.004 & -0.003 & $-0.111^{*}$ \\
\hline & {$[0.029]$} & {$[0.058]$} & {$[0.020]$} & {$[0.059]$} \\
\hline \multirow[t]{2}{*}{ P-value H1: $\alpha_{1}+\beta_{1}=0$} & $0.001^{* * *}$ & 0.727 & 0.259 & $0.000 * * *$ \\
\hline & \multicolumn{4}{|c|}{ Panel B. RD specifications } \\
\hline \multirow[t]{2}{*}{$\overline{\text { After Sky }\left(\alpha_{1}\right)}$} & $0.127^{* *}$ & $0.168^{*}$ & $0.063^{*}$ & -0.095 \\
\hline & {$[0.052]$} & [0.091] & {$[0.037]$} & [0.080] \\
\hline \multirow[t]{2}{*}{ After Sky $\times$ Female $\left(\beta_{1}\right)$} & $0.092^{* *}$ & 0.049 & -0.023 & 0.061 \\
\hline & {$[0.039]$} & {$[0.075]$} & {$[0.026]$} & [0.066] \\
\hline \multirow[t]{2}{*}{ Female } & -0.036 & -0.005 & -0.002 & $-0.093^{*}$ \\
\hline & {$[0.029]$} & {$[0.059]$} & {$[0.020]$} & {$[0.056]$} \\
\hline P-value H1: $\alpha_{1}+\beta_{1}=0$ & $0.000^{* * *}$ & $0.050^{* *}$ & 0.353 & 0.704 \\
\hline Observations & $1,1,811$ & $1,1,811$ & $1,1,811$ & 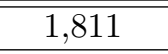 \\
\hline
\end{tabular}


Table 8 - Effects of Campaign Information by Gender in Cava, Full Sample

\begin{tabular}{lcccc}
\hline \hline & $\begin{array}{c}\text { Turnout } \\
\text { rate }\end{array}$ & $\begin{array}{c}\text { Opponent's } \\
\text { vote share }\end{array}$ & $\begin{array}{c}\text { Incumbent's } \\
\text { vote share }\end{array}$ & $\begin{array}{c}\text { Others' } \\
\text { vote share }\end{array}$ \\
\hline Positive campaign $\left(\alpha_{1}\right)$ & $0.098^{*}$ & 0.026 & -0.151 & 0.099 \\
& {$[0.059]$} & {$[0.045]$} & {$[0.101]$} & {$[0.109]$} \\
Negative campaign $\left(\alpha_{2}\right)$ & 0.069 & 0.089 & $-0.184^{*}$ & 0.106 \\
& {$[0.060]$} & {$[0.056]$} & {$[0.099]$} & {$[0.109]$} \\
Positive campaign $\times$ Female $\left(\beta_{1}\right)$ & $-0.134^{* *}$ & 0.052 & 0.009 & -0.062 \\
& {$[0.068]$} & {$[0.064]$} & {$[0.118]$} & {$[0.129]$} \\
Negative campaign $\times$ Female $\left(\beta_{2}\right)$ & -0.059 & -0.073 & 0.113 & -0.057 \\
& {$[0.068]$} & {$[0.068]$} & {$[0.118]$} & {$[0.129]$} \\
Female & 0.060 & 0.050 & -0.001 & -0.080 \\
& {$[0.053]$} & {$[0.040]$} & {$[0.096]$} & {$[0.100]$} \\
\hline$P$-value $H 1: \alpha_{1}+\beta_{1}=0$ & 0.300 & $0.082^{*}$ & $0.019 *$ & 0.598 \\
$P$-value $H 2: \alpha_{2}+\beta_{2}=0$ & 0.747 & 0.683 & 0.266 & 0.469 \\
$P$-value $H 3: \alpha_{1}-\alpha_{2}=0$ & 0.563 & 0.271 & 0.670 & 0.933 \\
$P$-value $H 4: \alpha_{1}+\beta_{1}-\left(\alpha_{2}+\beta_{2}\right)=0$ & 0.188 & 0.183 & 0.230 & 0.852 \\
$P$-value $H 5: \beta_{1}-\beta_{2}=0$ & 0.218 & $0.089^{*}$ & 0.281 & 0.963 \\
$P$-value $H 6: \alpha_{1}+\alpha_{2}=0$ & 0.121 & 0.170 & $0.071^{*}$ & 0.300 \\
$P$-value $H 7: \alpha_{1}+\beta_{1}+\alpha_{2}+\beta_{2}=0$ & 0.657 & 0.178 & $0.051^{*}$ & 0.468 \\
$P$-value $H 8: \beta_{1}+\beta_{2}=0$ & 0.115 & 0.853 & 0.569 & 0.606 \\
\hline Obs. & 857 & 448 & 448 & 448 \\
\hline
\end{tabular}

$\overline{\overline{\text { Notes. Estimated OLS regression: } Y_{i}=\alpha_{1} \mathrm{POS}_{i}+\alpha_{2} N E G_{i}+\beta_{1} P O S_{i} \times F E M A L E_{i}+\beta_{2} N E G_{i} \times F E M A L E_{i}+\delta F E M A L E_{i}+}}$ $\varepsilon_{i}$. (H1) Treatment effect of positive vs. no campaign for females: $\alpha_{1}+\beta_{1}=0$. (H2) Treatment effect of negative vs. no campaign for females: $\alpha_{2}+\beta_{2}=0$. (H3) Treatment effect of positive vs. negative campaign for males: $\alpha_{1}-\alpha_{2}=0$. (H4) Treatment effect of positive vs. negative campaign for females: $\left(\alpha_{1}+\beta_{1}\right)-\left(\alpha_{2}+\beta_{2}\right)=0$. (H5) Differential treatment effect of positive vs. negative campaign between males and females: $\beta_{1}-\beta_{2}=0$. (H6) Treatment effect of any campaign vs. no campaign for males: $\alpha_{1}+\alpha_{2}=0$. (H7) Treatment effect of any campaign vs. no campaign for females: $\left(\alpha_{1}+\beta_{1}\right)+\left(\alpha_{2}+\beta_{2}\right)=$ 0. (H8) Differential treatment effect of any campaign vs. no campaign between males and females: $\beta_{1}+\beta_{2}=0$. Robust standard errors are in brackets. Significance at the $10 \%$ level is represented by $*$, at the $5 \%$ level by ${ }^{* *}$, and at the $1 \%$ level by $* * *$. 
Table 9 - Effects of Campaign Information by Gender in Cava, Canvassed Sample

\begin{tabular}{|c|c|c|c|c|}
\hline & $\begin{array}{c}\text { Turnout } \\
\text { rate }\end{array}$ & $\begin{array}{l}\text { Opponent's } \\
\text { vote share }\end{array}$ & $\begin{array}{l}\text { Incumbent's } \\
\text { vote share }\end{array}$ & $\begin{array}{c}\text { Others' } \\
\text { vote share }\end{array}$ \\
\hline \multirow{2}{*}{ Positive campaign $\left(\alpha_{1}\right)$} & 0.041 & -0.031 & -0.144 & 0.166 \\
\hline & {$[0.074]$} & {$[0.031]$} & {$[0.117]$} & {$[0.123]$} \\
\hline \multirow{2}{*}{ Negative campaign $\left(\alpha_{2}\right)$} & 0.045 & $0.154^{*}$ & $-0.270 * * *$ & 0.110 \\
\hline & {$[0.070]$} & {$[0.082]$} & [0.099] & {$[0.125]$} \\
\hline \multirow{2}{*}{ Positive campaign $\times$ Female $\left(\beta_{1}\right)$} & -0.063 & $0.159^{* *}$ & -0.036 & -0.122 \\
\hline & {$[0.087]$} & {$[0.075]$} & {$[0.138]$} & {$[0.153]$} \\
\hline \multirow{2}{*}{ Negative campaign $\times$ Female $\left(\beta_{2}\right)$} & -0.059 & -0.099 & 0.132 & 0.036 \\
\hline & {$[0.083]$} & {$[0.100]$} & {$[0.125]$} & {$[0.152]$} \\
\hline \multirow[t]{2}{*}{ Female } & 0.060 & 0.050 & -0.001 & -0.080 \\
\hline & {$[0.053]$} & {$[0.041]$} & {$[0.096]$} & {$[0.100]$} \\
\hline 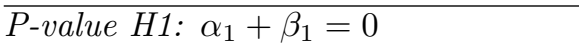 & 0.628 & $0.060^{*}$ & $0.014^{* *}$ & 0.622 \\
\hline P-value H2: $\alpha_{2}+\beta_{2}=0$ & 0.757 & 0.345 & $0.073^{*}$ & $0.094^{*}$ \\
\hline P-value Hз: $\alpha_{1}-\alpha_{2}=0$ & 0.956 & $0.015^{* *}$ & 0.189 & 0.649 \\
\hline$P$-value $H_{4}: \alpha_{1}+\beta_{1}-\left(\alpha_{2}+\beta_{2}\right)=0$ & 0.875 & 0.372 & 0.618 & 0.338 \\
\hline$P$-value $H 5: \beta_{1}-\beta_{2}=0$ & 0.963 & $0.021^{* *}$ & 0.188 & 0.334 \\
\hline$P$-value H6: $\alpha_{1}+\alpha_{2}=0$ & 0.480 & 0.211 & $0.035^{* *}$ & 0.199 \\
\hline P-value H7: $\alpha_{1}+\beta_{1}+\alpha_{2}+\beta_{2}=0$ & 0.615 & $0.059^{*}$ & $0.011^{* *}$ & 1.183 \\
\hline P-value H8: $\beta_{1}+\beta_{2}=0$ & 0.389 & 0.659 & 0.677 & 0.739 \\
\hline Obs. & 560 & 282 & 282 & 282 \\
\hline \multicolumn{5}{|c|}{$\begin{array}{l}\text { Notes. Estimated OLS regression: } Y_{i}=\alpha_{1} P O S_{i}+\alpha_{2} N E G_{i}+\beta_{1} P O S_{i} \times F E M A L E_{i}+\beta_{2} N E G_{i} \times F E M A L E_{i}+\delta F E M A L E_{i}+ \\
\varepsilon_{i} \text {. (H1) Treatment effect of positive vs. no campaign for females: } \alpha_{1}+\beta_{1}=0 \text {. (H2) Treatment effect of negative vs. no } \\
\text { campaign for females: } \alpha_{2}+\beta_{2}=0 \text {. (H3) Treatment effect of positive vs. negative campaign for males: } \alpha_{1}-\alpha_{2}=0 \text {. (H4) } \\
\text { Treatment effect of positive vs. negative campaign for females: }\left(\alpha_{1}+\beta_{1}\right)-\left(\alpha_{2}+\beta_{2}\right)=0 \text {. (H5) Differential treatment effect } \\
\text { of positive vs. negative campaign between males and females: } \beta_{1}-\beta_{2}=0 \text {. (H6) Treatment effect of any campaign vs. no } \\
\text { campaign for males: } \alpha_{1}+\alpha_{2}=0 \text {. (H7) Treatment effect of any campaign vs. no campaign for females: }\left(\alpha_{1}+\beta_{1}\right)+\left(\alpha_{2}+\beta_{2}\right)= \\
0 \text {. (H8) Differential treatment effect of any campaign vs. no campaign between males and females: } \beta_{1}+\beta_{2}=0 \text {. Robust } \\
\text { standard errors are in brackets. Significance at the } 10 \% \text { level is represented by } * \text {, at the } 5 \% \text { level by } * * \text {, and at the } 1 \% \text { level } \\
\text { by } * * * \text {. }\end{array}$} \\
\hline
\end{tabular}




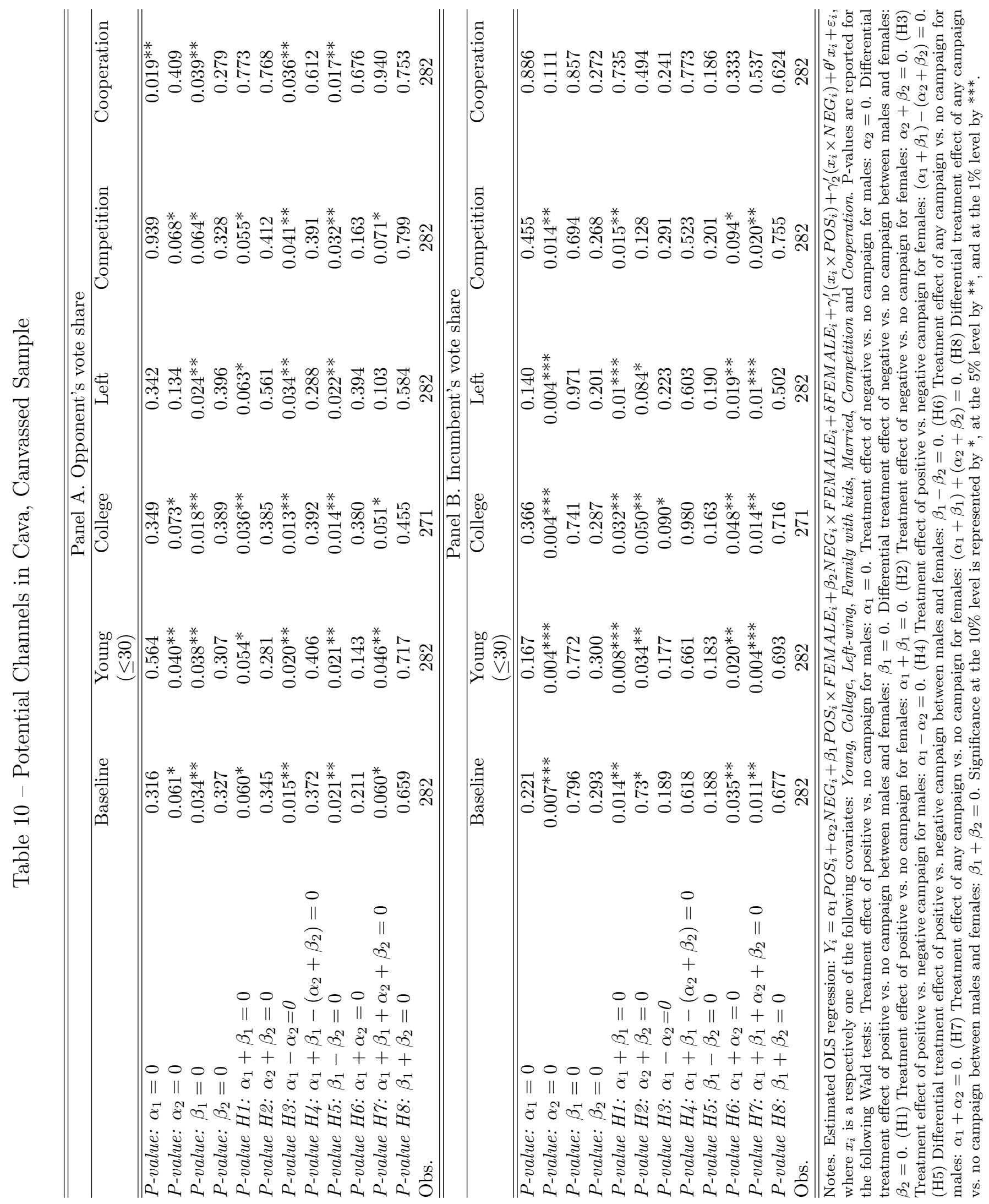




\section{A Appendix: Survey Experiment in Milan}

In the following sections, we report the English translation of our informational treatments, and the figures and tables. For complete materials (including original videos realized by professionals, online survey screenshots, etc.) please refer to the website: www.people.usi.ch/galassov/projects.html.

\section{A.1 Treatment}

We exposed individuals in the treatment groups to an entire electoral campaign by the opponent composed of four electoral tools either with a positive (group A) or a negative (group B) tone. All individuals in the two treatment groups were also exposed to the same electoral campaign by the incumbent, again characterized by the same four electoral tools. We now describe our informational treatments.

The first tool of the opponent's randomized campaign was a 100-second video interview to the candidate sitting at his office desk. The second tool was the opponent's main campaign slogan. The third tool was a letter to the voters, which described the opponent's main projects for the future of Milan or charged the incumbent for her mistakes while in office. The final tool was a 60 -second video ad endorsed by the opponent on relevant issues for the city (transportation, pollution, Expo). Each of these campaign tools addressed the same issues, with the same format and in the same setting, and was proposed in either a positive or a negative tone. The videos and all graphical information were realized by professionals and are available online at www.people.usi.ch/galassov/projects.html.

For our experiment, we also simulated the "entire" political campaign of the incumbent, Letizia Moratti, using the same tools of the opponent's campaign, and we then administered this (non-randomized) campaign to all groups during the second and third survey.

\section{A.1.1 Second Survey: Video Interview with the Opponent}

The 100-second videos featured a (single question) interview with the opponent, Giuliano Pisapia, sitting at his desk in his lawyer office. In both the positive and negative version of the video, the opponent addressed four issues: (i) public transportation, (ii) use of bikes, (iii) restrictions to use of the car, and (iv) green areas and parks. After an initial question 
asked by the same female voice, the candidate response lasted the entire length of the videos. Both videos showed the opponent wearing a white shirt and a tie at his desk, with a large bookshelf behind him for fifty percent of the time, as they were recorded on the same occasion. For the remaining time, his background voice was accompanied by imagines of traffic, bikes, public transportation, and parks in Milan.

The video with the positive tone - focused on the candidate's proposals on the above topics - ran under the header "my ideas for Milan." The video with the negative tonefocused on the incumbent's main missteps on the same topics during her tenure in officeran instead under the header "Moratti's mistakes." After each video, a question measured the impact reaction of the respondents to the message ("do you agree with what the candidate says in the video?").

\section{Positive Toned Video}

The video interview with the opponent characterized by a positive tone is available online at the following link: http://www.youtube.com/embed/kW-cxPistYM. The English translation of the text reads as follows.

Interviewer: "How does Giuliano Pisapia plan to solve these problems and increase the quality of life of Milan's citizens?"

Opponent: "I have various ideas. We need to make public transportation an actual alternative to private transport, in particular to cars. We should give everyone the possibility to get around using bicycles. This can be done by extending the bike sharing service, which cannot be limited only to the city center, but should be available also in suburbs. We need to give people the possibility to use bikes as means of transport across the whole city, in the center and in the suburbs. We need new proposals to reduce traffic throughout the city and eliminate it from the city center. I believe that a congestion charge that makes everyone pay a small amount would enhance citizens' well-being. Plus, it would reduce the use of private cars alleviating traffic and pollution. In addition, the revenues from this charge - which needs to be paid by everyone but that will not greatly affect people's budgets - should be invested in public transport. This is the only way to solve problems such as traffic and pollution. Milan should have once again many green spaces and parks; this would greatly benefit not only children, but also adults and elderly. These green spaces can make a positive difference in the lives of our citizens." 


\section{Negative Toned Video}

The video interview with the opponent characterized by a negative tone is available online at the following link: http://www.youtube.com/embed/243QcAeA4C8. The English translation of the text reads as follows.

Interviewer: "What are the main mistakes made by the Moratti administration in the past five years?"

Opponent: "The mayor proposed to raise the fare for public transportation even though, as citizens know very well, this has been totally inefficient. In these years public transport has been increasingly more off schedule and citizens have had to wait more for buses and trolley cars than in the past. Plus, the speed of transportation has declined continuously. In fact, Milan now ranks 20th in Europe for speed of public transportation with an average speed of $13.5 \mathrm{Km} / \mathrm{hr}$, well below the European average of $20 \mathrm{Km} / \mathrm{hr}$. The Ecopass system is a complete failure; in fact, the councillor who proposed it has been fired. It failed in every respect since it did not reduce traffic (except marginally in the center) and it did not improve the quality of the air we breathe. In Milan, the European critical level of Particulate Matters in the air has been crossed in 35 out of the first 38 days of the year, reaching the European annual limit. This proves that nothing has been done to alleviate traffic and to improve the quality of the air we breathe. Letizia Moratti not only didn't do anything effective to solve problems such as traffic and pollution, she also did not do anything to create more green spaces in Milan. The worst part is that she wasted a huge present that Maestro Abbado made to our city: 90,000 trees that certainly would have helped make Milan a greener city."

\section{A.1.2 Second Survey: Video Interview with the Incumbent}

The video (available online at the link: http://www.youtube.com/embed/AHnjRoawu_Q) runs under the header "we want to complete our good work" and broadcasts a public speech by Letizia Moratti, as mayor of Milan, launching her electoral campaign in Piazza San Babila (city center). Surrounded by supporters holding flags and balloons, she promises to complete the projects that were started during her first mandate, with new subway lines being a top priority. The text of the video interview with the incumbent is the following.

"In all these years the center-right administration has always governed well. I have 
found balanced budgets thanks to mayors Albertini, Formentini, and all those who preceded me. Thanks to this, I have had the possibility to continue to invest. We have invested 3.9 billion Euros in public infrastructures. This allowed us to extend the subway lines: the number 2 line up to Assago has already been inaugurated and the number 3 up to Comasina has also already been inaugurated. We have also already put aside - they are already registered in our budgets - all the funds necessary to complete the new subway lines 4 and 5 before the Expo."

\section{A.1.3 Second Survey: Electoral Campaign Slogan by the Opponent}

The main electoral campaign slogan was shown in a separate page of the survey in a large font and orange (the opponent's electoral campaign color) and black colors. In the positive tone campaign (group A), the slogan (see the original slogan at figure A1) was "Pisapia for Mayor = Less Traffic \& More Green. A Change for Milan is Possible." In the negative tone campaign (group B), the slogan (see the original slogan at figure A2) instead was "5 Years of Moratti = More Traffic \& Less Green. A Change for Milan is Possible." Each slogan was followed by a question aimed at measuring the respondent's impact reaction ("in general, how much do you feel you can trust Giuliano Pisapia?").

\section{A.1.4 Second Survey: Electoral Campaign Slogan by the Incumbent}

The electoral campaign slogan for Letizia Moratti was: "We are working to make Milan an even better place to live in. Letizia Moratti for Mayor."

\section{A.1.5 Third Survey: Open Letter to the Voters by the Opponent}

The third tool of the electoral campaign was a one-page (almost two-hundred words long) letter to the voters, signed by the opponent, Giuliano Pisapia. In the initial part of the letter, which was common to both treatments, the opponent expressed his view that the primary duty of a mayor is to increase the wellbeing of the citizens. Then, both in the letter with the positive and the negative tone, he touched upon four issues: (i) clean air; (ii) work ethics; (iii) public transportation; and (iv) involvement of the citizens.

The letter with the positive tone ran (to group A) under the header "this is my commitment with the city," and ended with a positive plea: "Milan deserves to become once 
again one of the capitals of Europe." The letter with the negative tone ran (to group B) under the header "Milan does not deserve to be led by Ms. Moratti," and ended with a negative plea: "Milan does not deserve other five years of Moratti administration." After each letter, respondents were asked to evaluate the main message ("abstracting from your political viewpoint, how much do you agree with the general sense of this letter?").

\section{Positive Toned Letter}

The text of the open letter sent to the eligible voters with a positive tone is the following.

"Can a mayor contribute to the happiness of his citizens? I believe he can. Moreover, I am convinced that the primary duty of those who govern in name of the general interest is to increase the wellbeing of their fellow citizens. Together with over a thousand volunteers of the Workshops for the City, I have defined four main goals:

1. I want to breathe with you new air, finally clean.

2. I want to live in a city in which work is considered a source of dignity, freedom, and a fundamental value.

3. I want less cars in the city center, more public transportation, a stop a few meters from everyone's house also in the suburbs, less traffic, and the possibility to move quickly throughout the city also by using bicycles.

4. I want to support those who dedicate their lives to culture; help it thrive sustaining creativity and free initiatives.

I commit to work for these goals. Milan deserves to become once again one of the capitals of Europe."

\section{Negative Toned Letter}

The text of the open letter sent to the eligible voters with a negative tone is the following.

"Can a mayor contribute to the happiness of his citizens? I believe he can. Moreover, I am convinced that the primary duty of those who govern in name of the general interest is to increase the wellbeing of their fellow citizens. In Mrs. Moratti's Milan this did not happen. 
She was indifferent to the city's problems and rarely present in the city council; therefore, she has proved to be unfit to serve our city.

1. City council. She only attended $5 \%$ of ballots, a record high level of absenteeism.

2. City's neighborhoods. Her indifference to the city's needs is obvious: the suburbs are completely abandoned.

3. Little attention was given to transportation and environment, particulate matters in the air are at the highest level since 2007, and $20 \%$ of the city's shops pay protection money to the Mafia.

4. Only now - during the electoral campaign - Letizia Moratti is creating a few bikeways and is spending millions of Euros to disseminate throughout the city huge pictures that portray her surrounded by the citizens of Milan.

Milan does not deserve other five years of Moratti administration. Change in Milan is possible."

\section{A.1.6 Third Survey: Open Letter to the Voters by the Incumbent}

The header of the incumbent's open letter is "Milan is the city I love." It describes the philosophy that Mrs. Moratti wished to continue to adopt in her second term: to aim high (as with the Expo), but also to take care of the citizens' everyday needs. The text of the letter is the following.

"Milan is the city I love: it is the city in which I was born and raised. It thought me kindness, discretion, and diligence. In my life I have had to deal with situations in which I had great responsibilities. However, nothing is comparable to the emotions I felt when working for my city as Mayor of Milan. In these five years we have aimed at great accomplishments but at the same time we took care of the small necessities of our citizens' everyday lives.

- We aimed high when competing and winning the contest for Expo 2015, which will make Milan capital of the world. 
- We took care of small necessities rising security controls in the city's outskirts, investing in street lighting, creating new kindergarten facilities, reaching out to a larger number of elderly, and planting new trees.

I would like to complete the projects we have started in the past five years and make Milan a better place to live in. I will do this with anyone who wants to give the home of all Milanese people more strength, openness and beauty."

\section{A.1.7 Third Survey: Video Ad Endorsed by the Opponent}

The last tool of the electoral campaign consisted of a 60-second video of political advertisement realized by professionals and endorsed by the opponent. Both (positive and negative) videos showed images of Milan (such as traffic situations, public transportation, people walking on the streets, the city center, and parks) recorded on the same occasion. The same (professional) speaker read statements on four issues, while relevant synthetic information appeared on the screen. The issues addressed in both videos were: (i) private versus public interest at the city hall; (ii) links between the Expo organization and the mafia; (iii) the management of public appointments; (iv) the city's urban plan.

The video ad with the positive tone ran under the header "my ideas for Milan." The video ad with the negative tone ran under the header "is Ms. Moratti's Milan also your Milan?" The English translations of the messages read in the two videos are in the Appendix. Both videos ended with a common last slogan of endorsement: "Giuliano Pisapia for Mayor." Also in this case, after each video, respondents were asked to evaluate the message ("overall, how truthful does this electoral message seem to you?").

\section{Positive Toned Letter}

The video ad endorsed by the opponent and characterized by a positive tone is available online at the following link: http://www.youtube.com/embed/909RgdaC6Mg. The English translation of the text reads as follows. "The 15th and 16th of May the citizens of Milan will vote to elect their Mayor. Giuliano Pisapia will challenge the incumbent Mayor. What does he plan to do for Milan? To make Milan closer to the needs of citizens, Giuliano Pisapia believes that public service rather than business interests should be a priority [video highlight appearing on the screen: 'Close to Citizens' Needs']. To truly fight organized crime, Giuliano Pisapia proposes an anti-Mafia commission that should over- 
see the works for Expo [video highlight: 'Anti-Mafia Commission']. To increase the city's efficiency, Giuliano Pisapia proposes to reward merit and to boost the skills of public employees and managers [video highlight: 'Merit and Competence']. To enhance transparency, Giuliano Pisapia believes that the town planning bill should be discussed with civil society and in the city council [video highlight: 'More Transparency']."

\section{Negative Toned Letter}

The video ad endorsed by the opponent and characterized by a negative tone is available online at the following link: http://www.youtube.com/embed/JcG0d6uZ-kk. The English translation of the text reads as follows. "[Video highlight appearing on the screen: "15/16 of May'], Letizia Moratti runs again for Mayor of Milan. Before choosing who to vote, ask yourself whether the Milan she has in mind is also your Milan. [Video highlight: "6th of October 2006'], Letizia Moratti undersells optic fibers. Private investors make a profit of $600 \%$, the city looses 50 million Euros [video highlight: '+ 600\% to private investors'; '50 million Euros to the citizens of Milan']. [Video highlight: '12th of March 2009'], Letizia Moratti eliminates the anti-Mafia commission that was supposed to oversee the works for Expo [video highlight: "infiltrations of the Mafia"]. [Video highlight: "24th of May 2009'], investigation on public appointments, the Court of Auditors condemns Letizia Moratti and asks her to refund the city of Milan [video highlight: "illegal public appointments]. [Video highlight: '4th of February 2011'], the town planning bill passed by Letizia Moratti tries to amend the one million Euro infringement of building regulations of her son Gabriele [video highlight: 'Bat-House']. Is this your Milan?"

\section{A.1.8 Third Survey: Video Ad Endorsed by the Incumbent}

The video ad endorsed by the incumbent is available at: http://youtu.be/F917BIexZc8. The English translation of the text reads as follows. The video plays under the header "Letizia Moratti: This is my Milan." "Our Milan says 'YES' to more homes for Italians, 'NO' to gypsy camps. 'YES' to a modern Milan, once again leader in the world, 'NO 'to those who live in the past. 'YES' to more assistance and support for the elderly, 'NO' to an administration that raises taxes. 'YES' to more safety and legality, 'NO' to illegal immigration. 'YES' to more aids for mothers." The last scene pictures Letizia Moratti saying "this is my Milan." 


\section{A.2 Figures and Tables}

Figure A.1: Positive Slogan

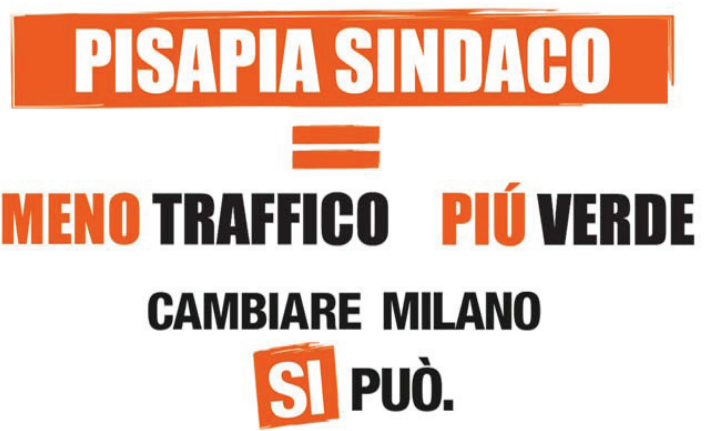

Figure A.2: Negative Slogan

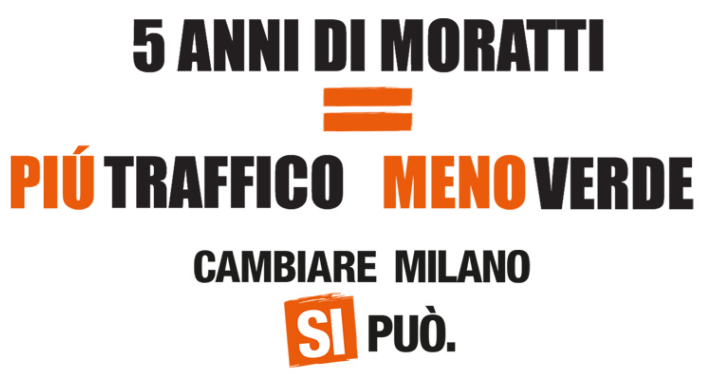



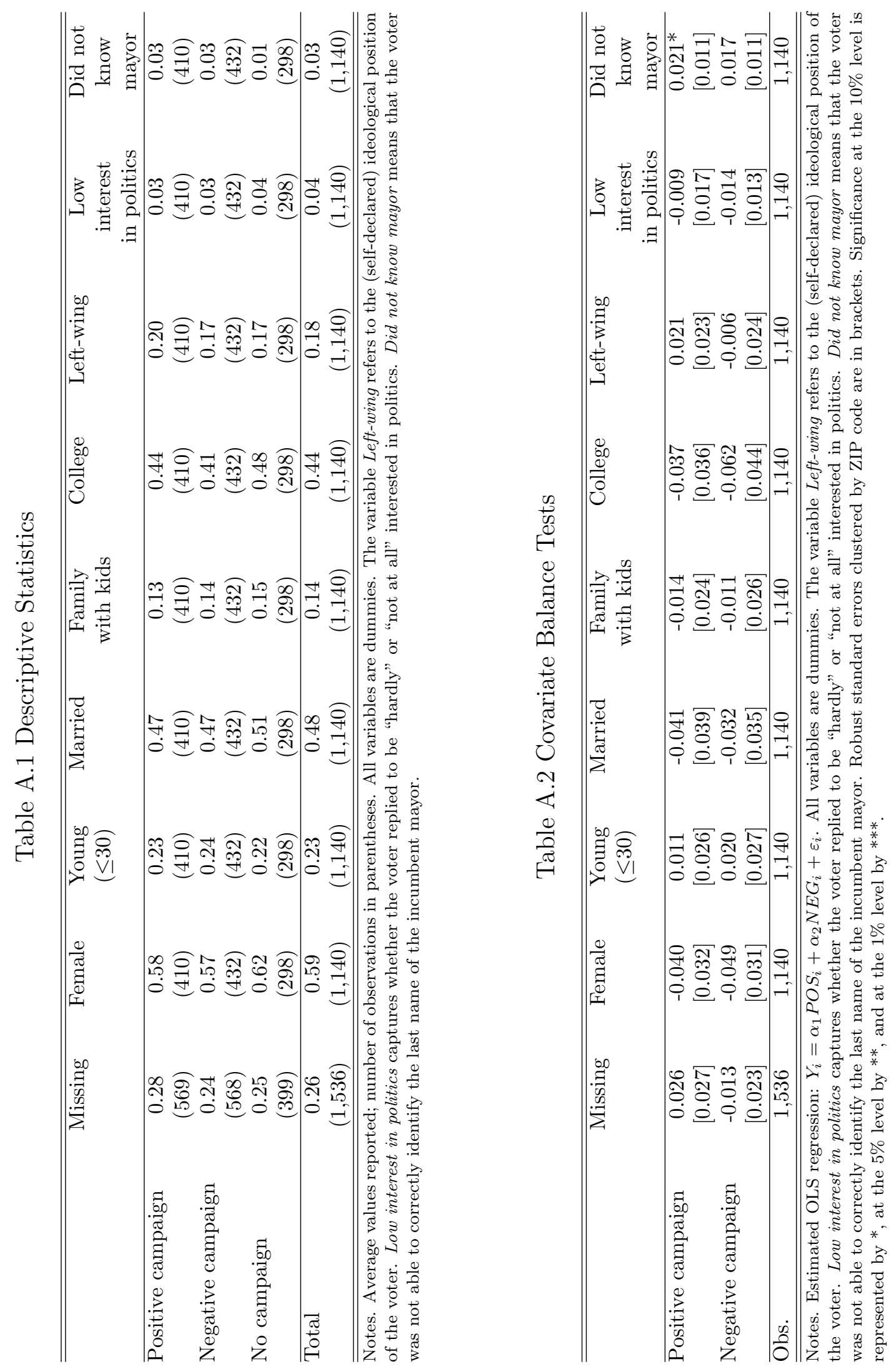
Table A.3 Average Treatment Effects, First Round

\begin{tabular}{lcccc}
\hline \hline & $\begin{array}{c}\text { Turnout } \\
\text { rate }\end{array}$ & $\begin{array}{c}\text { Opponent's } \\
\text { vote share }\end{array}$ & $\begin{array}{c}\text { Incumbent's } \\
\text { vote share }\end{array}$ & $\begin{array}{c}\text { Others' } \\
\text { vote share }\end{array}$ \\
\hline Positive campaign $\left(\alpha_{1}\right)$ & -0.018 & -0.002 & 0.004 & -0.002 \\
& {$[0.023]$} & {$[0.042]$} & {$[0.039]$} & {$[0.036]$} \\
Negative campaign $\left(\alpha_{2}\right)$ & 0.014 & -0.038 & 0.037 & 0.001 \\
& {$[0.022]$} & {$[0.041]$} & {$[0.036]$} & {$[0.030]$} \\
\hline P-value H1: $\alpha_{1}-\alpha_{2}=0$ & 0.162 & 0.321 & 0.402 & 0.922 \\
P-value H2: $\alpha_{1}+\alpha_{2}=0$ & 0.916 & 0.597 & 0.526 & 0.985 \\
\hline Obs. & 1,140 & 912 & 912 & 912 \\
\hline \hline
\end{tabular}

Notes. Estimated OLS regression: $Y_{i}=\alpha_{1} P O S_{i}+\alpha_{2} N E G_{i}+\varepsilon_{i}$. (H1) Treatment effect of positive vs. negative campaign: $\alpha_{1}-\alpha_{2}=0$. (H2) Treatment effect of any campaign vs. no campaign: $\alpha_{1}+\alpha_{2}=0$. Robust standard errors are in brackets. Significance at the $10 \%$ level is represented by $*$, at the $5 \%$ level by $* *$, and at the $1 \%$ level by *** .

Table A.4 Average Treatment Effects, Runoff

\begin{tabular}{|c|c|c|c|c|}
\hline & $\begin{array}{l}\text { Expected } \\
\text { turnout }\end{array}$ & $\begin{array}{c}\text { Vote for } \\
\text { opponent }\end{array}$ & $\begin{array}{c}\text { Vote for } \\
\text { incumbent }\end{array}$ & Undecided \\
\hline \multirow[t]{2}{*}{ Positive campaign $\left(\alpha_{1}\right)$} & 0.010 & 0.012 & 0.020 & -0.032 \\
\hline & {$[0.026]$} & {$[0.036]$} & {$[0.035]$} & {$[0.032]$} \\
\hline \multirow[t]{2}{*}{ Negative campaign $\left(\alpha_{2}\right)$} & 0.013 & 0.021 & 0.044 & $-0.065^{* *}$ \\
\hline & {$[0.025]$} & {$[0.032]$} & {$[0.034]$} & {$[0.027]$} \\
\hline$\overline{P \text {-value } H 1:} \alpha_{1}-\alpha_{2}=0$ & 0.860 & 0.811 & 0.505 & 0.150 \\
\hline P-value H2: $\alpha_{1}+\alpha_{2}=0$ & 0.630 & 0.558 & 0.283 & $0.080^{*}$ \\
\hline Obs. & 1,119 & 1,034 & 1,034 & 1,034 \\
\hline
\end{tabular}



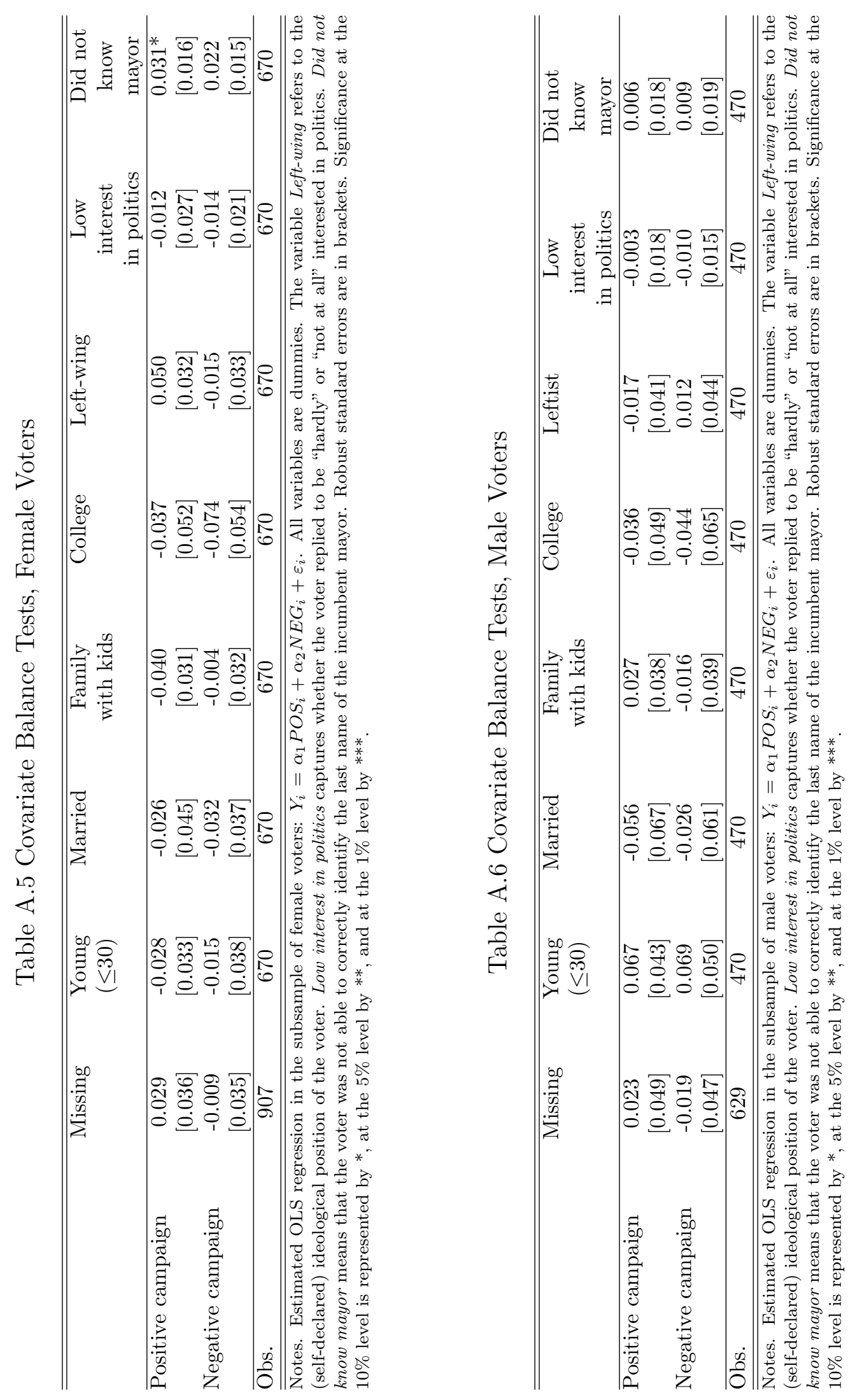

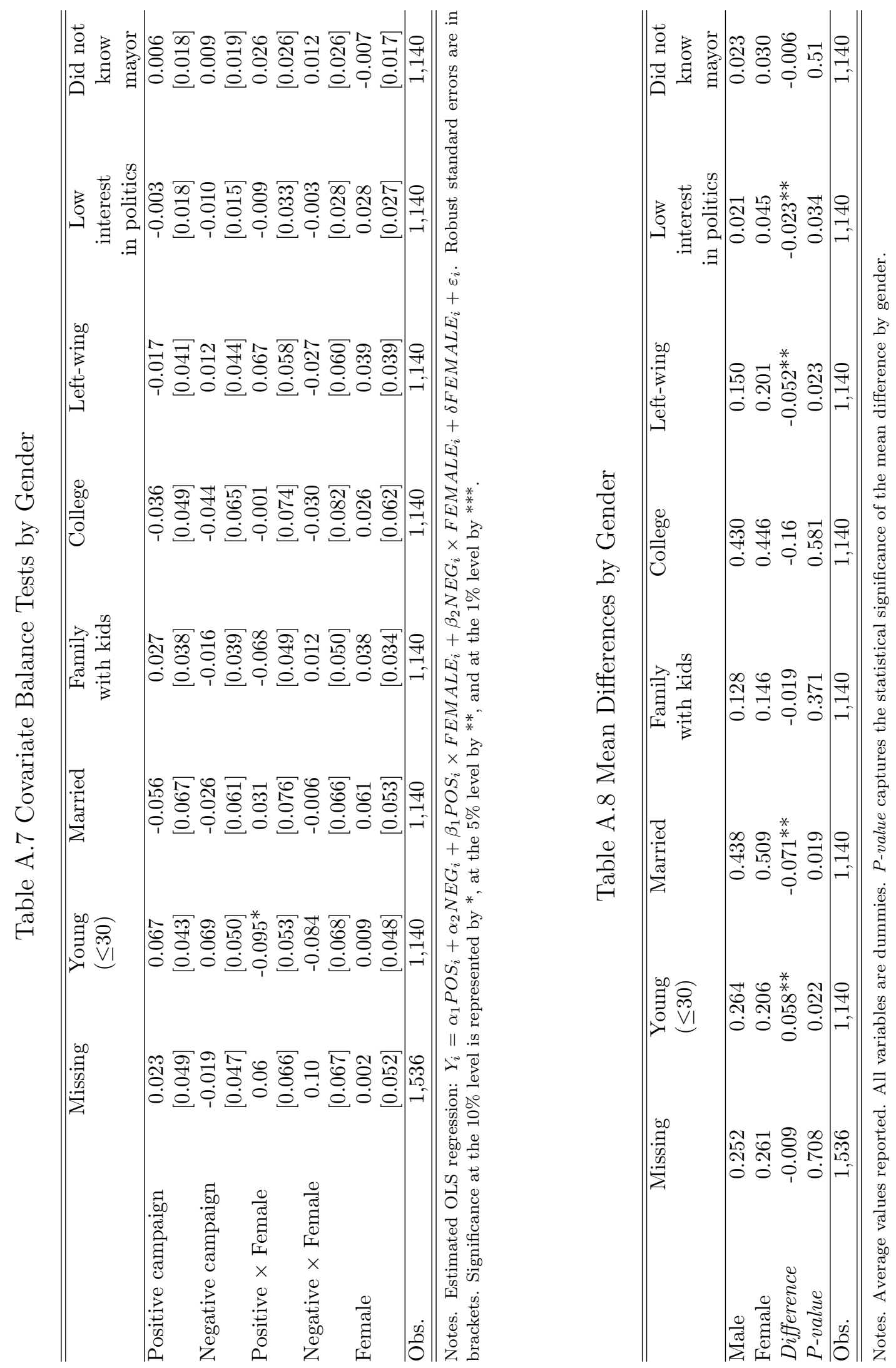
Table A.9 Effects on Voters' Perceptions in Milan ( $4^{\text {th }}$ Survey)

\begin{tabular}{lccccc}
\hline \hline & $\begin{array}{c}\text { Perceive } \\
\text { campaign } \\
\text { as harsh }\end{array}$ & $\begin{array}{c}\text { Perceive } \\
\text { opponent } \\
\text { as negative }\end{array}$ & $\begin{array}{c}\text { Perceive } \\
\text { incumbent } \\
\text { as negative }\end{array}$ & $\begin{array}{c}\text { Confident } \\
\text { about vote } \\
\text { choice }\end{array}$ & $\begin{array}{c}\text { Voted based on } \\
\text { candidates' } \\
\text { attributes }\end{array}$ \\
\hline Positive campaign $\left(\alpha_{1}\right)$ & $-0.085^{*}$ & $-0.089^{*}$ & -0.067 & -0.038 & 0.021 \\
Positive campaign $\times$ Female $\left(\beta_{1}\right)$ & {$[0.045]$} & {$[0.050]$} & {$[0.047]$} & {$[0.053]$} & {$[0.049]$} \\
& 0.007 & 0.032 & $0.130^{* *}$ & 0.091 & 0.000 \\
Female & {$[0.065]$} & {$[0.072]$} & {$[0.048]$} & {$[0.061]$} & {$[0.084]$} \\
& -0.050 & -0.081 & -0.035 & -0.041 & 0.039 \\
$P$-value H1: $\alpha_{1}+\beta_{1}=0$ & {$[0.048]$} & {$[0.049]$} & {$[0.044]$} & {$[0.052]$} & {$[0.044]$} \\
Obs. & $0.087^{*}$ & 0.217 & 0.172 & 0.319 & 0.727 \\
\hline
\end{tabular}

Notes. Estimated OLS regression: $Y_{i}=\alpha_{1} P O S_{i}+\beta_{1} P O S_{i} \times F E M A L E_{i}+\delta F E M A L E_{i}+\varepsilon_{i}$. (H1) Treatment effect of positive vs. negative campaign for females: $\alpha_{1}+\beta_{1}=0$. Robust standard errors are in brackets. Significance at the $10 \%$ level is represented by $*$, at the $5 \%$ level by ${ }^{* *}$, and at the $1 \%$ level by $* * *$. 
Table A.10 Potential Channels on Turnout

\begin{tabular}{|c|c|c|c|c|c|}
\hline & \multicolumn{5}{|c|}{ Panel A. First Round } \\
\hline & Baseline & $\begin{array}{l}\text { Young } \\
(\leq 30)\end{array}$ & College & Left & $\begin{array}{c}\text { Low Interest } \\
\text { in Politics }\end{array}$ \\
\hline P-value: $\alpha_{1}=0$ & 0.476 & 0.475 & 0.184 & 0.468 & 0.473 \\
\hline$P$-value: $\alpha_{2}=0$ & $0.031^{* *}$ & $0.078^{*}$ & $0.015^{* *}$ & $0.032^{* *}$ & $0.031^{* *}$ \\
\hline P-value: $\beta_{1}=0$ & 0.121 & 0.118 & 0.123 & 0.125 & 0.117 \\
\hline P-value: $\beta_{2}=0$ & $0.026^{* *}$ & $0.030^{* *}$ & $0.023^{* *}$ & $0.027 * *$ & $0.024^{* *}$ \\
\hline$P$-value $H 1: \alpha_{1}+\beta_{1}=0$ & $0.068^{*}$ & $0.091^{*}$ & 0.743 & 0.149 & $0.077^{*}$ \\
\hline$P$-value H2: $\alpha_{2}+\beta_{2}=0$ & 0.289 & 0.235 & 0.797 & 0.340 & 0.310 \\
\hline$P$-value H3: $\alpha_{1}-\alpha_{2}=0$ & $0.091^{*}$ & 0.288 & 0.257 & 0.113 & $0.087^{*}$ \\
\hline$P$-value $H_{4}: \alpha_{1}+\beta_{1}-\left(\alpha_{2}+\beta_{2}\right)=0$ & 0.556 & 0.818 & 0.924 & 0.662 & 0.511 \\
\hline$P$-value $H 5: \beta_{1}-\beta_{2}=0$ & 0.365 & 0.425 & 0.360 & 0.349 & 0.389 \\
\hline$P$-value $H 6: \alpha_{1}+\alpha_{2}=0$ & 0.137 & 0.187 & $0.050^{* *}$ & 0.144 & 0.138 \\
\hline P-value H\%: $\alpha_{1}+\beta_{1}+\alpha_{2}+\beta_{2}=0$ & 0.102 & 0.103 & 0.744 & 0.165 & 0.114 \\
\hline$P$-value $H 8: \beta_{1}+\beta_{2}=0$ & $0.042^{* *}$ & $0.045^{* *}$ & $0.040^{* *}$ & $0.043^{* *}$ & $0.039 * *$ \\
\hline \multirow[t]{3}{*}{ Obs. } & 1,140 & 1,140 & 1,140 & 1,140 & 1,140 \\
\hline & \multicolumn{5}{|c|}{ Panel B. Runoff } \\
\hline & Baseline & $\begin{array}{l}\text { Young } \\
(\leq 30)\end{array}$ & College & Left & $\begin{array}{c}\text { Low Interest } \\
\text { in Politics }\end{array}$ \\
\hline P-value: $\alpha_{1}=0$ & 0.634 & 0.628 & 0.111 & 0.539 & 0.598 \\
\hline P-value: $\alpha_{2}=0$ & $0.067^{*}$ & $0.098^{*}$ & $0.035^{* *}$ & $0.094^{*}$ & $0.062^{*}$ \\
\hline P-value: $\beta_{1}=0$ & 0.712 & 0.717 & 0.744 & 0.754 & 0.725 \\
\hline P-value: $\beta_{2}=0$ & $0.039 * *$ & $0.042^{* *}$ & $0.035^{* *}$ & $0.042^{* *}$ & $0.034^{* *}$ \\
\hline$P$-value $H 1: \alpha_{1}+\beta_{1}=0$ & 0.835 & 0.802 & 0.021 & 0.562 & 0.773 \\
\hline$P$-value H2: $\alpha_{2}+\beta_{2}=0$ & 0.459 & 0.496 & 0.963 & 0.521 & 0.489 \\
\hline$P$-value H3: $\alpha_{1}-\alpha_{2}=0$ & 0.141 & 0.195 & 0.701 & 0.247 & 0.129 \\
\hline$P$-value $H_{4}: \alpha_{1}+\beta_{1}-\left(\alpha_{2}+\beta_{2}\right)=0$ & 0.256 & 0.294 & $0.038 * *$ & 0.158 & 0.271 \\
\hline$P$-value $H 5: \beta_{1}-\beta_{2}=0$ & $0.058^{*}$ & $0.057^{*}$ & $0.054^{*}$ & $0.058^{*}$ & $0.060^{*}$ \\
\hline$P$-value $H 6: \alpha_{1}+\alpha_{2}=0$ & 0.251 & 0.277 & $0.055^{*}$ & 0.254 & 0.231 \\
\hline P-value H\%: $\alpha_{1}+\beta_{1}+\alpha_{2}+\beta_{2}=0$ & 0.716 & 0.750 & 0.227 & 0.786 & 0.283 \\
\hline P-value $H 8: \beta_{1}+\beta_{2}=0$ & 0.190 & 0.196 & 0.188 & 0.200 & 0.192 \\
\hline Obs. & 1,119 & 1,119 & 1,119 & 1,119 & 1,119 \\
\hline \multicolumn{6}{|c|}{$\begin{array}{l}\text { Notes. Estimated OLS regression: } Y_{i}=\alpha_{1} P O S_{i}+\alpha_{2} N E G_{i}+\beta_{1} P O S_{i} \times F E M A L E_{i}+\beta_{2} N E G_{i} \times F E M A L E_{i}+\delta F E M A L E_{i}+ \\
\gamma_{1}^{\prime}\left(x_{i} \times P O S_{i}\right)+\gamma_{2}^{\prime}\left(x_{i} \times N E G_{i}\right)+\theta^{\prime} x_{i}+\varepsilon_{i} \text {, where } x_{i} \text { is a respectively one of the following covariates: Young, College, Left-wing, } \\
\text { and Low interest in politics. P-values are reported for the following Wald tests: Treatment effect of positive vs. no campaign } \\
\text { for males: } \alpha_{1}=0 \text {. Treatment effect of negative vs. no campaign for males: } \alpha_{2}=0 \text {. Differential treatment effect of positive } \\
\text { vs. no campaign between males and females: } \beta_{1}=0 \text {. Differential treatment effect of negative vs. no campaign between } \\
\text { males and females: } \beta_{2}=0 \text {. (H1) Treatment effect of positive vs. no campaign for females: } \alpha_{1}+\beta_{1}=0 \text {. (H2) Treatment } \\
\text { effect of negative vs. no campaign for females: } \alpha_{2}+\beta_{2}=0 \text {. (H3) Treatment effect of positive vs. negative campaign for } \\
\text { males: } \alpha_{1}-\alpha_{2}=0 \text {. (H4) Treatment effect of positive vs. negative campaign for females: }\left(\alpha_{1}+\beta_{1}\right)-\left(\alpha_{2}+\beta_{2}\right)=0 \text {. (H5) } \\
\text { Differential treatment effect of positive vs. negative campaign between males and females: } \beta_{1}-\beta_{2}=0 \text {. (H6) Treatment } \\
\text { effect of any campaign vs. no campaign for males: } \alpha_{1}+\alpha_{2}=0 \text {. (H7) Treatment effect of any campaign vs. no campaign for } \\
\text { females: }\left(\alpha_{1}+\beta_{1}\right)+\left(\alpha_{2}+\beta_{2}\right)=0 \text {. (H8) Differential treatment effect of any campaign vs. no campaign between males and } \\
\text { females: } \beta_{1}+\beta_{2}=0 \text {. Significance at the } 10 \% \text { level is represented by } * \text { at the } 5 \% \text { level by } * * \text { and at the } 1 \% \text { level by } * * *\end{array}$} \\
\hline
\end{tabular}


Table A.11 Full Set of Interactions, First Round

\begin{tabular}{|c|c|c|c|c|}
\hline & $\begin{array}{c}\text { Turnout } \\
\text { rate }\end{array}$ & $\begin{array}{l}\text { Opponent's } \\
\text { vote share }\end{array}$ & $\begin{array}{l}\text { Incumbent's } \\
\text { vote share }\end{array}$ & $\begin{array}{c}\text { Others' } \\
\text { vote share }\end{array}$ \\
\hline \multirow[t]{2}{*}{ Positive campaign $\left(\alpha_{1}\right)$} & 0.027 & -0.037 & 0.130 & -0.093 \\
\hline & {$[0.051]$} & {$[0.067]$} & {$[0.078]$} & {$[0.075]$} \\
\hline \multirow[t]{2}{*}{ Negative campaign $\left(\alpha_{2}\right)$} & 0.061 & -0.066 & $0.140^{*}$ & -0.074 \\
\hline & {$[0.038]$} & {$[0.063]$} & {$[0.076]$} & {$[0.072]$} \\
\hline \multirow{2}{*}{ Positive campaign $\times$ Female $\left(\beta_{1}\right)$} & -0.076 & $0.141^{*}$ & $-0.172^{* *}$ & 0.031 \\
\hline & {$[0.050]$} & {$[0.075]$} & {$[0.068]$} & {$[0.068]$} \\
\hline \multirow{2}{*}{ Negative campaign $\times$ Female $\left(\beta_{2}\right)$} & $-0.107^{* *}$ & 0.056 & -0.098 & 0.042 \\
\hline & {$[0.048]$} & {$[0.083]$} & {$[0.074]$} & {$[0.063]$} \\
\hline \multirow[t]{2}{*}{ Female } & 0.058 & 0.008 & 0.058 & -0.066 \\
\hline & {$[0.040]$} & {$[0.070]$} & {$[0.055]$} & {$[0.050]$} \\
\hline$\overline{P \text {-value } H 1:} \alpha_{1}+\beta_{1}=0$ & 0.141 & 0.161 & 0.568 & 0.210 \\
\hline P-value H2: $\alpha_{2}+\beta_{2}=0$ & 0.173 & 0.869 & 0.510 & 0.570 \\
\hline$P$-value H3: $\alpha_{1}-\alpha_{2}=0$ & 0.356 & 0.634 & 0.890 & 0.668 \\
\hline$P$-value $H_{4}: \alpha_{1}+\beta_{1}-\left(\alpha_{2}+\beta_{2}\right)=0$ & 0.927 & $0.087^{*}$ & 0.194 & 0.472 \\
\hline$P$-value $H 5: \beta_{1}-\beta_{2}=0$ & 0.435 & 0.136 & 0.202 & 0.869 \\
\hline$P$-value $H 6: \alpha_{1}+\alpha_{2}=0$ & 0.290 & 0.373 & $0.056^{*}$ & 0.238 \\
\hline P-value H7: $\alpha_{1}+\beta_{1}+\alpha_{2}+\beta_{2}=0$ & $0.093^{*}$ & 0.423 & 0.997 & 0.333 \\
\hline$P$-value $H 8: \beta_{1}+\beta_{2}=0$ & $0.051^{*}$ & 0.187 & $0.044^{* *}$ & 0.532 \\
\hline Obs. & 1,140 & 912 & 912 & 912 \\
\hline
\end{tabular}


Table A.12 Full Set of Interactions, Runoff

\begin{tabular}{|c|c|c|c|c|}
\hline & $\begin{array}{l}\text { Expected } \\
\text { turnout }\end{array}$ & $\begin{array}{l}\text { Vote for } \\
\text { opponent }\end{array}$ & $\begin{array}{c}\text { Vote for } \\
\text { incumbent }\end{array}$ & Undecided \\
\hline \multirow[t]{2}{*}{ Positive campaign $\left(\alpha_{1}\right)$} & 0.041 & -0.107 & $0.221^{* * *}$ & $-0.114^{*}$ \\
\hline & [0.048] & [0.083] & {$[0.067]$} & {$[0.056]$} \\
\hline \multirow[t]{2}{*}{ Negative campaign $\left(\alpha_{2}\right)$} & $0.070^{*}$ & -0.122 & $0.178^{* *}$ & -0.056 \\
\hline & [0.039] & {$[0.086]$} & [0.069] & [0.058] \\
\hline \multirow[t]{2}{*}{ Positive campaign $\times$ Female $\left(\beta_{1}\right)$} & -0.014 & 0.120 & $-0.240 * * *$ & $0.120^{*}$ \\
\hline & {$[0.046]$} & [0.079] & {$[0.081]$} & [0.064] \\
\hline \multirow{2}{*}{ Negative campaign $\times$ Female $\left(\beta_{2}\right)$} & $-0.086^{* *}$ & 0.126 & $-0.139^{*}$ & 0.013 \\
\hline & {$[0.038]$} & {$[0.088]$} & {$[0.078]$} & {$[0.055]$} \\
\hline \multirow{2}{*}{ Female } & 0.050 & -0.041 & 0.093 & -0.052 \\
\hline & {$[0.033]$} & {$[0.072]$} & {$[0.067]$} & {$[0.053]$} \\
\hline P-value H1: $\alpha_{1}+\beta_{1}=0$ & 0.381 & 0.855 & 0.796 & 0.926 \\
\hline P-value H2: $\alpha_{2}+\beta_{2}=0$ & 0.676 & 0.945 & 0.554 & 0.355 \\
\hline$P$-value H3: $\alpha_{1}-\alpha_{2}=0$ & 0.370 & 0.789 & 0.566 & 0.209 \\
\hline$P$-value $H_{4}: \alpha_{1}+\beta_{1}-\left(\alpha_{2}+\beta_{2}\right)=0$ & 0.226 & 0.885 & 0.351 & 0.273 \\
\hline$P$-value $H 5: \beta_{1}-\beta_{2}=0$ & $0.058^{*}$ & 0.901 & $0.072^{*}$ & $0.070^{*}$ \\
\hline$P$-value H6: $\alpha_{1}+\alpha_{2}=0$ & 0.181 & 0.156 & $0.001^{* *}$ & 0.115 \\
\hline$P$-value H': $\alpha_{1}+\beta_{1}+\alpha_{2}+\beta_{2}=0$ & 0.851 & 0.883 & 0.873 & 0.699 \\
\hline$P$-value $H 8: \beta_{1}+\beta_{2}=0$ & 0.198 & 0.132 & $0.016^{* *}$ & 0.212 \\
\hline Obs. & 1,119 & 1,034 & 1,034 & 1,034 \\
\hline
\end{tabular}




\section{B Appendix: Natural Experiment in Milan}

Performing a sentiment analysis requires to identify a list of stems (root of a word, or of many words), which are relevant to infer the sentiment towards a candidate. A positive stem is related to an emotion, such as joy or love, or to an expression of political support, such as "vote for". Conversely, a negative stem is related to a pessimistic emotion, or to an expression of political dislike. We also included some emoticons as they are widely used on twitter to express feelings. The complete list - reported at table B.1 - contains 108 stems, of which 54 are coded as positive and 54 as negative.

Table B.1 Sentiment Analysis: Positive and Negative Stems

\begin{tabular}{ll||ll} 
Positive stem & Meaning & Negative stem & Meaning \\
\hline \hline$:)$ & smile & $:($ & sadness \\
$;)$ & wink & anti & against \\
accordo & agreement & accus- & blame \\
ador- & worship & arrog- & arrogant \\
amat- & loved & bugi- & lie \\
amo- & love & cattiv- & nasty \\
avanti & forward & coglion- & asshole \\
batte- & beat & colp- & guilt \\
bell- & good & comunist- & communist \\
ben- & well & contrari- & disagreement \\
brav- & clever & contro & against \\
buon- & good & criminal- & criminal \\
cambia- & change & debol- & weak \\
capac- & capable & delus- & disappointment \\
competent- & competent & disastr- & disaster \\
concerto & concert & error- & mistake \\
consens- & consensus & estrem- & extremism \\
content- & glad & fals- & false \\
corrett- & right & fascist- & fascist \\
dalla parte & support & furt- & theft \\
divers- & different & insicur- & insecure \\
\hline
\end{tabular}


Table B.1 Sentiment Analysis: Positive and Negative Stems (continued)

\begin{tabular}{|c|c|c|c|}
\hline Positive stem & Meaning & Negative stem & Meaning \\
\hline eccitat- & excited & insult- & insult \\
\hline favor- & favorite & ladr- & thief \\
\hline felic- & happy & idiot- & idiot \\
\hline fort- & strong & imbecill- & fool \\
\hline forza & incitement & inadeguat- & inadequate \\
\hline futuro & future & indegn- & unworthy \\
\hline gentile & kind & mal- & bad \\
\hline gioia & joy & merd- & shit \\
\hline giust- & right & mort- & death \\
\hline grand- & strong & non vot- & not vote for \\
\hline grazi- & thank & odio & hate \\
\hline innova- & innovate & opoli & scandal \\
\hline intelligent- & intelligent- & passat & past \\
\hline meglio & best & paur- & fear \\
\hline miglior- & better & pazz- & $\operatorname{mad}$ \\
\hline moderat- & moderate & peggio & worse \\
\hline nuov- & new & pena & distress \\
\hline onest- & honest & pericol- & danger \\
\hline orgoglio & pride & pessim- & very bad \\
\hline preferit- & favorite & pover- & poor \\
\hline pro & pro & problem- & problem \\
\hline salv- & safety & rabbia & angry \\
\hline sicur- & security & ridicol- & ridiculous \\
\hline sogn- & dream & ruba- & steal \\
\hline sostegno & support & sbagli- & wrong \\
\hline sosten- & support & scandal- & scandal \\
\hline speranz- & hope & scem- & fool \\
\hline stim- & esteem & schif- & disgust \\
\hline tif- & support & scorrett- & unfair \\
\hline vinc- & win & stronz- & asshole \\
\hline vittor- & victory & terror- & terror \\
\hline vot- & vote for & vecchi- & old \\
\hline $\mathrm{xd}$ & smile & violen- & violence \\
\hline
\end{tabular}




\section{Appendix: Field Experiment in Cava de' Tirreni}

In the following section, we report the English translation of our informational treatments. For complete materials (including original videos realized by professionals, online survey screenshots, etc.) please refer to the website: www.igier.unibocconi.it/cavaexperiment

\section{C.1 Treatment}

Our treatments consisted of positive and negative canvassing. During the three weeks prior to the election, a campaign team of volunteers (see figure C1), supporters of Armando Lamberti, knocked on doors of private residences, and buzzed private residences' intercoms (see figure $\mathrm{C} 2$ ), to engage in personal interaction with eligible voters. These personal interactions featured the campaign volunteers soliciting the voters to communicate their ideas about what the new mayor should do for Cava de' Tirreni. These ideas would then be reported to the candidate, Armando Lamberti. Volunteers then took the opportunity to present to these voters Armando Lamberti's ideas, and to distribute electoral material. Electoral material was also left in the mailboxes of other eligible voters, who were not engaged in personal interactions. These electoral materials are at figures C3 to C6. The following sections present respectively the general instructions provided to the volunteers for the canvassing, the script for the initial approach (two options) and the positive and negative messages.

\section{C.1.1 Canvassing Instructions to the Volunteers}

General norms to be followed:

- In order to get in touch with the voters and establish a dialogue, it is important to look cheerful, trustful (do not keep your hands in the pocket, do not lean on the wall, no chewing-gums, etc.) and nice. You have to let the voters know that you are not attempting to sell anything, nor you are asking for money, and that you are there to listen to their ideas.

- Avoid assuming aggressive behaviors, even if the person opening the door is clearly aggressive and rude, or if she/he states not to approve Lamberti as a candidate. Just say goodbye and leave. 
What to do if the front door of the apartment building is closed:

- If there is a doorman, first convince him/her to let you in the building for the canvassing. It might help starting the canvassing from him/her first. If you succeed, it is likely that he/she will let you in and warn the residents of your arrival. This will likely increase your chances of interviewing a greater number of voters.

- If there is no doorman, you will have to call on the intercom. In order to convince the person to let you in the building you will have to introduce yourselves with one of the introductions you find below.

Once inside the apartment building, how to get personal access to the voters:

- After having entered the building, you have to convince the person to open the door of his/her apartment! Ring the doorbell and when someone answers start introducing yourselves with one of the introductions you find below. The main advantage at this point is that they will see you through the peephole, and they will see your t-shirts.

- If a person, most likely an elderly, decides not to open the door but continues to talk to you from the other side of the door, you can still try to do the canvassing, as described below. You can slid the material under the door.

To enter or not to enter into an apartment:

- You do not need to enter into an apartment for the canvassing. You can give your introductions, listen to their ideas or complaints by remaining on the corridor outside the apartment's door.

- Do not ask to enter into the apartment, people may get frightened. Instead, if you notice that the person is frightened or suspicious, state clearly that you can talk standing at the door.

- If the person invites you to enter, you have two options: (i) If you know the person or he/she looks trustful to you, and you are at least two people, you can enter the apartment and do the canvassing inside; (ii) If you do not feel safe, state that the rules impose you not to enter. If he/she insists, greet him/her and leave. 


\section{C.1.2 Canvassing Script I}

Good morning/afternoon,

As you can see from our t-shirts, we are young supporters of the candidate mayor Professor Armando Lamberti.

As you might have learned from the newspapers, or as you might have heard from friends of from the streets, Professor Lamberti has promoted an electoral campaign called 'Around the City Listening to Citizens', in order to listen to the ideas and needs of the citizens of the municipality of Cava. We are the volunteers, who 'Listen to Citizens', and we are interviewing people door-to-door.

IF NECESSARY: We know that your time is important and we are not attempting to sell anything, nor we are asking for money. We would like to know what you think the new mayor should do in order to improve the situation in the neighborhood or in your household. Your opinion is fundamental, and Professor Lamberti wants to know which are the priorities to be addressed for the citizens of Cava.

If there is someone else here at home we would also like to talk to him/her in order to collect as many opinions as possible. Once every two or three days, we young supporters meet Professor Lamberti to tell him the citizens' opinions and let him know what really people need.

QUESTION: What is in your opinion the most important issue the new mayor should address? OR ALTERNATIVELY: If you were the mayor, what is the first thing you would do?

\section{C.1.3 Canvassing Script II}

Good morning/afternoon,

We are the volunteers, who 'Listen to Citizens'. Have you ever heard of the campaign promoted by the candidate mayor Armando Lamberti to hear the opinions of the citizens of Cava?

As you can see from our t-shirts, we are young supporters of the candidate mayor Professor Armando Lamberti and we would like to know from you what you think of the situation in your neighborhood or in your household, and what the new mayor should do in order to improve the situation. 
IF NECESSARY: We know that your time is important and we are not attempting to sell anything, nor we are asking for money. We would like to know what you think the new mayor should do in order to improve the situation in the neighborhood or in your household. Your opinion is fundamental, and professor Lamberti wants to know which are the priorities to be addressed for the citizens of Cava.

If there is someone else here at home we would also like to talk to him/her in order to collect as many opinions as possible. Once every two or three days, we young supporters meet Professor Lamberti to tell him the citizens opinions and let him know what really people need.

QUESTION: What is in your opinion the most important issue the new mayor should address? OR ALTERNATIVELY: If you were the mayor, what is the first thing you would do?

\section{C.1.4 Possible Reactions}

There are different tones of possible welcoming, after the opening of the door:

- VERY NEGATIVE WELCOMING (They do not let you speak, they interrupt you, they refuse to open the door or answer that they not have time, or are not interested): Just say thank you, goodbye and leave.

- NEGATIVE WELCOMING (They let you talk, but only in part; they do not open the door and talk from the other side of the door; they say that politicians are all crooks, and that they do not know Lamberti, and vote for XY). You can try one of the following three options: (i) Thank you. We understand that you might not trust politicians, but for us it is still important to know your opinion. What is in your opinion the most important issue the new mayor should address? (ii) Thank you. Even if you do not know Lamberti, for us it is still important to know your opinion. What is in your opinion the most important issue the new mayor should address? (iii) Thank you. Even if you will vote for XY, for us it is still important to know your opinion. What is in your opinion the most important issue the new mayor should address? 
- POSITIVE WELCOMING (they let you talk, you arrived successfully to the question in script I or II): After having listened to the answer to your question and having noted it down, you can deliver the following positive or negative message.

\section{C.1.5 Positive Canvassing}

How to start:

- Give the person a flyer with the positive message.

- Start from the topic most closely related to the one proposed by the person. Start by stating that that topic is also very important to Professor Lamberti.

- After having talked about the initial topic (the one that is most closely related to the topic proposed by the person), continue BRIEFLY with the two other messages.

Script for the three messages (Only suggestive: you do not need to state everything)

- Dialogue with the citizens: The initiative 'Around the City Listening to Citizens', that brought us here, is just one of the many initiatives Mr Lamberti is planning in order to collect the opinions of the citizens and to dialogue with them, with the goal of taking aware decisions. His dream is that of an inclusive municipality, where every citizen is seen as an important resource. FOR SUB-MUNICIPALITIES (FRAZIONI): This is especially true for the hamlets, which must feel part of the project of creating a unique municipality: Cava. This can be accomplished also through the promotion of public transportation.

- Competency and transparency: in his professional life as a professor of public law and as a member of several regional cabinets, Professor Lamberti has gained a great experience as an administrator, but he has always been very sensitive towards transparency. It is fundamental for him that citizens are aware of his actions and of the decision taken by his cabinet. The main objective is to reduce the burden of bureaucracy and costs, while increasing transparency in the procedures.

- More public services: Professor Lamberti has always been an active promoter of the improvement of the quality and quantity of health care services. He has always 
promoted Cava's hospital, and he has also proposed to improve the assistance to citizens by using regional funds that are already available. The project aims at including specialized doctors, a front desk, a nursey, pediatricians, and the launch of the 'Health Center (Casa della salute)', which will be conducting important functions (counseling in support of families, home assistance). The hospital should return to assist acute patients that need hospitalization and those who need emergency interventions, with an emergency service that will remain active 24 hours a day and with wards for cardiology, orthopedics, radiology, intensive care, surgery, pediatrics and the analytical laboratory. FOR SUB-MUNICIPALITIES: this means especially increasing the number of services here in hamlets with health centers and other specialized services of assistance to citizens.

How to finish:

- After having briefly talked about the three themes, ask the person if she/he has any comments. If yes, let the person talk and kindly end the discussion; leave the campaign material, greet him/her and leave.

- If the person interrupts you while you are giving your short presentation, let them him/her talk, try with kindness and BREVITY to talk about all three points. Kindly end the conversation, leave the campaign material, greet him/her and leave.

How to end the conversation if the person wants to continue with the discussion: You can invite him/her to visit Lamberti's committees, which are located in via Verdi. State that the person can meet professor Lamberti and the candidate counselors there.

IMPORTANT: Avoid talking too much if the person is not interested. Better to be brief and avoid getting people bored

\section{C.1.6 Negative Canvassing}

How to start:

- Give the person a flyer with the negative message.

- Start from the topic most closely related to the one proposed by the person. Start by stating that over the past five years that issue has not been addressed by Galdi's cabinet. 
- After having talked about the initial topic (the one that is most closely related to the topic proposed by the person), continue BRIEFLY with the two other messages.

Script for the three messages (Only suggestive: you do not need to state everything)

- Too much old politics: Galdi's administration has been absent from people's life. Instead of listening to citizens and try to assist their needs, it kept politics distant from people. With Galdi's administration, Cava established a record of cabinets' turnovers: nine turnovers. The main interest of the administration was to keep its 'seats' instead of addressing the citizens' needs. FOR SUB-MUNICIPALITIES: This is especially true for sub-municipalities that joined Cava recently. Lamberti proposes a different style, starting from this initiative of the 'Around the City Listening to Citizens', which brought us here today.

- Too much waste of public money and too many municipal taxes: Galdi's administration pursued a series of wrong public expenditure choices that did not benefit the citizens of Cava. The renovation of the Abbro square with the famous chess-board created many troubles to citizens and waste of public resources. Municipal taxes also increased. For an average household, total municipal taxes increased by 250 Euro per year over the five years of Galdi's administration.

- Too much debt burdening citizens: the purchase of the 'ex-COFIMA' plant by the municipality has raised the level of the municipal debt. The interests on the debt for the purchase of the plant are equal to 1,000 Euro per day. This represents a considerable waste of money, especially because the plant is not yet being used.

How to finish:

- After having briefly talked about the three themes, ask the person if she/he has any comments. If yes, let the person talk and kindly end the discussion; leave the campaign material, greet him/her and leave.

- If the person interrupts you while you are giving your short presentation, let them him/her talk, try with kindness and BREVITY to talk about all three points. Kindly end the conversation, leave the campaign material, greet him/her and leave. 
- What to do if the person criticizes your statements about the Galdi's administration? (i) Let him/her talk and interrupt him/her with courtesy; (ii) You can say that the situations you are talking about are complex political and economic issues, and that there can be many different opinions. State that according to you Galdi's administration could have handled certain situations in a better way; (iii) Do not be aggressive and do not attempt to impose your opinion; (iv) Avoid continuing the conversation on Galdi's administration. Kindly greet the person, leave the campaign material and leave.

How to end the conversation if the person wants to continue with the discussion: You can invite him/her to visit Lamberti's committees, which are located in via Verdi. State that the person can meet Professor Lamberti and the candidate counselors there.

IMPORTANT: Avoid talking too much if the person is not interested. Better to be brief and avoid getting people bored. 


\section{C.2 Figures and Tables}

Figure C.1: Mr Lamberti's Volunteers, Field Experiment in Cava

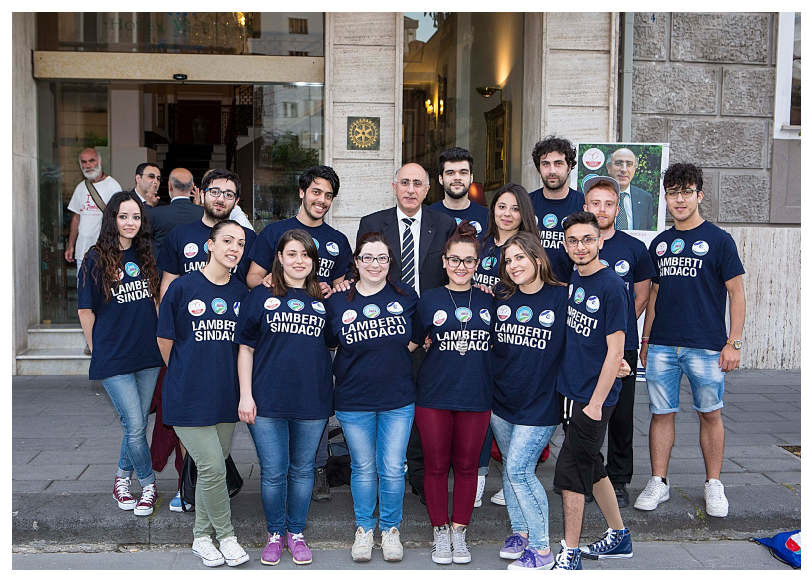

Figure C.2: Mr Lamberti's Volunteers in Action, Field Experiment in Cava

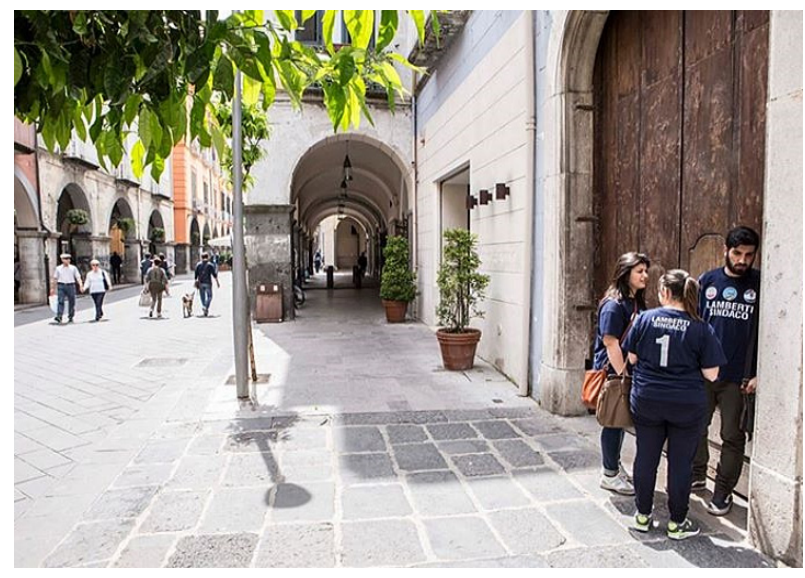


Figure C.3: Flyer with Positive Message, Field Experiment in Cava

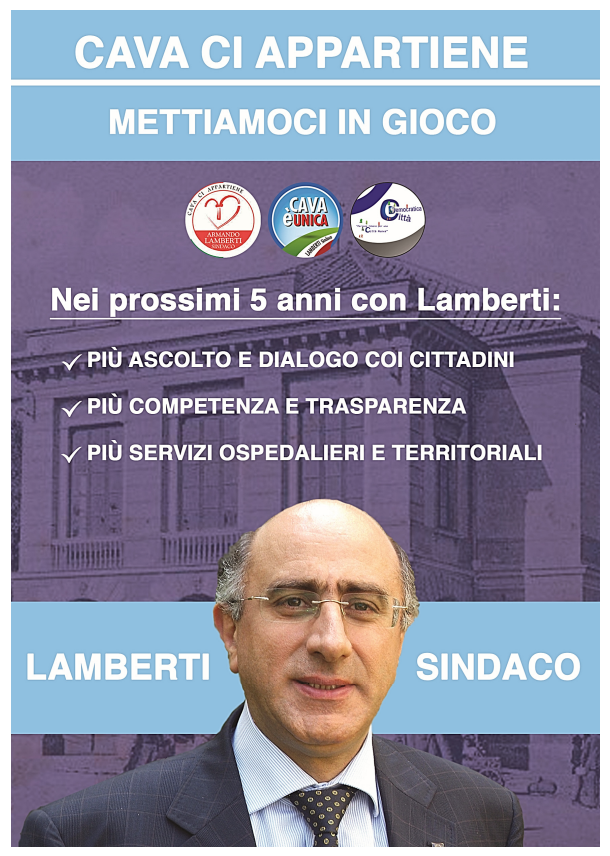

Figure C.4: Flyer with Negative Message, Field Experiment in Cava

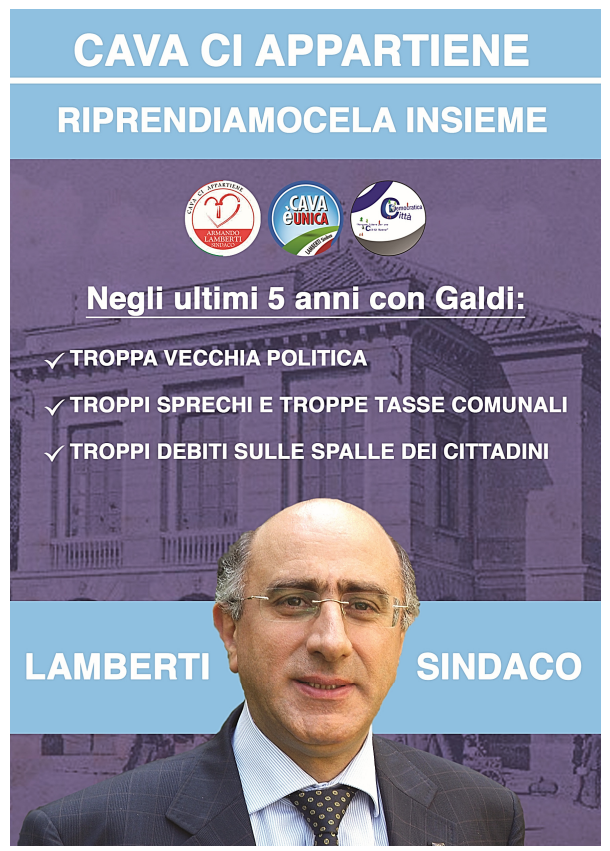


Figure C.5: Hanger with Positive Message, Field Experiment in Cava
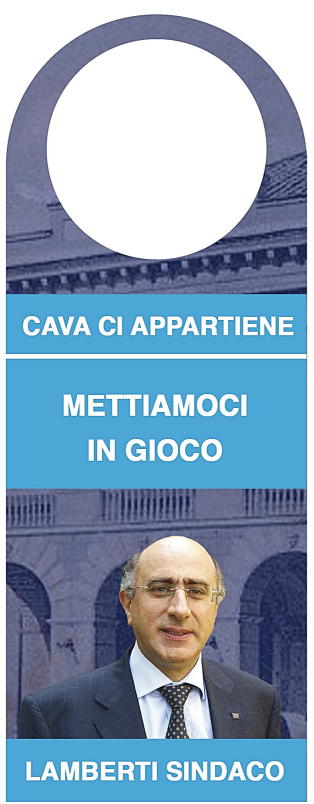

Figure C.6: Hanger with Negative Message, Field Experiment in Cava
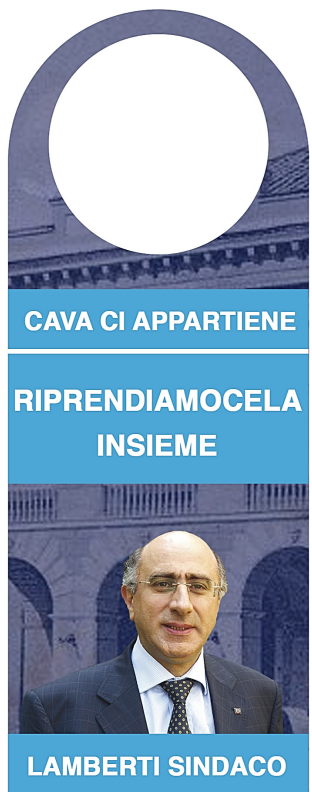
Table C.1 Ex-Ante Balancing Tests at the Precinct Level

\begin{tabular}{|c|c|c|c|}
\hline & $\begin{array}{l}\text { Negative } \\
\text { Message }\end{array}$ & $\begin{array}{l}\text { Positive } \\
\text { Message }\end{array}$ & $\begin{array}{l}\text { Difference } \\
\text { (P-Values) }\end{array}$ \\
\hline Eligible Voters 2010 & $\begin{array}{c}25.354 \\
{[43.216]}\end{array}$ & $\begin{array}{c}27.576 \\
{[45.529]}\end{array}$ & 0.963 \\
\hline Eligible Male Voters 2010 & $\begin{array}{c}14.517 \\
{[21.926]}\end{array}$ & $\begin{array}{c}18.073 \\
{[23.976]}\end{array}$ & 0.885 \\
\hline Eligible Female Voters 2010 & $\begin{array}{c}10.836 \\
{[22.448]}\end{array}$ & $\begin{array}{c}9.503 \\
{[22.349]}\end{array}$ & 0.956 \\
\hline Turnout 2010 & $\begin{array}{l}-0.018 \\
{[0.021]}\end{array}$ & $\begin{array}{l}-0.011 \\
{[0.013]}\end{array}$ & 0.746 \\
\hline Center-Right Candidate 2010 & $\begin{array}{c}0.017 \\
{[0.029]}\end{array}$ & $\begin{array}{c}0.029 \\
{[0.031]}\end{array}$ & 0.764 \\
\hline Center-Left Candidate 2010 & $\begin{array}{l}-0.013 \\
{[0.030]}\end{array}$ & $\begin{array}{l}-0.025 \\
{[0.031]}\end{array}$ & 0.657 \\
\hline Other Candidates 2010 & $\begin{array}{l}-0.004 \\
{[0.004]}\end{array}$ & $\begin{array}{c}0.000 \\
{[0.005]}\end{array}$ & 0.382 \\
\hline Center-Right List 2010 & $\begin{array}{c}0.016 \\
{[0.028]}\end{array}$ & $\begin{array}{c}0.024 \\
{[0.028]}\end{array}$ & 0.769 \\
\hline Center-Left List 2010 & $\begin{array}{l}-0.011 \\
{[0.029]}\end{array}$ & $\begin{array}{l}-0.027 \\
{[0.029]}\end{array}$ & 0.516 \\
\hline Other Lists 2010 & $\begin{array}{l}-0.006 \\
{[0.005]}\end{array}$ & $\begin{array}{c}0.003 \\
{[0.006]}\end{array}$ & 0.109 \\
\hline Eligible Voters 2006 & $\begin{array}{c}33.725 \\
{[40.195]}\end{array}$ & $\begin{array}{c}20.781 \\
{[39.889]}\end{array}$ & "0.774 \\
\hline Eligible Male Voters 2006 & $\begin{array}{c}16.634 \\
{[20.452]}\end{array}$ & $\begin{array}{c}12.690 \\
{[21.305]}\end{array}$ & 0.866 \\
\hline Eligible Female Voters 2006 & $\begin{array}{c}17.091 \\
{[20.899]}\end{array}$ & $\begin{array}{c}8.091 \\
{[19.628]}\end{array}$ & 0.689 \\
\hline Turnout 2006 & $\begin{array}{l}-0.009 \\
{[0.019]}\end{array}$ & $\begin{array}{l}-0.011 \\
{[0.012]}\end{array}$ & 0.956 \\
\hline Center-Right Candidate 2006 & $\begin{array}{l}-0.028 \\
{[0.022]}\end{array}$ & $\begin{array}{l}-0.030 \\
{[0.016]}\end{array}$ & 0.258 \\
\hline Center-Left Candidate 2006 & $\begin{array}{l}-0.026 \\
{[0.030]}\end{array}$ & $\begin{array}{l}-0.006 \\
{[0.028]}\end{array}$ & 0.473 \\
\hline Other Candidates 2006 & $\begin{array}{c}0.054 \\
{[0.041]}\end{array}$ & $\begin{array}{c}0.008 \\
{[0.031]}\end{array}$ & 0.210 \\
\hline Center-Right List 2006 & $\begin{array}{l}-0.012 \\
{[0.022]}\end{array}$ & $\begin{array}{l}-0.000 \\
{[0.019]}\end{array}$ & 0.580 \\
\hline Center-Left List 2006 & $\begin{array}{l}-0.028 \\
{[0.024]}\end{array}$ & $\begin{array}{l}-0.023 \\
{[0.026]}\end{array}$ & 0.812 \\
\hline Other Lists 2006 & $\begin{array}{c}0.041 \\
{[0.027]}\end{array}$ & $\begin{array}{c}0.023 \\
{[0.026]}\end{array}$ & 0.509 \\
\hline
\end{tabular}

Notes. Observations: 55 precincts. OLS coefficients reported; dependent variables in row headings and treatment groups in column headings. Eligible voters is the number of voters in the precinct. The other variables are the electoral outcomes in the 2010 and 2006 elections and are expressed in vote shares. Robust standard errors clustered by ZIP code are in brackets. Significance at the $10 \%$ level is represented by $*$, at the $5 \%$ level by $* *$, and at the $1 \%$ level by $* * *$. 


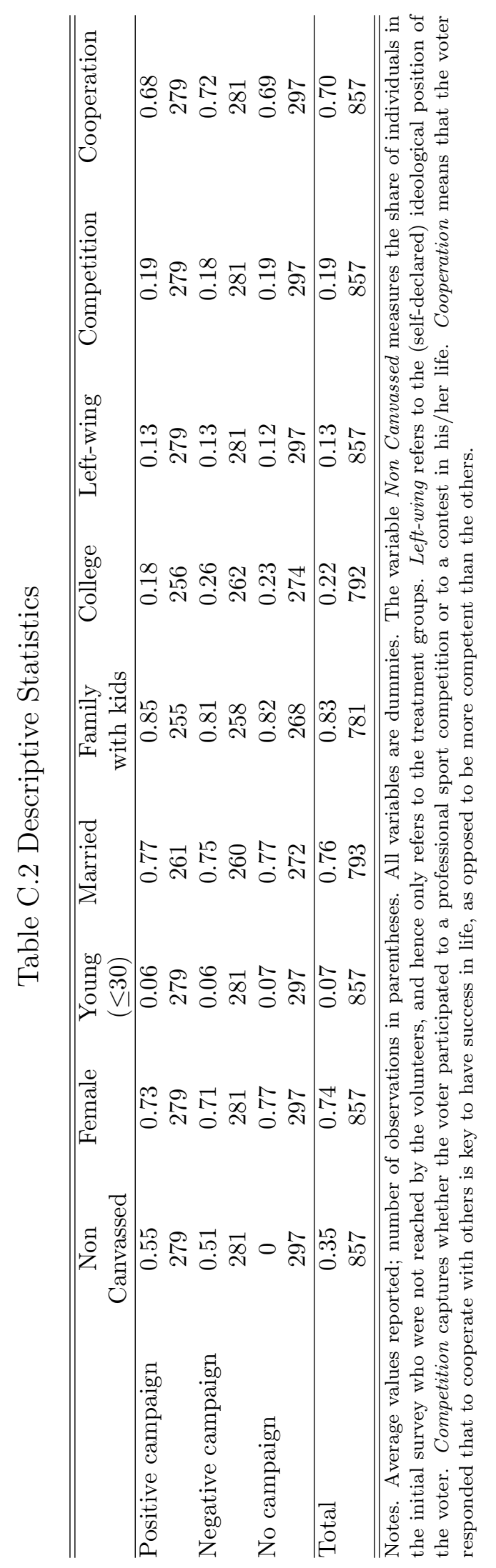


Table C.3 Average Treatment Effects, Full Sample

\begin{tabular}{lcccc}
\hline \hline & $\begin{array}{c}\text { Turnout } \\
\text { rate }\end{array}$ & $\begin{array}{c}\text { Opponent's } \\
\text { vote share }\end{array}$ & $\begin{array}{c}\text { Incumbent's } \\
\text { vote share }\end{array}$ & $\begin{array}{c}\text { Others' } \\
\text { vote share }\end{array}$ \\
\hline Positive campaign $\left(\alpha_{1}\right)$ & -0.002 & 0.055 & $-0.145^{* * *}$ & 0.067 \\
Negative campaign $\left(\alpha_{2}\right)$ & {$[0.029]$} & {$[0.034]$} & {$[0.051]$} & {$[0.058]$} \\
& -0.024 & 0.035 & $-0.107^{* *}$ & 0.076 \\
\hline P-value H1: $\alpha_{1}-\alpha_{2}=0$ & {$[0.028]$} & {$[0.033]$} & {$[0.053]$} & {$[0.058]$} \\
P-value H2: $\alpha_{1}+\alpha_{2}=0$ & 0.368 & 0.511 & 0.423 & 0.871 \\
\hline Obs. & 0.666 & 0.111 & $0.007^{* *}$ & 0.155 \\
\hline \hline
\end{tabular}

Notes. Estimated OLS regression: $Y_{i}=\alpha_{1} P O S_{i}+\alpha_{2} N E G_{i}+\varepsilon_{i}$. (H1) Treatment effect of positive vs. negative campaign: $\alpha_{1}-\alpha_{2}=0$. (H2) Treatment effect of any campaign vs. no campaign: $\alpha_{1}+\alpha_{2}=0$. Robust standard errors are in brackets. Significance at the $10 \%$ level is represented by *, at the $5 \%$ level by $* *$, and at the $1 \%$ level by ***.

Table C.4 Average Treatment Effects, Canvassed Sample

\begin{tabular}{lcccc}
\hline \hline & $\begin{array}{c}\text { Turnout } \\
\text { rate }\end{array}$ & $\begin{array}{c}\text { Opponent's } \\
\text { vote share }\end{array}$ & $\begin{array}{c}\text { Incumbent's } \\
\text { vote share }\end{array}$ & $\begin{array}{c}\text { Others' } \\
\text { vote share }\end{array}$ \\
\hline Positive campaign $\left(\alpha_{1}\right)$ & -0.007 & 0.062 & $-0.166^{* * *}$ & 0.101 \\
& {$[0.038]$} & {$[0.047]$} & {$[0.061]$} & {$[0.072]$} \\
Negative campaign $\left(\alpha_{2}\right)$ & -0.000 & $0.085^{*}$ & $-0.187^{* * *}$ & $0.145^{* *}$ \\
& {$[0.036]$} & {$[0.048]$} & {$[0.059]$} & {$[0.070]$} \\
\hline$P$-value H1: $\alpha_{1}-\alpha_{2}=0$ & 0.872 & 0.706 & 0.734 & 0.590 \\
$P$-value H2: $\alpha_{1}+\alpha_{2}=0$ & 0.902 & $0.046^{* *}$ & $0.001^{* * *}$ & $0.036^{* *}$ \\
\hline Obs. & 560 & 282 & 282 & 282 \\
\hline \hline
\end{tabular}

Notes. Estimated OLS regression: $Y_{i}=\alpha_{1} P O S_{i}+\alpha_{2} N E G_{i}+\varepsilon_{i}$. (H1) Treatment effect of positive vs. negative campaign: $\alpha_{1}-\alpha_{2}=0$. (H2) Treatment effect of any campaign vs. no campaign: $\alpha_{1}+\alpha_{2}=0$. Robust standard errors are in brackets. Significance at the $10 \%$ level is represented by $*$, at the $5 \%$ level by **, and at the $1 \%$ level by ***. 

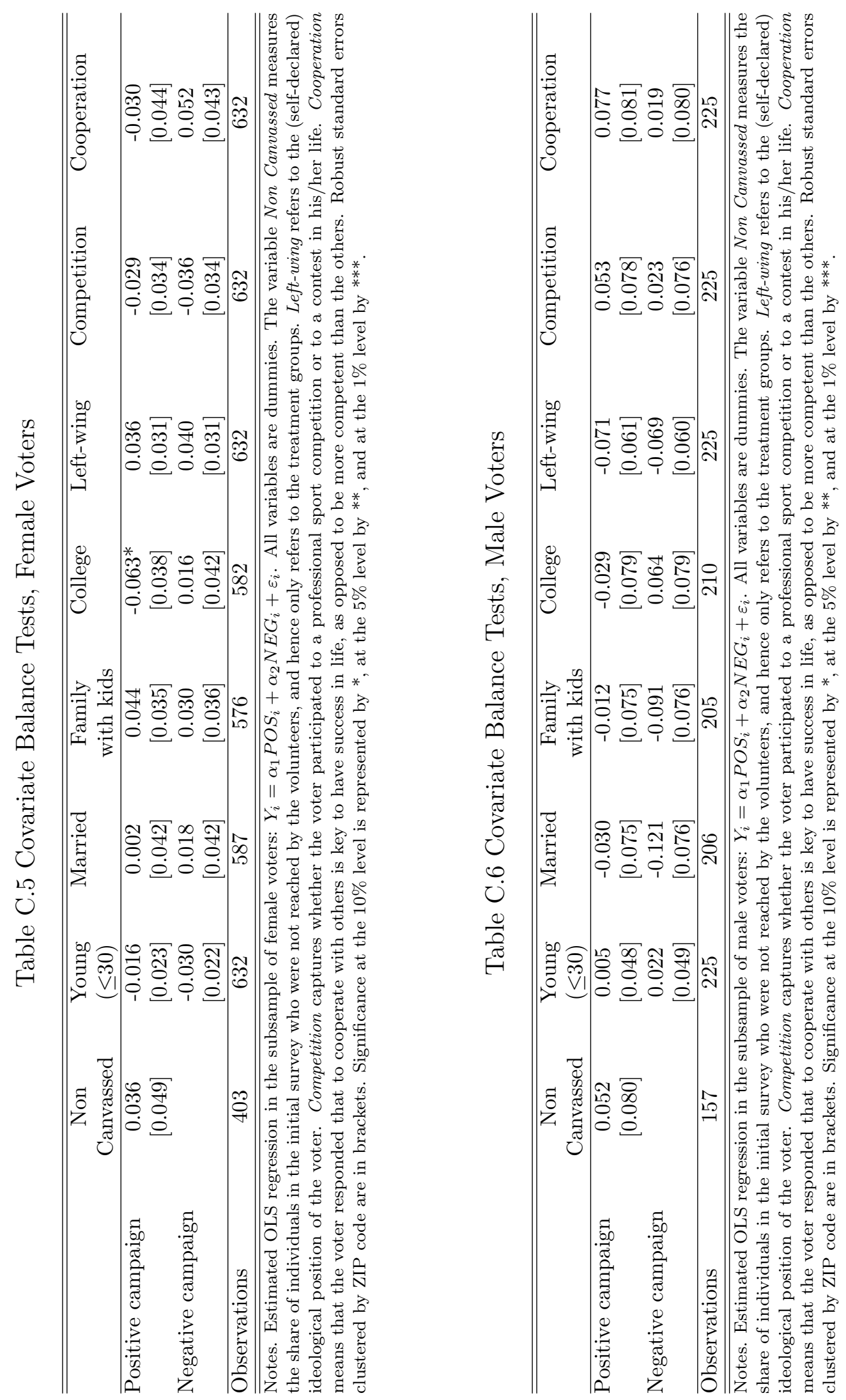

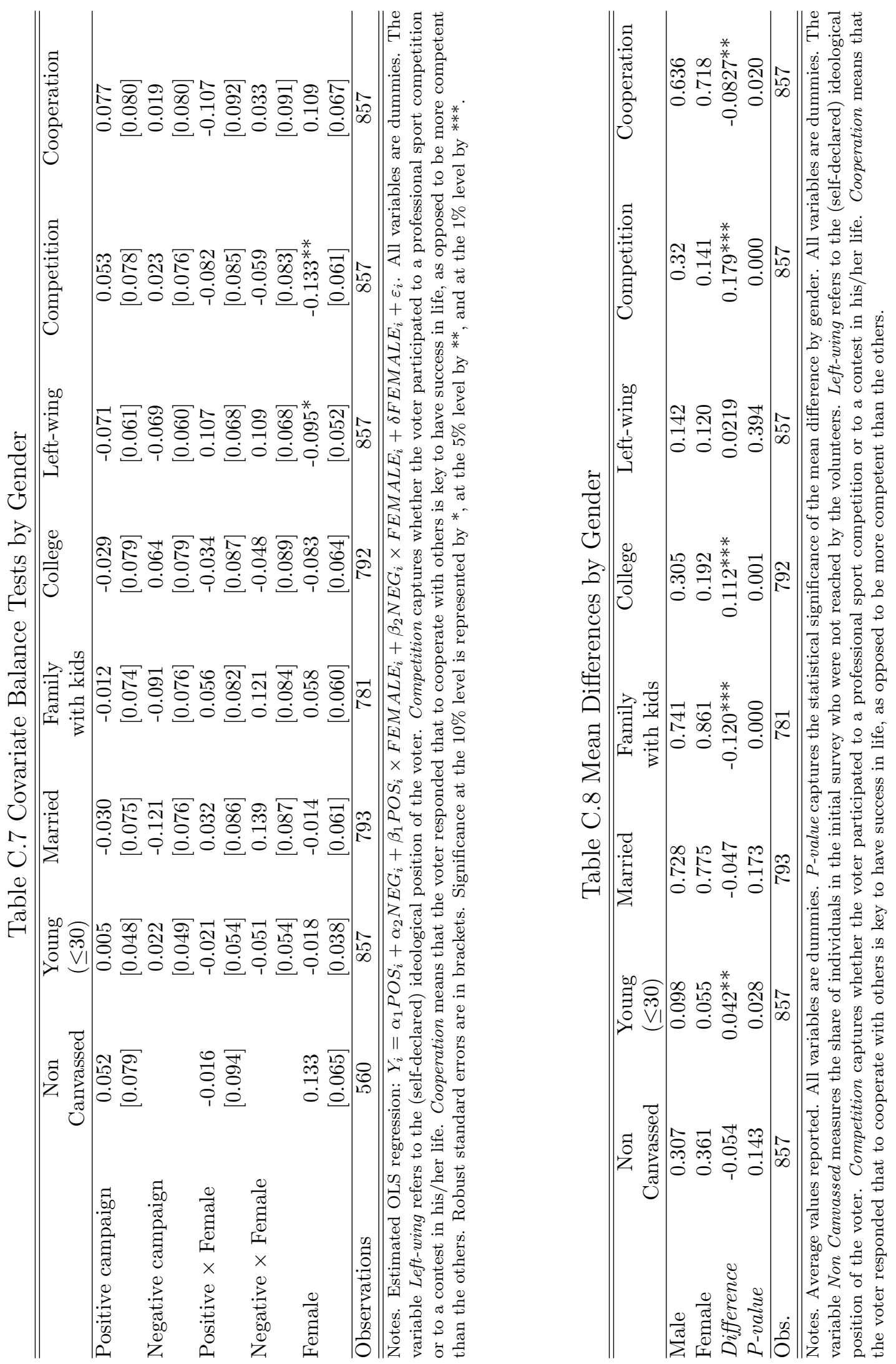


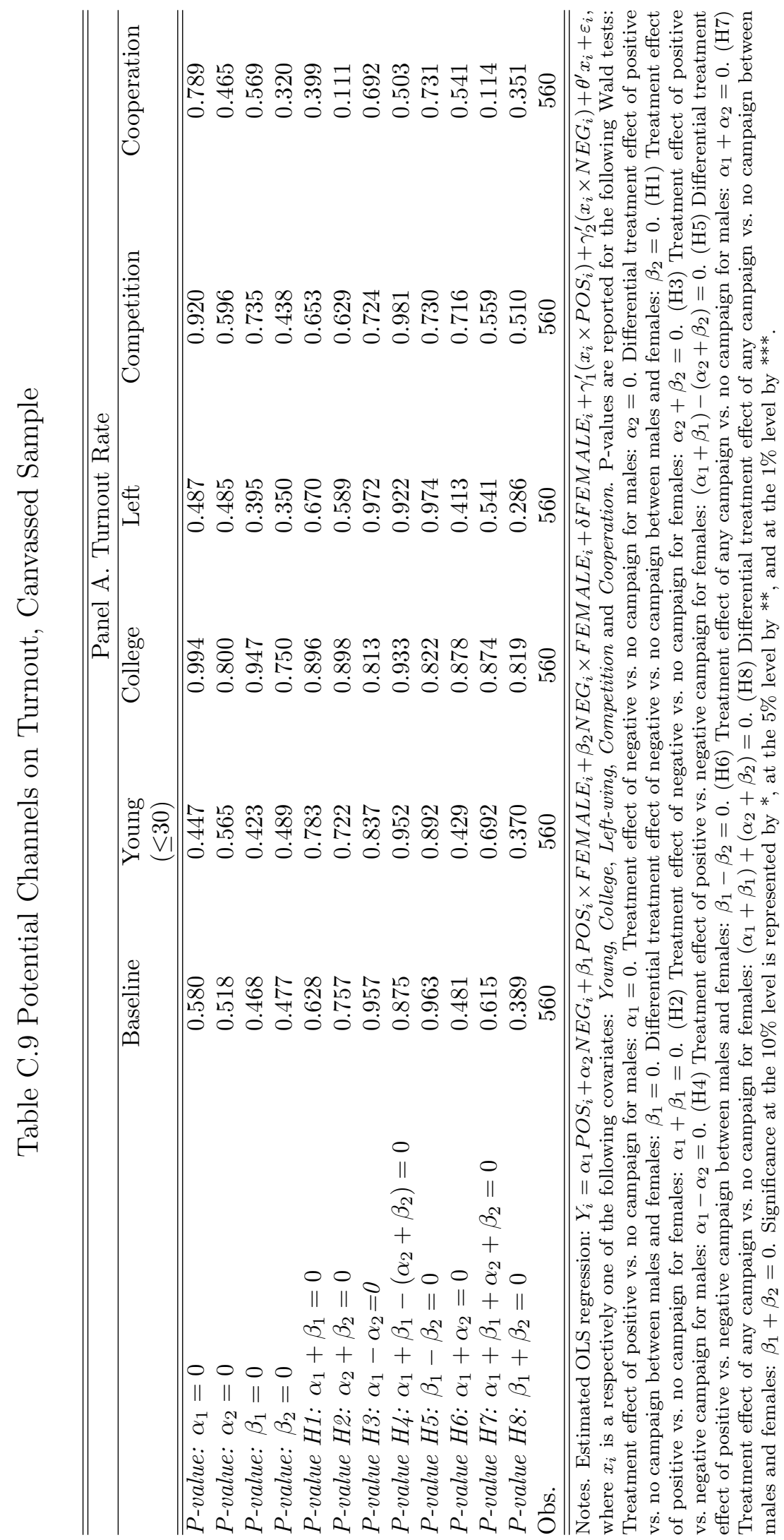


Table C.10 Full Set of Interactions, Canvassed Sample

\begin{tabular}{|c|c|c|c|c|}
\hline & $\begin{array}{c}\text { Turnout } \\
\text { rate }\end{array}$ & $\begin{array}{l}\text { Opponent's } \\
\text { vote share }\end{array}$ & $\begin{array}{l}\text { Incumbent's } \\
\text { vote share }\end{array}$ & $\begin{array}{c}\text { Others' } \\
\text { vote share }\end{array}$ \\
\hline \multirow{2}{*}{ Positive campaign $\left(\alpha_{1}\right)$} & -0.084 & 0.154 & -0.216 & 0.060 \\
\hline & {$[0.168]$} & {$[0.220]$} & {$[0.296]$} & {$[0.361]$} \\
\hline \multirow{2}{*}{ Negative campaign $\left(\alpha_{2}\right)$} & -0.078 & 0.216 & -0.038 & -0.073 \\
\hline & {$[0.153]$} & [0.186] & [0.263] & {$[0.272]$} \\
\hline \multirow{2}{*}{ Positive campaign $\times$ Female $\left(\beta_{1}\right)$} & 0.035 & 0.123 & 0.015 & -0.080 \\
\hline & {$[0.090]$} & [0.085] & {$[0.185]$} & [0.201] \\
\hline \multirow{2}{*}{ Negative campaign $\times$ Female $\left(\beta_{2}\right)$} & 0.006 & -0.111 & 0.173 & -0.032 \\
\hline & [0.081] & {$[0.106]$} & {$[0.127]$} & {$[0.152]$} \\
\hline \multirow{2}{*}{ Female } & 0.039 & 0.043 & -0.027 & -0.046 \\
\hline & [0.052] & {$[0.053]$} & [0.104] & {$[0.111]$} \\
\hline$\overline{P \text {-value } H 1:} \alpha_{1}+\beta_{1}=0$ & 0.743 & 0.152 & 0.327 & 0.945 \\
\hline P-value H2: $\alpha_{2}+\beta_{2}=0$ & 0.619 & 0.529 & 0.583 & 0.700 \\
\hline P-value H3: $\alpha_{1}-\alpha_{2}=0$ & 0.972 & 0.822 & 0.569 & 0.716 \\
\hline P-value $H_{4}: \alpha_{1}+\beta_{1}-\left(\alpha_{2}+\beta_{2}\right)=0$ & 0.892 & 0.491 & 0.156 & 0.790 \\
\hline$P$-value $H 5: \beta_{1}-\beta_{2}=0$ & 0.760 & $0.039^{* *}$ & 0.350 & 0.806 \\
\hline$P$-value H6: $\alpha_{1}+\alpha_{2}=0$ & 0.543 & 0.217 & 0.585 & 0.980 \\
\hline$P$-value H7: $\alpha_{1}+\beta_{1}+\alpha_{2}+\beta_{2}=0$ & 0.615 & 0.144 & 0.866 & 0.786 \\
\hline$P$-value $H 8: \beta_{1}+\beta_{2}=0$ & 0.773 & 0.940 & 0.482 & 0.708 \\
\hline Observations & 501 & 268 & 268 & 268 \\
\hline
\end{tabular}

